Journal of Chromatography A

April 2015, Volume 1388, Pages 87-101

http://dx.doi.org/10.1016/i.chroma.2015.02.015

http://archimer.ifremer.fr/doc/00252/36302/

(c) 2015 Elsevier B.V. All rights reserved.

\title{
Characterization of ovatoxin-h, a new ovatoxin analogue, and evaluation of chromatographic columns for ovatoxin analysis and purification
}

\author{
Brissard Charline ${ }^{1}$, Herve Fabienne ${ }^{1}$, Sibat Manoella ${ }^{1}$, Sechet Veronique ${ }^{1}$, Hess Philipp ${ }^{1}$, \\ Amzil Zouher ${ }^{1}$, Herrenknecht Christine ${ }^{2,{ }^{*}}$
}

${ }^{1}$ Ifremer, Phycotoxins Laboratory, rue de l'lle d'Yeu, BP 21105, F-44311 Nantes, France

2 LUNAM, University of Nantes, MMS EA2160, Pharmacy Faculty, 9 rue Bias, F-44035 Nantes, France

* Corresponding author : Christine Herrenknecht, Tel.: +33253484312 ;

email address : $\underline{\text { Christine.Herrenknecht@univ-nantes.fr }}$

\begin{abstract}
:
The presence of Ostreopsis cf. ovata on the Mediterranean coast represents a serious concern to human health due to production of toxins-putative palytoxin and ovatoxins (ovatoxin-a, -b, -c, -d, -e, -f and $-\mathrm{g}$ ). However, purified ovatoxins are not widely available and their toxicities are still unknown. In the present study, we report on HR LC-MS/MS analysis of a French Ostreopsis cf. ovata strain (IFR-OST$0.3 \mathrm{~V}$ ) collected at Villefranche-sur-Mer (France) during a bloom in 2011. Investigation of this strain of Ostreopsis cf. ovata cultivated in our laboratory by ultra-high performance liquid chromatography coupled to high resolution mass spectrometry (UHPLC-HRMS) confirmed the production of ovatoxins -a to-e and revealed the presence of a new ovatoxin analogue, named ovatoxin-h. Ostreopsis cf. ovata extracts were pre-purified by Sephadex LH-20 to obtain a concentrated fraction of ovatoxins (OVTXs). This method provided a recovery of about $85 \%$ of OVTXs and a cleanup efficiency of $93 \%$. Different stationary phases were tested with this fraction of interest to elucidate the structure of the new OVTX congener and to obtain purified ovatoxins. Eight reversed phase sorbents were evaluated for their capacity to separate and purify ovatoxins. Among them Kinetex C18, Kinetex PFP and Uptisphere C18TF allowed for best separations almost achieving baseline resolution. Kinetex C18 is able to sufficiently separate these toxins, allowing us to identify the toxins present in the extract purified by Sephadex LH20 , and to partly elucidate the structure of the new ovatoxin congener. This toxin possesses one oxygen atom less and two hydrogens more than ovatoxin-a. Investigations using liquid chromatography coupled to high resolution tandem mass spectrometry suggest that the part of the molecule where ovatoxin-h differs from ovatoxin-a is situated between C42 and C49. Uptisphere C18-TF was proposed as a first step preparative chromatography as it is able to separate a higher number of ovatoxins (especially ovatoxin-d and ovatoxin-e) and because it separates ovatoxins from unknown compounds, identified using full scan single quadrupole mass spectrometry. After pre-purification with Sephadex LH-20, purification and separation of individual ovatoxins was attempted using an Uptisphere C18-TF column. During recovery of purified toxins, problems of stability of OVTXs were observed, leading us to investigate experimental conditions responsible for this degradation.
\end{abstract}




\section{Highlights}

A new analogue of ovatoxin is described. Uptisphere $C_{18}$-TF is a suitable column to separate ovatoxins. A protocol is proposed for the purification of ovatoxins.

Keywords : Ostreopsis cf. ovata, palytoxin, ovatoxins, U-HPLC/HR-MSn, chromatographic separation

\section{Introduction}

Benthic dinoflagellates of the genus Ostreopsis are common in tropical and subtropical areas, but have recently been observed in increasing intensity and frequency in temperate seas [1] and [2]. Over the last decade, Ostreopsis sp. produced significant blooms during summer around the Mediterranean basin [3], [4], [5], [6], [7] and [8]. Ostreopsis bloom events may have important environmental and health consequences. Indeed, the occurrence of potentially toxic dinoflagellates in the ecosystem can have impact at several levels. Palytoxins can enter the food web and accumulate in marine organisms, and then can lead to food intoxications in seafood consumers. Moreover, Ostreopsis sp. was also involved in intoxication via inhalation [9]; irritations by direct contact, mainly skin irritations [10]; and mass mortalities of invertebrates [1], [7], [11] and [12].

Along the Mediterranean coasts of Europe, North Africa and the Atlantic coast of Portugal, blooms of Ostreopsis confer (cf.) ovata and less frequently of Ostreopsis cf. siamensis have been occurring over the last two decades [3], [6], [8] and [13]. In France, only blooms of Ostreopsis cf. ovata have been observed to date. This dinoflagellate produces putative palytoxin ( $p$-PLTX) and ovatoxins (OVTXs), a class of palytoxin analogues that have recently been identified in both field and cultured samples. Seven OVTXs have been described OVTX-a, -b, -c, -d, -e, -f [14], [15] and [16]. and OVTX-g, a novel ovatoxin isolated very recently in the South of Catalonia (NW Mediterranean Sea) [17]. Among them, only the structure of OVTX-a was elucidated by both $\mathrm{MS}^{n}$ and NMR [18]; the other ones only being structurally characterized by their high resolution mass spectrum (HRMS) and/or by $\mathrm{MS}^{n}$ data, in comparison with OVTX-a and PLTX ( $\underline{\text { Table 1 }}$ ). 
Palytoxin presents a long and highly functionalized chain with both hydrophilic and lipophilic parts. The molecule consists of a long partially unsaturated aliphatic backbone containing 2 amide groups, 1 amine function, 42 hydroxyl groups, 7 ether rings, ketal/hemiketal rings and 8 double bonds [20]. In comparison with PLTX, OVTX-a possesses an extra hydroxyl group at the 42-position and a lack of three hydroxyl groups at the 17-, 44-, and 64- positions [17] (Figure 1) [18]. The fragmentation pattern of palytoxin, with informative cleavages all along the backbone of the molecule could provide direct strategy to get structural information on uncharacterized palytoxin congeners, available in quantities too small to be studied by NMR.

Production of different analogues depends on the strain of Ostreopsis. Both in the field and in culture, the toxin profile of Ostreopsis cf. ovata is generally dominated by OVTX-a, followed by OVTX-b, OVTX-d/e, OVTX-c and p-PLTX [15,21,22]. Recently, a strain of Ostreopsis cf. ovata was found to produce $50 \%$ of OVTX-f [16]. However, due to a lack of calibration standards for ovatoxins, LC-MS results are typically expressed as palytoxin equivalents (PLTX-equiv.), assuming that toxins of the palytoxin group possess the same molecular response factor in MS detection [14]. Hence, ovatoxins need to be purified and isolated for a better understanding of the molecular bases of their bioactivity.

Most authors have used reversed phase chromatography to analyze ovatoxins, mostly with $\mathrm{C}_{18}$ [23] and particularly Gemini $\mathrm{C}_{18}[9,15,16,24,25], \mathrm{C}_{8}$ sorbents [26] or Hydrophilic Interaction Liquid Chromatography (HILIC) [27,28]. These columns were suitable for OVTX identification and quantification, in association with MS detection, but not sufficiently efficient for complete separation and purification of OVTXs.

For purification of PLTX-analogues, several protocols were described in literature either from Palythoa sp. [29,30] or from Ostreopsis sp. [18,23,31]. Among these protocols, liquid-liquid extraction, solid phase extraction (SPE) or flash chromatography, and finally preparative chromatography were generally used.

In the case of Ostreopsis cf. ovata, as ovatoxins possess very close chemical and physical properties, purification of these toxins into individual toxins remains difficult in spite of the complex protocols described in the literature. Several purification steps were reported, including partitioning [23], solid phase extraction (SPE) with $\mathrm{C}_{18}$ or ion-exchange sorbents [32,33], and flash chromatography [18]. Sometimes, several methods were combined [34]. Among the purification methods starting from Ostreopsis cf. ovata cells, Hwang et al (2013) purpose they used liquid-liquid partitioning with butanol followed by purification via flash 
100 chromatography with silica gel, then Sephadex LH-20 and, finally, preparative $\mathrm{C}_{18}$ 101 chromatography [35]. Uchida et al (2013) isolated OVTX analogues in purified extracts of 102 Ostreopsis cf. ovata from Japanese IK2 strain using liquid-liquid partition with 103 dichloromethane followed by purification through SPE cartridge (OASIS HLB) [34].

104 Ciminiello et al. (2012) succeeded in isolating OVTX-a using an Ostreopsis cf. ovata strain 105 which produced $77 \%$ of OVTX-a, and which did not produce any OVTX-b and OVTX-c 106 (OVTXs eluting very close to OVTX-a) [18]. The cell extract was first partitioned with 107 dichloromethane followed by flash chromatography and preparative chromatography both

108

\section{EXPERIMENTAL SECTION}

\subsection{Chemicals}

Acetonitrile (ACN) for LC-MS/MS analysis and methanol $(\mathrm{MeOH})$ were obtained as HPLC grade solvents (JT Baker) from Atlantic Labo (Bruges, France). Milli-Q water used for mobile phase and extraction was supplied by a Milli-Q integral 3 system (Millipore). Formic acid (Puriss quality), ammonium formate (Purity for MS), and acetic acid (99\% purity) were from Sigma Aldrich (Saint Quentin Fallavier, France). PLTX standard for LC-MS/MS analysis was purchased from Wako Chemicals GmbH (Neuss, Germany). Sephadex LH-20 was purchased from VWR (Strasbourg, France). Acetonitrile and water used for LC- HR MS ${ }^{\mathrm{n}}$ analysis were optima purity from Fisher Scientific (Illkirch, France). 


\subsection{Ostreopsis cf. ovata cultures}

Purification of ovatoxins was carried out from cells of cultured Ostreopsis cf. ovata. Cells were originally isolated by capillary pipet from field water collected in the bay of Villefranche-sur-Mer in summer 2011, during a bloom of Ostreopsis cf. ovata.

After initial growth in microplates, the cells were cultured in $350 \mathrm{~mL}$ flasks at $22^{\circ} \mathrm{C}$ under 16L:8D cycle $\left(420 \mu \mathrm{mol} \cdot \mathrm{m}^{-2} \cdot \mathrm{s}^{-1}\right)$. Culture conditions were previously optimized [36] and were established in filtered natural seawater, at salinity of 38, adding nutrients at L1 concentration and soil extract. Cells were harvested during late stationary phase, between 25 and $30 \mathrm{~d}$, when biomass and toxin concentrations were optimum [22]. Cells were gently removed from the flask bottom, and subsequently the homogenized culture was centrifuged at $3000 \mathrm{~g}$ for $15 \mathrm{~min}$. Supernatants were discarded and cell pellets were kept at $-20^{\circ} \mathrm{C}$ until extraction.

\subsection{Cell extraction}

Methanol $(\mathrm{MeOH}) /$ water $(50 \mathrm{~mL}, 1 / 1: \mathrm{v} / \mathrm{v})$ was added to $20 \mathrm{~g}$ of algal paste, obtained from $10 \mathrm{~L}$ of Ostreopsis cf. ovata cultures. The mixture was sonicated twice, with ultrasonic probe, during $40 \mathrm{~min}$, while cooling the solution with an ice bath. Once cells were disrupted, the sample was centrifuged at $3000 \mathrm{~g}$ at $4^{\circ} \mathrm{C}$ for $15 \mathrm{~min}$. The resulting pellets were rinsed twice with $20 \mathrm{~mL}$ of methanol/water (1/1: v/v) and supernatants were combined and adjusted to $100 \mathrm{~mL}$ with methanol/water $(1 / 1: \mathrm{v} / \mathrm{v})$. The extract was separated into 3 homogenized fractions. The first part $(10 \mathrm{~mL})$ was kept as crude extract and used for purification monitoring, while the two other fractions $(45 \mathrm{~mL})$ were used for purification. These last two samples were filtered through $0.45 \mu \mathrm{m}$ membrane and concentrated to $5 \mathrm{~mL}$ under a gentle stream of nitrogen before purification using Sephadex LH-20.

\subsection{Pre-prurification by Sephadex LH-20}

Prior to use, Sephadex LH-20 sorbent (60 g) was conditioned with MeOH over night, then packed in a glass column $(76 \times 2 \mathrm{~cm})$ and finally rinsed with $\mathrm{MeOH}$. The two concentrated extracts of Ostreopsis cf. ovata $(5 \mathrm{~mL})$ were loaded separately onto the Sephadex LH-20 column. Thirty-three fractions of 5 or $10 \mathrm{~mL}$ of $\mathrm{MeOH}$ were collected. Fractions were filtered (Nanosep MF $0.2 \mu \mathrm{m}$ ) and analyzed by LC-MS/MS in order to identify fractions containing OVTXs. Fractions which contained significant quantities of OVTXs were gathered and concentrated under nitrogen stream. 


\subsection{Chromatographic systems and conditions}

160

161

162

163

164

165

166

167

168

169

170

171

172

173

174

175

176

177

178

179

180

181

182

183

184

185

186

187

188

189

Four chromatographic systems were used: 1) to quantify the toxins during purification steps (system 1);2) to analyze and to characterize toxins present in some extracts and purified fractions (system 2);3) to characterize and to select the columns for chromatographic purification and analysis process (system 3); 4) to monitor extracts during purification process and to confirm the column choice for chromatographic purification (system 4).

All these chromatographic systems included solvent reservoir, online degasser, quaternary pump, thermostated autosampler and thermostated column compartment.

\subsubsection{System 1: LC-MS/MS quantification}

LC-MS/MS experiments were performed using a LC system (UFLC XR, Shimadzu, Champs-sur-Marne, France) coupled to a hybrid triple quadrupole/linear ion-trap mass spectrometer (API 4000 Qtrap, AB SCIEX, Les Ulis, France) equipped with a turbospray interface. Toxins were separated on a $\mathrm{C}_{18}$ Gemini column $(150 \times 2.0 \mathrm{~mm}, 3 \mu \mathrm{m})$ (Phenomenex, Le Pecq, France), thermostated at $22^{\circ} \mathrm{C}$, with water (A) and $95 \%$ acetonitrile/water (B), both containing $2 \mathrm{mM}$ ammonium formate and $50 \mathrm{mM}$ formic acid at $0.2 \mathrm{~mL} / \mathrm{min}$ flow rate. The gradient was raised from $20 \%$ to $100 \% \mathrm{~B}$ over $10 \mathrm{~min}$ and was held for 4 min before dropping down to the initial conditions.

Mass spectral detection was carried out using multiple reactions monitoring (MRM) mode (positive ions). MRM experiments were established using the following source settings: curtain gas set at $30 \mathrm{psi}$, ion spray at $5000 \mathrm{~V}$, a turbogas temperature of $300^{\circ} \mathrm{C}$, gas 1 and 2 set at 30 and 40 psi, respectively, and an entrance potential of $10 \mathrm{~V}$. For highest selectivity, each toxin was quantified with three transitions (Table 2).

A collision energy (CE) of $47 \mathrm{eV}$ was applied for bi-charged ions $[\mathrm{M}+2 \mathrm{H}]^{2+},[\mathrm{M}+2 \mathrm{H}-$ $\left.\mathrm{H}_{2} \mathrm{O}\right]^{2+}$, and a CE of $31 \mathrm{eV}$ for the tri-charged ions $\left[\mathrm{M}+3 \mathrm{H}-\mathrm{H}_{2} \mathrm{O}\right]^{3+}$ to give the characteristic product ion at $m / z, 327,343$ or 371 (Part A) $\left[\mathrm{M}+\mathrm{H}-\mathrm{B} \text { moiety }-\mathrm{H}_{2} \mathrm{O}\right]^{+}$(see palytoxin structure, figure 1). Declustering potential (DP) was set at $56 \mathrm{~V}$ for all transitions and cell exit potentials (CXP) were 20 and $18 \mathrm{~V}$ for bi-charged ions and tri-charged ions, respectively. Transitions in Table 2 were monitored with a dwell time of $25 \mathrm{~ms}$ per transition. As only the palytoxin standard was available, quantitative determination of putative-palytoxin, ovatoxin$\mathrm{a},-\mathrm{b},-\mathrm{c},-\mathrm{d},-\mathrm{e},-\mathrm{f}$ and $-\mathrm{h}$, in extracts was carried out assuming that their molar responses were identical to that of palytoxin, at concentrations of $0.05,0.1,0.5,1,2,4,8$ and $10 \mu \mathrm{g} / \mathrm{mL}$. 


\subsubsection{System 2: HR LC-MS and $M S^{n}$ analysis}

Analyses were performed using a UHPLC system (1290 Infinity, Agilent Technologies, Waldbronn, Germany) coupled to a 6540 UHD accurate-Mass Q-TOF (Agilent Technologies, Santa Clara, USA) equipped with a dual ESI source. Chromatographic separation was achieved on a Kinetex $\mathrm{C}_{18}(100 \times 2.1 \mathrm{~mm}, 1.7 \mu \mathrm{m})$ (Phenomenex, Le Pecq, France) column, maintained at $40^{\circ} \mathrm{C}$ and with a flow rate of $300 \mu \mathrm{L} / \mathrm{min}$. The binary mobile phase consisted of water (A) and acetonitrile/water (95/5, v/v) (B), both containing $0.2 \%$ acetic acid. The gradient was as follows: $0-20$ min from $20 \%$ to $30 \% \mathrm{~B}, 20-21$ min from $30 \%$ to $100 \% \mathrm{~B}$, 21-25 min $100 \% \mathrm{~B}, 25-26 \mathrm{~min}$ from $100 \%$ to $20 \% \mathrm{~B}$, and 4 min re-equilibration with $20 \%$ B.

The instrument was operated in positive mode performing full-scan analysis over $\mathrm{m} / \mathrm{z} 100$ to 1700 range with an acquisition rate of 2 spectra/s and targeted MS/MS analysis at 5 spectra/s. Capillary voltage was $3500 \mathrm{~V}$ and fragmentor voltage $150 \mathrm{~V}$. The temperature of the Jet Stream Technologies ${ }^{\mathrm{TM}}$ source was set at $200^{\circ} \mathrm{C}$ with drying gas at $5 \mathrm{~L} / \mathrm{min}$ and sheath gas at $11 \mathrm{~L} / \mathrm{min}$ at $350^{\circ} \mathrm{C}$. Three different collision energies were applied to the precursor ions to obtain an overview of the fragmentation pathways. The instrument control, data processing and analysis were conducted using Mass Hunter ${ }^{\mathrm{TM}}$ software.

Calculation of elemental formula in full scan MS and CID $\mathrm{MS}^{2}$ spectra were performed by using the mono-isotopic ion peak of each ion cluster.

2.5.3. System 3: LC-UV column characterization and selection for chromatographic purification and analysis process

LC-UV experiments were performed using an Ultimate 3000RS LC system (Thermo Fisher, Villebon sur Yvette, France), including diode array detector. All the acquisition and analysis data were controlled by Chromeleon 6.8 (Thermo Fisher, Villebon sur Yvette, France).

Eight columns were tested to find a column able to separate the OVTXs in order to analyze and/or prepurify Ostreopsis extracts and Sephadex LH-20 fractions (See supplementary data Table S1).

\subsection{3.a. Evaluation of column characteristics}

Part of the procedure described by Engelhardt et al [38] was used, with a test mixture containing toluene and ethylbenzene to evaluate hydrophobicity and methylene selectivity, dimethylaniline to evaluate silanol activity and thiourea to evaluate the void volume of 
columns. Chromatographic conditions were as follows: mobile phase, methanol/water (6:4, $\mathrm{v} / \mathrm{v}$ ); injection volume, 5 or $1 \mu \mathrm{L}$ (according to void volume); temperature, $30^{\circ} \mathrm{C}$; and $\mathrm{UV}$ detection at $254 \mathrm{~nm}$. Extra-column volumes were subtracted for all columns in order to calculate their real intrinsic void volume. This void volume was required to calculate the true retention factors for the compounds injected to thus characterize different columns.

- Methylene selectivity between toluene and ethylbenzene was calculated as follows:

$$
\alpha_{\mathrm{E} / \mathrm{T}}=\mathrm{k}_{\text {ethylbenzene }} / \mathrm{k}_{\text {toluene }}=\mathrm{k}_{\mathrm{E}} / \mathrm{k}_{\mathrm{T}}
$$

with $\mathrm{k}_{\text {toluene }}\left(\mathrm{k}_{\mathrm{T}}\right)$ and $\mathrm{k}_{\text {ethylbenzene }}\left(\mathrm{k}_{\mathrm{E}}\right)$ being retention factors of toluene and ethylbenzene, respectively.

- Selectivity between toluene and dimethylaniline was calculated as follows:

$$
\alpha_{\mathrm{DMA} / \mathrm{T}}=\mathrm{k}_{\text {dimethylaniline }} / \mathrm{k}_{\text {toluene }}=\mathrm{k}_{\mathrm{DMA}} / \mathrm{k}_{\mathrm{T}}
$$

with $\mathrm{k}_{\text {toluene }}\left(\mathrm{k}_{\mathrm{T}}\right)$ and $\mathrm{k}_{\text {dimethylaniline }}\left(\mathrm{k}_{\mathrm{DMA}}\right)$ being retention factors of toluene and dimethylaniline, respectively.

\subsection{3.b. Selection of columns able to separate PLTXs-group toxins}

A fraction containing ovatoxins, after clean-up of an Ostreopsis cf. ovata extract, using Sephadex LH-20, was injected to make an initial selection of columns. Chromatographic conditions were as follows: injection volume, 10 or $2 \mu \mathrm{L}$ (according to void volume); temperature, $25^{\circ} \mathrm{C}$; UV detection at $263 \mathrm{~nm}$. Linear gradient elution was accomplished in approximately 60 min with water (eluent A) and $95 \%$ acetonitrile/water (eluent B) both containing $0.2 \%$ of acetic acid (See supplementary data Figure S1). To compare the retention and the separation of the PLTX-group toxins we adapted the gradient parameters to the column dimensions, i.e. the isocratic time $(\mathrm{x})$ at the beginning of the gradient and the flow rate (See supplementary data Table S2).

Separation between peaks was evaluated by calculating resolution with the following formula [39]:

$$
R=1.18 \frac{t_{r 2}-t_{r 1}}{w_{1 / 2-2}+w_{1 / 2-1}}
$$

where $t_{r 1}$ and $t_{r 2}$ denote the retention times of the first peak and the second peak, respectively; $\mathrm{w}_{1 / 2-1}$ and $\mathrm{w}_{1 / 2-2}$ are peak widths at the half height of the first and the second peak, respectively. 
LC-MS experiments were performed using an Agilent 1160 LC/MS (Agilent, Les Ulis,

254

255

256

257

258

259

260

261

262

263

264

265

266

267

268

269

270

271

272

273

274

275

276

277

278

279

280

281

282

France) including a simple quadrupole MS detector and a diode array detector. Full scan analyses were carried out in positive mode, with the mass range set to $m / z 300-1450$. The conditions of API-ESI source were as follows: drying gas $\left(\mathrm{N}_{2}\right)$, flow rate, $12 \mathrm{~mL} / \mathrm{min}$; drying gas temperature, $325^{\circ} \mathrm{C}$; nebulizer, $50 \mathrm{psi}$; capillary voltage, $4800 \mathrm{~V}$; fragmentor $165 \mathrm{~V}$. All acquisition and analysis data were controlled by Agilent LC/MSD ChemStation (Agilent, Les Ulis, France). ). This chromatographic system was firstly used to confirm the choice of the columns that would then be subsequently evaluated in the analysis of extracts and fractions from purification steps.

\subsection{4.a. Column choice for analysis and purification}

Three stationary phases, among the eight stationary phases previously tested, were selected by comparison of the chromatograms of the same pre-purified extract obtained in full scan: Kinetex $\mathrm{C}_{18}(100 \times 4.6 \mathrm{~mm}, 2.6 \mu \mathrm{m})$; Kinetex PFP $(150 \times 2.1 \mathrm{~mm}, 2.6 \mu \mathrm{m})$; Uptisphere $\mathrm{C}_{18}$-TF $(250 \times 4.6 \mathrm{~mm}, 5 \mu \mathrm{m})$.

A fraction containing ovatoxins, after clean-up of an Ostreopsis cf. ovata extract, using Sephadex LH-20, was injected. The chromatographic conditions were as follows: injection volume, $20 \mu \mathrm{L}$; temperature, $25^{\circ} \mathrm{C}$. Linear gradient elution was accomplished in 40 min with water (eluent $\mathrm{A}$ ) and $95 \%$ acetonitrile/water (eluent B) both containing $0.2 \%$ of acetic acid. The gradient was as follows: $0-40 \mathrm{~min}$ from $20 \%$ to $50 \% \mathrm{~B}, 40-41 \mathrm{~min}$ from $50 \%$ to $100 \%$ $\mathrm{B}, 41-46 \min 100 \% \mathrm{~B}, 46-47 \mathrm{~min}$ from $100 \%$ to $20 \% \mathrm{~B}$, and re-equilibration with $20 \% \mathrm{~B}$. To compare the retention and the separation of the PLTX-group toxins the flow rate were respectively: Kinetex $\mathrm{C}_{18}, 0.7 \mathrm{~mL} / \mathrm{min}$; Kinetex PFP, $0.2 \mathrm{~mL} / \mathrm{min}$; Uptisphere $\mathrm{C}_{18}-\mathrm{TF}, 1$ $\mathrm{mL} / \mathrm{min}$.

\subsection{4.b. Analyses of extracts and fractions}

Monitoring of purification steps was carried out in full scan on the Kinetex $\mathrm{C}_{18}(100 \times 4.6$ $\mathrm{mm}, 2.6 \mu \mathrm{m}$ ) column, thermostated at $25^{\circ} \mathrm{C}$. Linear gradient elution was accomplished in $20 \mathrm{~min}$ with water (eluent $\mathrm{A}$ ) and $95 \%$ acetonitrile/water (eluent B) both containing $0.2 \%$ of acetic acid, at $0.7 \mathrm{~mL} / \mathrm{min}$ flow rate. The gradient was as follows: $0-20 \mathrm{~min}$ from $20 \%$ to $40 \% \mathrm{~B}$, 20-21 min from $40 \%$ to $100 \% \mathrm{~B}, 21-28 \mathrm{~min} 100 \% \mathrm{~B}, 28-29 \mathrm{~min}$ from $100 \%$ to $20 \% \mathrm{~B}$, and re-equilibration with $20 \% \mathrm{~B}$. 


\section{RESULTS AND DISCUSSION}

\subsection{Toxin profile of Ostreopsis cf. ovata IFR-OST-0.3 V}

An intense bloom of Ostreopsis cf. ovata occurred in 2011 on Villefranche-sur-Mer coast (France). Cells were harvested and cultivated (IFR-OST-0.3 V strain) with the optimized culture conditions. Ostreopsis cf. ovata produced up to $20 \mathrm{~g}$ of biomass for approximately $10 \mathrm{~L}$ of culture, with an average of $92 \mathrm{pg}^{-1}$ cell $^{-1}$ (PLTX equivalent) of toxins. Crude extract of cells were analyzed by UHPLC-HRMS (Q-TOF) in full MS and CID MS ${ }^{2}$ modes with the Kinetex $\mathrm{C}_{18}$ column $(100 \times 2.1 \mathrm{~mm}, 1.7 \mu \mathrm{m})$. The separation was not totally complete but sufficient to obtain mass spectra of OVTXs. In the absence of standards for any of the ovatoxin analogues, compounds were identified by high resolution MS and by comparison with both an in-house developed database and published ovatoxin spectra (2) $[15,16,40]$.

The elemental formulae attributed to ovatoxins-a, -b, -c, $-\mathrm{d}$ and -e (Table 3) were obtained from their $[\mathrm{M}+2 \mathrm{H}]^{2+},\left[\mathrm{M}+2 \mathrm{H}-\mathrm{H}_{2} \mathrm{O}\right]^{2+},[\mathrm{M}+\mathrm{H}+\mathrm{Ca}]^{3+}$ and $\left[\mathrm{M}-\text { Fragment } \mathrm{B}-\mathrm{H}_{2} \mathrm{O}\right]^{+}$ ions, confirming that these ovatoxins were very closed to the ones described by Ciminiello et al [15]. Indeed, they present the same elemental formulae, and errors of the different fragments attributed were generally lower than $10 \mathrm{ppm}$ (see Tables S3 and S4 in supplementary data). Precision was lower than typically achieved on this instrument, at least partly due to the low abundance of the mono-isotopic ions of the molecular clusters mentioned above. Use of the mono-isotopic ions is however required in order to facilitate the interpretation of fragmentation patterns.

The order of elution of OVTXs was the same as already reported $[15,16]$ : OVTX-c, then OVTX-d and OVTX-e, OVTX-b and OVTX-a as major product. Moreover, another component, eluting after OVTX-a, could be attributed to an ovatoxin analogue thanks to its fragmentation characteristics: [M-fragment $\left.\mathrm{B}-\mathrm{H}_{2} \mathrm{O}\right]^{+}$at $\mathrm{m} / z$ 327.1914, bi-charged and tricharged clusters characterized by multiple water loss and retention time close to ovatoxins. Moreover, it was be noticed that this analogue had the same UV spectra as the other OVTXs $(\lambda \max =233$ and $263 \mathrm{~nm})$, confirming the presence of the same chromophores. This compound was named ovatoxin-h (OVTX-h).

\subsection{Characterization of ovatoxin-h}

As already outlined by Ciminiello, assignment of elemental formulae of OVTXs is complicated because of their high molecular weight, numerous possible combinations of $\mathrm{C}$, 
$\mathrm{H}, \mathrm{O}$ and $\mathrm{N}$ atoms, water losses and various adducts formed with mono and divalent cations [16]. The elemental formula assigned to ovatoxin-h $\left(\mathrm{C}_{129} \mathrm{H}_{225} \mathrm{~N}_{3} \mathrm{O}_{51}\right)$ was deduced by combining assignment of the most abundant doubly and triply charged ions of full MS spectra of OVTX-h, namely:

- $[\mathrm{M}+2 \mathrm{H}]^{2+} m / z 1317.7602$ (mono-isotopic $m / z$ 1317.2569, $\mathrm{C}_{129} \mathrm{H}_{227} \mathrm{~N}_{3} \mathrm{O}_{51}, \Delta=-3.45$ ppm)

- $\left[\mathrm{M}+2 \mathrm{H}-1 \mathrm{H}_{2} \mathrm{O}\right]^{2+} \mathrm{m} / \mathrm{z}, 1308.7580$ (mono-isotopic $\mathrm{m} / \mathrm{z}, 1308.2519, \mathrm{C}_{129} \mathrm{H}_{225} \mathrm{~N}_{3} \mathrm{O}_{50}, \Delta=$ $1.15 \mathrm{ppm})$

- $\left[\mathrm{M}+2 \mathrm{H}-2 \mathrm{H}_{2} \mathrm{O}\right]^{2+} m / z 1299.7493$ (mono-isotopic $m / z$ 1299.2474, $\mathrm{C}_{129} \mathrm{H}_{223} \mathrm{~N}_{3} \mathrm{O}_{49}, \Delta=$ 3.77 ppm)

- $\left[\mathrm{M}+2 \mathrm{H}-3 \mathrm{H}_{2} \mathrm{O}\right]^{2+} \mathrm{m} / \mathrm{z} 1290.7453$ (mono-isotopic $m / z$ 1290.2434, $\mathrm{C}_{129} \mathrm{H}_{221} \mathrm{~N}_{3} \mathrm{O}_{48}, \Delta=$ $3.77 \mathrm{ppm})$

- $[\mathrm{M}+\mathrm{H}+\mathrm{Ca}]^{3+} m / z 891.4937$ (mono-isotopic $m / z$ 891.1586, $\mathrm{C}_{129} \mathrm{H}_{226} \mathrm{~N}_{3} \mathrm{O}_{51} \mathrm{Ca}, \Delta=-1.19$ ppm)

- $\left[\mathrm{M}+\mathrm{H}+\mathrm{Ca}-1 \mathrm{H}_{2} \mathrm{O}\right]^{3+} \mathrm{m} / \mathrm{z} 885.4921$ (mono-isotopic $m / z$ 885.1542, $\mathrm{C}_{129} \mathrm{H}_{224} \mathrm{~N}_{3} \mathrm{O}_{50} \mathrm{Ca}, \Delta=$ 0.97 ppm)

- $\left[\mathrm{M}+\mathrm{H}+\mathrm{Ca}-2 \mathrm{H}_{2} \mathrm{O}\right]^{3+} \mathrm{m} / \mathrm{z} 879.4890$ (mono-isotopic $m / z$ 879.1517, $\mathrm{C}_{129} \mathrm{H}_{222} \mathrm{~N}_{3} \mathrm{O}_{49} \mathrm{Ca}, \Delta=$ $-1.78 \mathrm{ppm})$.

All these attributions were confirmed by the comparison of all theoretical and experimental ions of the isotopic profile (see Tables S5 and S6 in supplementary data). Therefore, OVTX-h contains 1 oxygen atom less and 2 hydrogen atoms more than OVTX-a. An alternative formulae $\left(\mathrm{C}_{128} \mathrm{H}_{221} \mathrm{~N}_{3} \mathrm{O}_{52}\right)$ could have been assigned but was rejected due to the mass error exceeding 10 ppm in most cases (Tables S5 and S6 in supplementary data).

HR LC-MS/MS spectra of these two OVTXs were acquired and analyzed in parallel in order to identify the region of the molecule where structural differences occurred between OVTX-a and OVTX-h. The structure of OVTX-a was recently determined by nuclear resonance magnetic (NMR) [18]. This study was based on a previous one by Ciminiello et al., in which the authors demonstrated characteristic fragmentations at several sites of the backbone of OVTX-a and PLTX. Structural information was obtained by $\mathrm{MS}^{2}$ experiments, using both the $[\mathrm{M}+2 \mathrm{H}]^{2+}$ ion $\mathrm{m} / z, 1317.7627$ and the $[\mathrm{M}+\mathrm{H}+\mathrm{Ca}]^{3+}$ ion $\mathrm{m} / z 891.4935$ for OVTX-h and $[\mathrm{M}+2 \mathrm{H}]^{2+}$ ion $m / z \quad 1324.7543$ and the $[\mathrm{M}+\mathrm{H}+\mathrm{Ca}]^{3+}$ ion $m / z \quad 896.1549$ for OVTX-a as precursors (Figure 4).

In accordance with the study by Ciminiello et al., different types of fragments could be observed on the HR CID MS ${ }^{2}$ spectra (Figure 4). First of all, some fragments were the result 
of cleavage of the molecule, generating mono- or bi-charged ions and corresponding to the Aside (containing $2 \mathrm{~N}$ ) and/or the B-side (containing $1 \mathrm{~N}$ ). Most of these ions were calcium adduct fragments, whereas the others were protonated fragments. These fragmentations were also characterized by several water losses. Secondly, combinations of several consecutive fragmentations may occur, leading to mono- or di-charged fragments.

Comparison of elemental formulae of OVTX-h fragments with OVTX-a fragments suggested that they shared the same backbone and indicated the region where structural difference occurred (Figure 4; Table 4 and Table 5). Numbers attributed to fragments in this work are the same as those attributed in the studies by Ciminiello et al. [16,40], in order to facilitate comparison and comprehension between the studies.

In the parts of the structure ranging from $\mathrm{C} 1$ to $\mathrm{C} 9$ and from $\mathrm{C} 50$ to $\mathrm{C} 115$ (Figure 4) cleavages occurred at the same sites in both OVTX-a and OVTX-h, and generated \#4A-side and \#17B-side having the same elemental composition in both compounds (Table 4), suggesting that the structural differences occurred between C9 and C50. Moreover, \#4B-side and \#17A-side have a difference of elemental composition corresponding to one $\mathrm{O}$ atom less and two $\mathrm{H}$ more for OVTX-h as compared to OVTX-a. The internal fragment corresponding to cleavages \# $4+\# 12$ indicated the same elemental formulae for OVTX-a and OVTX-h, suggesting that they share the same structure between $\mathrm{C} 9$ and $\mathrm{C} 41$. This was corroborated by the internal fragments corresponding to cleavages, \# $7+\# 12$, \# $9+\# 12$ and \# $10+\# 12$ found identical in both molecules. All these observations lead us to conclude that structural differences occurred between $\mathrm{C} 42$ and C49. Comparing relative double bonds of OVTX-a and OVTX-h for the \#4 B-side (RDB = 17 and 16 respectively) and the \#17 A-side (RDB = 9 and 8 respectively), we could suggest a ring opening in the part of the OVTX-h molecule comprised between $\mathrm{C} 42$ and $\mathrm{C} 49$.

However, clearly more investigations will be required for the full structure elucidation of OVTX-h.

\subsection{Prepurification by Sephadex LH-20 and fractions of interest}

The strategy pursued to purify OVTXs was to initially pre-purify a high quantity of Ostreopsis cf. ovata extract, in order to eliminate the majority of undesirable compounds, then to separate OVTXs with a semi-preparative column and individually collect them. A previous study demonstrated the efficacy of Sephadex LH-20 sorbent to pre-purify Ostreopsis extracts [22], and purification of toxins from their algal producer had previously been achieved with a 
383

384

385

386

387

388

389

390

391

392

393

394

395

396

397

398

399

400

401

402

403

404

405

406

407

408

409

410

411

412

413

414

415

reduced number of purification steps for other toxins [41]. The Sephadex LH-20 sorbent was chosen since it provides separations on the basis of molecular size with an exclusion limit of MW 4,000-5,000 Da. This purification-step provided a cleanup efficiency of $93 \%$ and a recovery of about $85 \%$, representing an increase of toxin percentage of 13 -fold. The percentage of toxins in Ostreopsis crude extract had been $0.4 \%$ while the percentage of toxins in the relevant Sephadex LH-20 fraction was increased to $5.1 \%$ (Figure 5). While the chromatogram of the crude extract showed numerous peaks corresponding to unknown compounds and a high base line, the chromatogram of the purified extract shows almost only OVTXs (set aside the well separated solvent/matrix front). This visual confirmation shows that a large proportion of undesirable compounds was eliminated after passage through Sephadex LH-20 stationary phase. Moreover, the separation of PLTX-group toxins was improved, with less shouldered peaks, suggesting that Sephadex LH-20 had also eliminated molecules eluting at the same retention time as PLTX-group toxins. PLTX-group toxins were identified by their characteristic mass spectra in comparison with the literature [15].

Sephadex LH-20 fractions containing OVTXs were combined in order to decrease the number of purification steps and purify a high quantity of OVTXs at once. In general, a loss of compounds is observed in any purification step. During the optimization of the purification step with Sephadex LH-20, important losses of toxins were observed when using glass tubes. The amount lost was different for different elution solvents $(\mathrm{MeOH}$ or $\mathrm{MeOH} /$ water $(1 / 1$ v/v)). For example, a loss of $83 \%$ of OVTXs was observed during the storage over two months of methanolic fractions (concentration about $58 \mu \mathrm{g} / \mathrm{mL}$ of ovatoxins), even at $-20^{\circ} \mathrm{C}$, whereas the loss was much less important $(30 \%)$ with $\mathrm{MeOH} /$ water $(1 / 1 \mathrm{v} / \mathrm{v})$ fractions (concentration about $26 \mu \mathrm{g} / \mathrm{mL}$ of ovatoxins) over the same time period and even at $-20^{\circ} \mathrm{C}$. It was supposed either transformation of ovatoxins or interactions between OVTXs and silanols of glass tubes could occur. These interactions diminished when $50 \%$ of water is present in solution. This protective effect of water could be due to an increase of dielectric constant of the solvent, diminishing the electrostatic interactions, and/or to an increase of OVTXs solubility in the medium. Polypropylene tubes were then used for later experiments to avoid such losses.

Another loss of OVTXs during purification processes could be observed during the evaporation of chromatographic fractions, even if when a gentle stream of nitrogen was used. Indeed, after evaporation to dryness, re-dissolution of toxins in $\mathrm{MeOH} / \mathrm{H}_{2} \mathrm{O}(1 / 1 \mathrm{v} / \mathrm{v})$ was very difficult, a loss of $33 \%$ of toxins being typically observed. Complete evaporation to 
dryness was therefore avoided and evaporation was only used for sample concentration, with a final volume of solvent always being retained.

\subsection{Column selection and evaluation}

Purification and separation of OVTXs is difficult, mainly because they have high molecular weight and small structural differences. Otherwise, they possess an amphiphilic character due to long carbon chains and numerous hydroxyl groups. Considering these characteristics we compared the chromatographic behavior of OVTXs in a pre-purified extract with different columns possessing different potential interaction modes: hydrophobic, dipolar and electrostatic interactions (See supplementary data Table S7).

The selected columns differed by their bonded structure (long alkyl chain $\left(\mathrm{C}_{18}\right)$ or polar embedded $\mathrm{C}_{18}$ or pentafluorophenyl (PFP)) and their grafting mode (mono or tri-anchored). Chromatographic separation using HILIC interaction had been initially considered, however, was not finally used as ovatoxins appeared more soluble in $\mathrm{MeOH} /$ water mixtures, not recommended as injection solvent with these columns. Gemini $\mathrm{C}_{18}$ stationary phase was envisaged because it is the most widely used stationary phase for detection and quantification of OVTXs. Kinetex $\mathrm{C}_{18}$ stationary phase is a recent, silica-based stationary phase with $\mathrm{C}_{18}$ bonding. This column is characterized by its Core-shell ${ }^{\mathrm{TM}}$ technology that results in narrower peaks compared to porous silica $\mathrm{C}_{18}$ columns. Such better peak shape would be advantageous for the separation of closely eluting ovatoxins. Uptisphere $\mathrm{C}_{18}-\mathrm{TF}$ stationary phase is a trifunctional $\mathrm{C}_{18}$ stationary phase that possesses an alternative selectivity compared to classical $\mathrm{C}_{18}$ phases [42]. Acclaim Polar Advantage II (PA2), Synergy Fusion RP and Polaris Amide- $\mathrm{C}_{18}$ stationary phases possess a $\mathrm{C}_{18}$ grafting with a polar embedded functional group inserted near the silica resulting in balanced polar and hydrophobic interactions. Finally, another Kinetex stationary phase was used with pentafluorophenyl (PFP) grafting. This column may provide a very high degree of steric selectivity to separate structural isomers and high selectivity for cationic compounds due to the electronegative fluorine groups. These four last columns could facilitate interactions with polar groups of OVTXs, and could influence their separation.

\subsubsection{Evaluation of column characteristics}

Toluene $(\mathrm{T})$ and ethylbenzene (E) retention factors $\left(\mathrm{k}_{\mathrm{T}}\right.$ and $\mathrm{k}_{\mathrm{E}}$ respectively) and methylene selectivity $\left(\alpha_{\mathrm{E} / \mathrm{T}}=\mathrm{k}_{\mathrm{E}} / \mathrm{k}_{\mathrm{T}}\right)$ were lower for the Uptisphere $\mathrm{C}_{18}-\mathrm{TF}$, the Polaris amide 
$449 \mathrm{C}_{18}$ and the Kinetex PFP columns, showing their low hydrophobicity and methylene selectivity in comparison with the other columns (see Table S6 in supplementary data). This would be expected for Polaris Amide $\mathrm{C}_{18}$ and Kinetex PFP since their stationary phases possess functions allowing polar interactions. The lower retention factors of the Uptisphere $\mathrm{C}_{18}$ - TF column could be attributed mainly to lower bonding density, this column showing a comparable methylene selectivity to the other $\mathrm{C}_{18}$ columns. Surprisingly, the two other embedded $\mathrm{C}_{18}$ columns (Synergi Fusion RP and Acclaim polar advantage II) showed hydrophobic characteristics and methylene selectivity close to Gemini $\mathrm{C}_{18}$ and Kinetex $\mathrm{C}_{18}$.

The analysis of the tailing factor of dimethylaniline $\left(\mathrm{A}_{\mathrm{S}_{\mathrm{DMA}}}\right)$ compared to the tailing factor of ethylbenzene $\left(\mathrm{A}_{\mathrm{S}_{\mathrm{E}}}\right)$ showed that Uptisphere $\mathrm{C}_{18}$-TF and the Kinetex PFP possess a high silanol activity or high accessibility to polar sites (as previously described by Lesellier et al. [42]). The specific behavior of these two columns is corroborated by the high value obtained for selectivity between DMA and toluene.

\subsubsection{Pre-selection of columns able to separate PLTXs-group toxins}

To date, there is no official method for PLTX-group toxin analyses; consequently, each laboratory develops their own methodology in order to confirm or not the presence of toxins in samples [43]. A pre-purified extract of Ostreopsis cf. ovata was analyzed by LC with these eight selected columns to verify their selectivity for ovatoxins (for chromatographic separation see Figure 6, for resolutions Table 6). Chromatographic detection was carried out using both UV (at $263 \mathrm{~nm}$ ) and full scan mass spectrometric detection. Interestingly, an ovatoxin-a isomer, showing the same MS spectra as OVTX-a but different retention time, was observed only with the Uptispher C18-TF stationary phase. This isomer was named OVTXa'.

Despite the potentially different interaction modes of these eight columns, ovatoxins surprisingly eluted in the same order independent of the column: OVTX-c, OVTX-d and/or OVTX-e, OVTX-b, OVTX-a and -a' and OVTX-h. However, p-PLTX was not detected in any of our samples. Among the seven ovatoxins detected in the extract:

- Gemini $C_{18}$ and Polar advantage II columns were able to separate only four peaks. With these columns, OVTX-d and -e were indistinguishable, and OVTX-a and OVTX-h were not separated.

- Synergi Fusion and Polaris Amide columns were able to separate five peaks. With these columns the resolutions were generally superior to 1.6, i.e. baseline separation 
was almost achieved. However, even if resolutions were sufficient for most OVTXs, some analogues were not well separated. Indeed OVTX-d and -e were indistinguishable and OVTX-a and OVTX-h were totally (Polaris amide) or partially (Synergi Fusion) separated.

- Kinetex $C_{18}$ and Kinetex PFP columns could separate more or less efficiently six peaks: OVTX-c, OVTX-d, OVTX-e, OVTX-b, OVTX-a and OVTX-h. Generally, resolutions were higher than 1.6 with these columns, except between OVTX-d and OVTX-e. These two compounds are isomers; therefore, separation between them was expected to be more complicated.

- Uptisphere $C_{18}-T F$ was the only column able to separate all seven OVTXs present in our samples. All resolutions were not superior to 1.5, however, partial separation was possible for OVTX-a and OVTX-a' and OVTX-d and OVTX-e.

With the UV detection mode, three stationary phases were then first selected as they were able to give the best separation of OVTXs: Kinetex $\mathrm{C}_{18}$, Kinetex PFP and Uptisphere $\mathrm{C}_{18} \mathrm{TF}$.

\subsubsection{Final selection of columns able to separate PLTXs-group toxins}

The advantage of UV detection at $\lambda=263 \mathrm{~nm}$ was to selectively detect OVTXs present in the samples. Subsequently, the same samples were analyzed in Full Scan MS mode with these three selected columns (Kinetex $\mathrm{C}_{18}$, Kinetex PFP and Uptisphere $\mathrm{C}_{18}$-TF) in order to confirm our choice, both in terms of separation of OVTXs between themselves, and in terms of the separation from unknown compounds eluted in the same fraction as OVTXs, named P1 to P6 (See supplementary data: figures S2.a to S2.f for P1 to P6 spectra and S2.g to S2.m for OVTXs spectra). The chromatograms obtained with these three columns are reported Figure 8.

The chromatograms obtained for these three columns confirmed the separations previously obtained (UV detection at $263 \mathrm{~nm}$ ). Peaks obtained with the Kinetex $\mathrm{C}_{18}$ column were very narrow, proving the efficacy of Core-shell ${ }^{\mathrm{TM}}$ technology. Also, compounds all eluted with lower retention times than those of the two other columns, permitting lower analysis time. However, six unknown compounds (P1-P6) were also present in this sample. Three of these unknowns had retention times very close to OVTXs, hence it may be more difficult to separate these compounds from OVTXs by semi-preparative chromatography. Separation of OVTXs with the Kinetex PFP column seemed to be poor with these chromatographic conditions similar to the Kinetex $\mathrm{C}_{18}$ column. This was possibly related to 
515 the high injection volume $(20 \mu \mathrm{L})$. Indeed, there was no separation between OVTX-d, -e, and -b. Moreover, only five unknown compounds were observed, and they were not well separated. The Uptisphere $\mathrm{C}_{18}-\mathrm{TF}$ column allowed for a satisfactory separation between OVTXs, comparable to the chromatogram recorded with UV detection. With this column, the six unknown compounds (P1-P6) were also better separated from ovatoxins. Considering that their mass spectra revealed numerous water losses and clusters of tri- and di-charged ions, these compounds may be structurally related to OVTXs. However, they have molecular weights significantly lower than OVTXs, and compounds with their mass-spectra were, to our knowledge, not yet reported in the literature.

The particular selectivity of the Uptisphere $\mathrm{C}_{18}$-TF stationary phase could be due to the tri-anchored grafting mode. With this column, the $\mathrm{C}_{18}$ alkyl chains would therefore be more distant from each other, allowing for better insertion of OVTXs between the $\mathrm{C}_{18}$ alkyl chains, leading to higher interactions with the stationary phase. Separation of ovatoxin-d and ovatoxin-e is a particular challenge as these two molecules are isomers. Uptisphere $\mathrm{C}_{18}-\mathrm{TF}$ allowed for their separation, however separation between ovatoxin-e and ovatoxin-b was decreased. An attempt to improve separation on the Uptisphere column was carried out by varying some parameters including acetic acid percentage in the mobile phase $(0,0.1$ or $0.2 \%$ ), gradient steepness and percentage of organic solvent (acetonitrile) at the beginning and at the end of the linear gradient. Higher acidity of the mobile phase $(0.2 \%$ of acetic acid) provided sharper peaks and reduced ovatoxin retention times confirming the choice of $0.2 \%$ acetic acid percentage. Moreover, best separation and repeatable retention times were obtained with a slow, linear gradient from $20 \%$ to $40 \%$ over 40 min. The Uptisphere $\mathrm{C}_{18}-\mathrm{TF}$ column was thus selected for first step of semi-preparative chromatography $(250 \times 10 \mathrm{~mm}$, $5 \mu \mathrm{m}$ ) for separation of higher quantities of OVTXs. Ideally, this column should be combined with Kinetex $\mathrm{C}_{18}$ for better isolation of OVTXs.

\section{CONCLUSION}

A new ovatoxin analog, named ovatoxin-h, has been detected in a French Ostreopsis cf. ovata strain collected at Villefranche-sur-Mer. It represents almost $15 \%$ of the ovatoxin profile of Ostreopsis cf. ovata [22]. Ovatoxin-h elemental composition presents one oxygen atom less and two hydrogens more than ovatoxin-a. The LC-HR MS ${ }^{2}$ data suggest that structural differences between molecules could be between C42 and C49. Chromatographic separations with different reversed phase sorbents showed that Kinetex $\mathrm{C}_{18}$, Kinetex PFP and 
Uptisphere $\mathrm{C}_{18}$ - $\mathrm{TF}$ allowed for the best separations, almost achieving baseline resolution for most ovatoxins and thus allowing for their easy identification and quantification. Uptisphere $\mathrm{C}_{18}$-TF is proposed for preparative chromatography, as it is able to separate a higher number of ovatoxins (especially ovatoxin-d and ovatoxin-e) and it is able to separate ovatoxins from unknown compounds. In combination with our previous work [22], we propose a purification method for ovatoxins from the biomass of cultured Ostreopsis cf. ovata, using first a chromatographic step separation with a Sephadex-LH-20 phase, and then a separation step with an Uptisphere $\mathrm{C}_{18}$-TF column. However, preliminary purification tests (data not shown) underlined loss of ovatoxins during the purification process, probably due to adsorptions and/or transformation of ovatoxins. Before accomplishment of complete purification, purity and stability tests have to be completed.

\section{ACKNOWLEDGMENTS}

The authors would like to thank Carmela Dell'Aversano for sharing information on ovatoxins relevant to this paper. We thank Rodolphe Lemée for his help during the collection of Ostreopsis cf. ovata strain. The authors also would like to thank Drs. Thomas Glauner, Thierry Faye and John Lee of Agilent Technologies for their collaboration through provision of the Agilent 6540 Q-ToF instrument. Finally, the authors acknowledge the financial contribution of the Regional Council of the "Pays de la Loire" toward the PhD thesis of Charline Brissard.

\section{CONFLIC OF INTEREST}

The authors declare no conflict of interest

\section{REFERENCES}

[1] N.T. Shears, P.M. Ross, Blooms of benthic dinoflagellates of the genus Ostreopsis; an increasing and ecologically important phenomenon on temperate reefs in New Zealand and worldwide, Harmful Algae 8 (2009) 916-925.

[2] L. Rhodes, World-wide occurrence of the toxic dinoflagellate genus Ostreopsis Schmidt, Toxicon 57 (2011) 400-407.

[3] M. Vila, E. Garces, M. Maso, Potentially toxic epiphytic dinoflagellate assemblages on macroalgae in the NW Mediterranean, Aquatic Microbial Ecology 26 (2001) 51-60.

[4] A. Penna, M. Vila, S. Fraga, M.G. Giacobbe, F. Andreoni, P. Riobo, C. Vernesi, Characterization of Ostreopsis and Coolia (Dinophyceae) isolates in the western Mediterranean Sea based on morphology, toxicity and internal transcribed spacer $5.8 \mathrm{~s}$ rDNA sequences, Journal of Phycology 41 (2005) 212-225.

[5] L. Mangialajo, R. Bertolotto, R. Cattaneo-Vietti, M. Chiantore, C. Grillo, R. Lemee, N. Melchiorre, P. Moretto, P. Povero, N. Ruggieri, The toxic benthic dinoflagellate 
Ostreopsis ovata: Quantification of proliferation along the coastline of Genoa, Italy Marine Pollution Bulletin 56 (2008) 1209-1214.

[6] L. Mangialajo, N. Ganzin, S. Accoroni, V. Asnaghi, A. Blanfune, M. Cabrini, R. Cattaneo-Vietti, F. Chavanon, M. Chiantore, S. Cohu, E. Costa, D. Fornasaro, H. Grossel, F. Marco-Miralles, M. Maso, A. Rene, A. Maria Rossi, M. Montserrat Sala, T. Thibaut, C. Totti, M. Vila, R. Lemee, Trends in Ostreopsis proliferation along the Northern Mediterranean coasts, Toxicon 57 (2011) 408-420.

[7] C. Totti, S. Accoroni, F. Cerino, E. Cucchiari, T. Romagnoli, Ostreopsis ovata bloom along the Conero Riviera (northern Adriatic Sea): Relationships with environmental conditions and substrata, Harmful Algae 9 (2010) 233-239.

[8] K. Aligizaki, G. Nikolaidis, The presence of the potentially toxic genera Ostreopsis and Coolia (Dinophyceae) in the north Aegean sea, Greece Harmful Algae 5 (2006) 717730.

[9] P. Ciminiello, C. Dell'Aversano, E. Fattorusso, M. Forino, G.S. Magno, L. Tartaglione, C. Grillo, N. Melchiorre, The Genoa 2005 outbreak. Determination of putative palytoxin in Mediterranean Ostreopsis ovata by a new liquid chromatography tandem mass spectrometry method, Analytical Chemistry 78 (2006) 6153-6159.

[10] L. Tichadou, M. Glaizal, A. Armengaud, H. Grossel, R. Lemee, R. Kantin, J.-L. Lasalle, G. Drouet, L. Rambaud, P. Malfait, L. de Haro, Health impact of unicellular algae of the Ostreopsis genus blooms in the Mediterranean Sea: experience of the French Mediterranean coast surveillance network from 2006 to 2009, Clinical Toxicology 48 (2010) 839-844.

[11] R. Simonini, M. Orlandi, M. Abbate, Is the toxic dinoflagellate Ostreopsis cf. ovata harmful to Mediterranean benthic invertebrates? Evidences from ecotoxicological tests with the polychaete Dinophilus gyrociliatus, Marine Environmental Research 72 (2011) 230-233.

[12] E. Graneli, N.K. Vidyarathna, E. Funari, P.R.T. Cumaranatunga, R. Scenati, Can increases in temperature stimulate blooms of the toxic benthic dinoflagellate Ostreopsis ovata?, Harmful Algae 10 (2011) 165-172.

[13] W. Iddir-Ihaddaden, K.O. Abdellah, G. Merbout, R. Abtroun, B. Alamir, L. de Haro, Health impact of unicellular algae of the Ostreopsis genus blooms in Algeria during summer 2009 Presse medicale (Paris, France : 1983) 42 (2013) 1281-1283.

[14] P. Ciminiello, C. Dell'Aversano, E. Fattorusso, M. Forino, L. Tartaglione, C. Grillo, N. Melchiorre, Putative palytoxin and its new analogue, ovatoxin-a, in Ostreopsis ovata collected along the Ligurian coasts during the 2006 toxic outbreak, Journal of the American Society for Mass Spectrometry 19 (2008) 111-120.

[15] P. Ciminiello, C. Dell'Aversano, E. Dello Iacovo, E. Fattorusso, M. Forino, L. Grauso, L. Tartaglione, F. Guerrini, R. Pistocchi, Complex palytoxin-like profile of Ostreopsis ovata. Identification of four new ovatoxins by high-resolution liquid chromatography/mass spectrometry, Rapid Communications in Mass Spectrometry 24 (2010) 2735-2744.

[16] P. Ciminiello, C. Dell'Aversano, E. Dello Iacovo, E. Fattorusso, M. Forino, L. Tartaglione, C. Battocchi, R. Crinelli, E. Carloni, M. Magnani, A. Penna, Unique toxin profile of a Mediterranean Ostreopsis cf. ovata strain: HR LC-MSn characterization of ovatoxin-f, a new palytoxin congener, Chemical Research in Toxicology 25 (2012) 1243-1252.

[17[17]M. García-Altares, L. Tartaglione, C. Dell'Aversano, O. Carnicer, P. de la Iglesia, M. Forino, J. Diogène, P. Ciminiello, The novel ovatoxin-g and isobaric palytoxin (so far referred to as putative palytoxin) from Ostreopsis cf. ovata (NW Mediterranean Sea): 
structural insights by LC-high resolution MSn. Analytical and Bioanalytical Chemistry (2014) DOI 10.1007/s00216-014-8338-y.

[18] P. Ciminiello, C. Dell'Aversano, E. Dello Iacovo, E. Fattorusso, M. Forino, L. Grauso, L. Tartaglione, F. Guerrini, L. Pezzolesi, R. Pistocchi, S. Vanucci, Isolation and structure elucidation of ovatoxin-a, the major toxin produced by Ostreopsis ovata, Journal of the American Chemical Society 134 (2012) 1869-1875.

[19] P. Ciminiello, C. Dell'Aversano, E. Dello Iacovo, E. Fattorusso, M. Forino, L. Tartaglione, T. Yasumoto, C. Battocchi, M. Giacobbe, A. Amorim, A. Penna, Investigation of toxin profile of Mediterranean and Atlantic strains of Ostreopsis cf. siamensis (Dinophyceae) by liquid chromatography-high resolution mass spectrometry, Harmful Algae 23 (2013) 19-27.

[20] P. Ciminiello, C. Dell'Aversano, E. Dello Iacovo, E. Fattorusso, M. Forino, L. Tartaglione, R. Rossi, V. Soprano, D. Capozzo, L. Serpe, Palytoxin in seafood by liquid chromatography tandem mass spectrometry: investigation of extraction efficiency and matrix effect, Analytical and Bioanalytical Chemistry 401 (2011) 10431050.

[21] S. Accoroni, T. Romagnoli, F. Colombo, C. Pennesi, C.G. Di Camillo, M. Marini, C. Battocchi, P. Ciminiello, C. Dell'Aversano, E. Dello Iacovo, E. Fattorusso, L. Tartaglione, A. Penna, C. Totti, Ostreopsis cf. ovata bloom in the northern Adriatic Sea during summer 2009: Ecology, molecular characterization and toxin profile, Marine Pollution Bulletin 62 (2011) 2512-2519.

[22] C. Brissard, C. Herrenknecht, V. Sechet, F. Herve, F. Pisapia, J. Harcouet, R. Lemee, N. Chomerat, P. Hess, Z. Amzil, Complex toxin profile of French Mediterranean Ostreopsis cf. ovata strains, seafood accumulation and ovatoxins prepurification, Marine Drugs 12 (2014) 2851-2876.

[22] S.[23] S. Lenoir, L. Ten-Hage, J. Turquet, J.P. Quod, C. Bernard, M.C. Hennion, First evidence of palytoxin analogues from an Ostreopsis mascarenensis (Dinophyceae) benthic bloom in Southwestern Indian Ocean, Journal of Phycology 40 (2004) 10421051.

[24] S.M. Nascimento, E.V. Correa, M. Menezes, D. Varela, J. Paredes, S. Morris, Growth and toxin profile of Ostreopsis cf. ovata (Dinophyta) from Rio de Janeiro, Brazil, Harmful Algae 13 (2012) 1-9.

[25] Z. Amzil, M. Sibat, N. Chomerat, H. Grossel, F. Marco-Miralles, R. Lemee, E. Nezan, V. Sechet, Ovatoxin-a and palytoxin accumulation in seafood in relation to Ostreopsis cf. ovata blooms on the French Mediterranean Coast, Marine Drugs 10 (2012) 477496.

[26] T. Suzuki, R. Watanabe, R. Matsushima, K. Ishihara, H. Uchida, S. Kikutsugi, T. Harada, H. Nagai, M. Adachi, T. Yasumoto, M. Murata, LC-MS/MS analysis of palytoxin analogues in blue humphead parrotfish Scarus ovifrons causing human poisoning in Japan, Food Additives and Contaminants Part a-Chemistry Analysis Control Exposure \& Risk Assessment 30 (2013) 1358-1364.

[27] R. Rossi, V. Castellano, E. Scalco, L. Serpe, A. Zingone, V. Soprano, New palytoxinlike molecules in Mediterranean Ostreopsis cf. ovata (dinoflagellates) and in Palythoa tuberculosa detected by liquid chromatography-electrospray ionization time-of-flight mass spectrometry, Toxicon 56 (2010) 1381-1387.

[28] E. Scalco, C. Brunet, F. Marino, R. Rossi, V. Soprano, A. Zingone, M. Montresor, Growth and toxicity responses of Mediterranean Ostreopsis cf. ovata to seasonal irradiance and temperature conditions, Harmful Algae 17 (2012) 25-34.

[29] R.E. Moore, P.J. Scheuer, Science, Palytoxin: a new marine toxin from a coelenterate, 172 (1971) 495-498. 
[30] A. Tubaro, G. Del Favero, D. Beltramo, M. Ardizzone, M. Forino, M. De Bortoli, M. Pelin, M. Poli, G. Bignami, P. Ciminiello, S. Sosa, Acute oral toxicity in mice of a new palytoxin analog: 42-Hydroxy-palytoxin, Toxicon 57 (2011) 755-763.

[31] T. Ukena, M. Satake, M. Usami, Y. Oshima, H. Naoki, T. Fujita, Y. Kan, T. Yasumoto, Structure elucidation of ostreocin D, a palytoxin analog isolated from the dinoflagellate Ostreopsis siamensis, Bioscience Biotechnology and Biochemistry 65 (2001) 2585-2588.

[32] P. Ciminiello, C. Dell'Aversano, E. Dello Iacovo, E. Fattorusso, M. Forino, L. Grauso, L. Tartaglione, C. Florio, P. Lorenzon, M. De Bortoli, A. Tubaro, M. Poli, G. Bignami, Stereostructure and biological activity of 42-hydroxy-palytoxin: A New palytoxin analogue from Hawaiian Palythoa subspecies, Chemical Research in Toxicology 22 (2009) 1851-1859.

[33] A.I. Selwood, R. van Ginkel, D.T. Harwood, P.S. McNabb, L.R. Rhodes, P.T. Holland, A sensitive assay for palytoxins, ovatoxins and ostreocins using LC-MS/MS analysis of cleavage fragments from micro-scale oxidation, Toxicon 60 (2012) 810-820.

[34] H. Uchida, Y. Taira, T. Yasumoto, Structural elucidation of palytoxin analogs produced by the dinoflagellate Ostreopsis ovata IK2 strain by complementary use of positive and negative ion liquid chromatography/quadrupole time-of-flight mass spectrometry, Rapid Communications in Mass Spectrometry 27 (2013) 1999-2008.

[35] B.S. Hwang, E.Y. Yoon, H.S. Kim, W. Yih, J.Y. Park, H.J. Jeong, J.-R. Rho, Ostreol A: A new cytotoxic compound isolated from the epiphytic dinollagellate Ostreopsis cf. ovata from the coastal waters of Jeju Island, Korea, Bioorganic \& Medicinal Chemistry Letters 23 (2013) 3023-3027.

[36] V. Sechet, M. Sibat, N. Chomerat, E. Nezan, H. Grossel, J.-B. Lehebel-Peron, T. Jauffrais, N. Ganzin, F. Marco-Miralles, R. Lemee, Z. Amzil, Ostreopsis cf. ovata in the French Mediterranean coast: molecular characterisation and toxin profile Cryptogamie Algologie 33 (2012) 89-98.

[37] C. West, E. Lesellier, Orthogonal screening system of columns for supercritical fluid chromatography, Journal of Chromatography A 1203 (2008) 105-113.

[38] H. Engelhardt, M. Arangio, T. Lobert, A chromatographic test procedure for reversedphase HPLC column evaluation, LC GC-Magazine of Separation Science 15 (1997) 856-\&.

[38[39]V. Meyer, Practical high-performance liquid chromatography, fourth ed, John Wiley \& Sons, Weinheim, 2004.

[40] P. Ciminiello, C. Dell'Aversano, E. Dello Iacovo, E. Fattorusso, M. Forino, L. Grauso, L. Tartaglione, High resolution LC-MSn fragmentation pattern of palytoxin as template to gain new insights into ovatoxin-a structure. The key role of calcium in MS behavior of palytoxins, Journal of the American Society for Mass Spectrometry 23 (2012) 952-963.

[41] T. Jauffrais, J. Kilcoyne, V. Sechet, C. Herrenknecht, P. Truquet, F. Herve, J.B. Berard, C. Nulty, S. Taylor, U. Tillmann, C.O. Miles, P. Hess, Production and isolation of azaspiracid-1 and-2 from Azadinium spinosum culture in pilot scale photobioreactors, Marine Drugs 10 (2012) 1360-1382.

[42] E. Lesellier, A. Tchapla, A simple subcritical chromatographic test for an extended ODS high performance liquid chromatography column classification, Journal of Chromatography A 1100 (2005) 45-59.

[43] P. Riobo, L. E., J.M. Franco, Chemical methods for phycotoxins detection: LC and LC/MS/MS, in: A.G. Cabado, J.M. Vieites (Eds.), New trends in marine freshwater toxins, Nova Science Publishers, Inc., New York 2012. pp 215-267. 


\section{FIGURE CAPTIONS}

734 Figure 1. Palytoxin and ovatoxin-a structures. Cleavage between carbons 8 and 9 originates A and B structural moieties.

Figure 2. 2OVTXs detected in the extract of Ostreopsis cf. ovata. HR-MS/MS spectra were obtained by fragmentation of bi-charged ions at three different collision energies of 20,40 and $60 \mathrm{eV}$. The average spectra are shown here.

Figure 4. HR MS/MS spectra of the di-charged ion $[\mathrm{M}+2 \mathrm{H}]^{2+}$ of $(\mathrm{A})$ ovatoxin-a [1324.7543] and (B) ovatoxin-h [1317.7627], both at CE $20 \mathrm{eV}$. Figures (C), (E) represent MS/MS spectra of the triply charged ion $[\mathrm{M}+\mathrm{H}+\mathrm{Ca}]^{3+}$ of ovatoxin-a [896.1549] at $\mathrm{CE} 30$ and $40 \mathrm{eV}$, respectively. Figures (D), (F) represent ovatoxin-h [891.4935] at CE 30 and $40 \mathrm{eV}$, respectively.

747 Figure 5. Structure of ovatoxin-a and cleavages resulting from various HR CID MS ${ }^{2}$ spectra 748 of OVTX-a and OVTX-h. Cleavage numeration was the same as that reported in literature 749 [40]. Solid lines correspond to cleavages that generated two fragments (left and right hand 750 side of the molecule) while dotted lines correspond to internal fragments (missing left and right hand side of the molecule). The two regions marked in red denote those where differences are observed in fragments between OVTX-a and OVTX-h.

754 Figure 6. Comparison of crude extract (in red) and a fraction containing toxins eluted from 755 Sephadex LH-20 (in green). The blue line represents an injection of a solvent blank. 756 Chromatograms were obtained with chromatographic conditions as follows: Kinetex $\mathrm{C}_{18}(100$ $757 \times 4.6 \mathrm{~mm}, 2.6 \mu \mathrm{m}$ ) gradient elution during 20 minutes with water (eluent A) and $95 \%$ 758 acetonitrile/water (eluent $\mathrm{B}$ ) both containing $0.2 \%$ of acetic acid, at $0.7 \mathrm{~mL} / \mathrm{min}$ flow rate, and with percentage of B varying from $20 \%$ to $40 \%$. Analyses were obtained in full scan $\mathrm{m} / \mathrm{z}$ [300-1450]. 
762 Figure 7. Comparison of the portion of the chromatograms containing the OVTXs and 763 obtained for a Sephadex LH-20 pre-purified extract analyzed with eight different columns 764 (See Table S1 in supplementary data). Separations were carried out with gradient elution with 765 water (eluent A) and $95 \%$ acetonitrile/water (eluent B), both containing $0.2 \%$ of acetic acid, 766 and changing percentage of B from $20 \%$ to $40 \%$ over $40 \mathrm{~min}$. Flow rate was adapted for 767 each column (See Table S2 in supplementary data). Detection was carried out using UV at $768263 \mathrm{~nm}$.

770 Figure 8. Comparison of chromatograms of a fraction containing ovatoxins after clean-up 771 using Sephadex LH-20 obtained using three different columns: (A) Kinetex $\mathrm{C}_{18}(100 \times 4.6 \mathrm{~mm}$, $7722.6 \mu \mathrm{m})$, (B) Kinetex PFP $(150 \times 2.1 \mathrm{~mm}, 2.6 \mu \mathrm{m})$ and $(\mathrm{C})$ Uptisphere $\mathrm{C}_{18}$-TF $(250 \times 4.6 \mathrm{~mm}, 5$ $773 \mu \mathrm{m})$. Separation was carried out using linear gradient elution with water (eluent A) and $95 \%$ 774 acetonitrile/water (eluent B), both containing $0.2 \%$ of acetic acid, and changing percentage of 775 B from $20 \%$ to $50 \%$ over $40 \mathrm{~min}$. Flow rate was adapted for each column: (A) $0.7 \mathrm{~mL} / \mathrm{min}$, 776 (B) $0.2 \mathrm{~mL} / \mathrm{min}$, (C) $1 \mathrm{~mL} / \mathrm{min}$. Injected volumes: $20 \mu \mathrm{L}$. Detection used: Full Scan MS ( $\mathrm{m} / \mathrm{z}$ 777 [300-1450]).

778

779

780 
783

784

785

786

787

788

\begin{tabular}{cccc}
\hline Toxins & {$[\mathbf{M}+\mathbf{2} \mathbf{H}]^{\mathbf{2 +}} \rightarrow \mathbf{P a r t} \mathbf{A}$} & {$\left[\mathbf{M}+\mathbf{2} \mathbf{H}-\mathbf{H}_{\mathbf{2}} \mathbf{O}\right]^{\mathbf{2 +}} \rightarrow \mathbf{P a r t} \mathbf{A}$} & {$\left[\mathbf{M}+\mathbf{3} \mathbf{H}-\mathbf{H}_{\mathbf{2}} \mathbf{O}\right]^{\mathbf{3}} \rightarrow \mathbf{P a r t} \mathbf{A}$} \\
\hline p-PLTX & $1340.3 \rightarrow 327.3$ & $1331.3 \rightarrow 327.3$ & $887.8 \rightarrow 327.3$ \\
OVTX-a & $1324.3 \rightarrow 327.3$ & $1315.3 \rightarrow 327.3$ & $877.2 \rightarrow 327.3$ \\
OVTX-b & $1346.3 \rightarrow 371.2$ & $1337.3 \rightarrow 371.2$ & $891.8 \rightarrow 371.2$ \\
OVTX-c & $1354.3 \rightarrow 371.2$ & $1345.3 \rightarrow 371.2$ & $897.2 \rightarrow 371.2$ \\
OVTX-d & $1332.3 \rightarrow 327.3$ & $1323.3 \rightarrow 327.3$ & $882.5 \rightarrow 327.3$ \\
OVTX-e & $1332.3 \rightarrow 343.2$ & $1323.3 \rightarrow 343.2$ & $882.5 \rightarrow 343.2$ \\
OVTX-f & $1338.3 \rightarrow 327.3$ & $1329.3 \rightarrow 327.3$ & $886.5 \rightarrow 327.3$ \\
OVTX-h & $1317.6 \rightarrow 327.3$ & $1308.8 \rightarrow 327.3$ & $872.5 \rightarrow 327.3$ \\
\hline
\end{tabular}

Table 1. Structural information concerning PLTX and OVTXs: elementary formulae, elemental composition of A- and B- moieties resulting from cleavage between C8 and C9 and an additional water loss, molecular weight $[15,16,17,19]$

\begin{tabular}{cccccc}
\hline Toxins & Elementary formulae & A moiety $\left[\mathrm{M}-\mathrm{B}-\mathrm{H}_{2} \mathrm{O}\right]^{+}(\mathrm{m} / \mathrm{z})$ & $\mathrm{B}$ moiety & MW Da \\
\hline Palytoxin/ & $\mathrm{C}_{129} \mathrm{H}_{223} \mathrm{~N}_{3} \mathrm{O}_{54}$ & $\mathrm{C}_{16} \mathrm{H}_{26} \mathrm{~N}_{2} \mathrm{O}_{5}$ & $(327.3)$ & $\mathrm{C}_{113} \mathrm{H}_{195} \mathrm{NO}_{48}$ & 2680.14 \\
p-PLTX* & $\mathrm{C}_{129} \mathrm{H}_{223} \mathrm{~N}_{3} \mathrm{O}_{52}$ & $\mathrm{C}_{16} \mathrm{H}_{26} \mathrm{~N}_{2} \mathrm{O}_{5}$ & $(327.3)$ & $\mathrm{C}_{113} \mathrm{H}_{195} \mathrm{NO}_{46}$ & 2648.14 \\
Ovatoxin-a & $\mathrm{C}_{131} \mathrm{H}_{227} \mathrm{~N}_{3} \mathrm{O}_{53}$ & $\mathrm{C}_{18} \mathrm{H}_{30} \mathrm{~N}_{2} \mathrm{O}_{6}$ & $(371.3)$ & $\mathrm{C}_{113} \mathrm{H}_{195} \mathrm{NO}_{46}$ & 2692.20 \\
Ovatoxin-b & $\mathrm{C}_{131} \mathrm{H}_{227} \mathrm{~N}_{3} \mathrm{O}_{54}$ & $\mathrm{C}_{18} \mathrm{H}_{30} \mathrm{~N}_{2} \mathrm{O}_{6}$ & $(371.3)$ & $\mathrm{C}_{113} \mathrm{H}_{195} \mathrm{NO}_{47}$ & 2708.20 \\
Ovatoxin-c & $\mathrm{C}_{129} \mathrm{H}_{223} \mathrm{~N}_{3} \mathrm{O}_{53}$ & $\mathrm{C}_{16} \mathrm{H}_{26} \mathrm{~N}_{2} \mathrm{O}_{5}$ & $(327.3)$ & $\mathrm{C}_{113} \mathrm{H}_{195} \mathrm{NO}_{47}$ & 2664.14 \\
Ovatoxin-d & $\mathrm{C}_{129} \mathrm{H}_{223} \mathrm{~N}_{3} \mathrm{O}_{53}$ & $\mathrm{C}_{16} \mathrm{H}_{26} \mathrm{~N}_{2} \mathrm{O}_{6}$ & $(343.3)$ & $\mathrm{C}_{113} \mathrm{H}_{195} \mathrm{NO}_{46}$ & 2664.14 \\
Ovatoxin-e & $\mathrm{C}_{131} \mathrm{H}_{227} \mathrm{~N}_{3} \mathrm{O}_{52}$ & $\mathrm{C}_{16} \mathrm{H}_{26} \mathrm{~N}_{2} \mathrm{O}_{5}$ & $(327.3)$ & $\mathrm{C}_{115} \mathrm{H}_{199} \mathrm{NO}_{46}$ & 2676.20 \\
Ovatoxin-f & $\mathrm{C}_{129} \mathrm{H}_{223} \mathrm{~N}_{3} \mathrm{O}_{51}$ & $\mathrm{C}_{16} \mathrm{H}_{26} \mathrm{~N}_{2} \mathrm{O}_{5}$ & $(327.3)$ & $\mathrm{C}_{113} \mathrm{H}_{195} \mathrm{NO}_{45}$ & 2632.14 \\
Ovatoxin-g & \multicolumn{2}{c}{ palytoxin and putative palytoxin are chromatographically separated yet present the same mass spectral characteristics }
\end{tabular}

Table 2. LC-MS/MS PLTX-group toxin transitions.
789

7913

792 Elemental formulae and molecular mass propositions, retention times and exact masses of the most important peak of principal ions $(\mathrm{m} / \mathrm{z}$ ) of ovatoxins in the IFR-OST-0.3 V extract as measured by QTOF LC-HR-MS in positive mode

\begin{tabular}{|c|c|c|c|c|c|}
\hline & OVTX-a & OVTX-b & OVTX-c & OVTX-d & OVTX-e \\
\hline Elemental formulae & $\begin{array}{c}\mathrm{C}_{129} \mathrm{H}_{223} \mathrm{~N}_{3} \mathrm{O}_{5} \\
2\end{array}$ & $\mathrm{C}_{131} \mathrm{H}_{227} \mathrm{~N}_{3} \mathrm{O}_{5}$ & $\mathrm{C}_{131} \mathrm{H}_{227}$ & $\mathrm{~S}_{1}$ & $\mathrm{C}_{129} \mathrm{H}_{223} \mathrm{~N}_{3} \mathrm{O}_{53}$ \\
\hline $\begin{array}{l}\text { Mono-isotopic } \\
\text { molecular ion }\end{array}$ & 2646.4898 & 2990.5160 & 2706.5109 & 2662.4847 & 2662.4847 \\
\hline Retention time (min) & 15.95 & 15.49 & 14.27 & 14.80 & 15.00 \\
\hline
\end{tabular}




\begin{tabular}{ccccccc}
\hline & {$[\mathrm{M}+2 \mathrm{H}]^{2+}$} & 1324.2505 & 1346.2653 & 1354.2627 & 1332.2471 & 1332.2488 \\
lons & {$\left[\mathrm{M}+2 \mathrm{H}-\mathrm{H}_{2} \mathrm{O}\right]^{2+}$} & 1315.2469 & 1337.2589 & 1345.2441 & 1323.2442 & 1323.2287 \\
$\mathbf{m} / \mathbf{z}$ & {$[\mathrm{M}+\mathrm{H}+\mathrm{Ca}]^{3+}$} & 896.1556 & 910.4952 & 916.1609 & 901.1480 & 901.1518 \\
& {$\left[\mathrm{M}-\text { Fragment B }-\mathrm{H}_{2} \mathrm{O}\right]^{+}$} & 327.1904 & 371.2174 & 371.2165 & 327.1900 & 343.1861 \\
\hline
\end{tabular}

795

796 
Table 4 Assignment of A- and -B side fragments observed in HR CID MS ${ }^{2}$ spectra of OVTX-a and OVTX-h, assigned to corresponding 797 cleavages according to Ciminello et al. [40].

\begin{tabular}{|c|c|c|c|c|c|c|c|c|c|c|c|c|}
\hline \multirow[b]{2}{*}{ Cleavage [40] } & \multicolumn{6}{|c|}{ OVTX-a } & \multicolumn{6}{|c|}{ OVTX-h } \\
\hline & $\mathrm{m} / \mathrm{z}$ & $\begin{array}{l}\text { Water } \\
\text { loss }\end{array}$ & $\begin{array}{c}\text { lon } \\
\text { charge }\end{array}$ & Formula & $\mathrm{RDB}^{\star}$ & $\Delta \mathrm{ppm}^{\bullet}$ & $\mathrm{m} / \mathrm{z}$ & $\begin{array}{c}\text { Water } \\
\text { loss }\end{array}$ & $\begin{array}{c}\text { lon } \\
\text { charge }\end{array}$ & Formula* & $\mathrm{RDB}^{\star}$ & $\Delta \mathrm{ppm}^{\star}$ \\
\hline \#4 / A side & $327.1912^{a, b, c}$ & $-1 \mathrm{H}_{2} \mathrm{O}$ & $1+$ & $\mathrm{C}_{16} \mathrm{H}_{27} \mathrm{O}_{5} \mathrm{~N}_{2}$ & 4.5 & -2.45 & $327.1911^{\mathrm{a}}$ & $-1 \mathrm{H}_{2} \mathrm{O}$ & $1+$ & $\mathrm{C}_{16} \mathrm{H}_{27} \mathrm{O}_{5} \mathrm{~N}_{2}$ & 4.5 & -2.75 \\
\hline \#4 / B side & $1171.6305^{\mathrm{a}}$ & & $2+$ & $\mathrm{C}_{113} \mathrm{H}_{195} \mathrm{O}_{46} \mathrm{NCa}$ & 17 & -5.46 & $1164.6396^{\mathrm{a}}$ & & $2+$ & $\mathrm{C}_{113} \mathrm{H}_{197} \mathrm{O}_{45} \mathrm{NCa}$ & 16 & -1.07 \\
\hline \#12 / A side & $\begin{array}{l}536.8003^{\mathrm{a}} \\
527.2896^{\mathrm{a}}\end{array}$ & $-1 \mathrm{H}_{2} \mathrm{O}$ & $2+$ & $\begin{array}{l}\mathrm{C}_{52} \mathrm{H}_{92} \mathrm{O}_{18} \mathrm{~N}_{2} \mathrm{Ca} \\
\mathrm{C}_{52} \mathrm{H}_{90} \mathrm{O}_{17} \mathrm{~N}_{2} \mathrm{Ca}\end{array}$ & 8 & $\begin{array}{c}0.09 \\
-6.96\end{array}$ & $527.2916^{a}$ & $-1 \mathrm{H}_{2} \mathrm{O}$ & $2+$ & $\mathrm{C}_{52} \mathrm{H}_{90} \mathrm{O}_{17} \mathrm{~N}_{2} \mathrm{Ca}$ & 8 & -3.17 \\
\hline \#15 / A side & $588.3217^{\mathrm{a}}$ & & $2+$ & $\mathrm{C}_{56} \mathrm{H}_{100} \mathrm{O}_{21} \mathrm{~N}_{2} \mathrm{Ca}$ & 8 & -0.93 & nd* & & & & & \\
\hline \#16 / A side & $625.3378^{a}$ & & $2+$ & $\mathrm{C}_{59} \mathrm{H}_{106} \mathrm{O}_{23} \mathrm{~N}_{2} \mathrm{Ca}$ & 8 & -4.48 & nd* & & & & & \\
\hline \#16 / B side & $\begin{array}{l}737.8607^{\mathrm{a}} \\
728.8589^{\mathrm{a}} \\
719.8518^{\mathrm{a}}\end{array}$ & $\begin{array}{l}-1 \mathrm{H}_{2} \mathrm{O} \\
-2 \mathrm{H}_{2} \mathrm{O}\end{array}$ & $2+$ & $\begin{array}{l}\mathrm{C}_{70} \mathrm{H}_{117} \mathrm{O}_{29} \mathrm{NCa} \\
\mathrm{C}_{70} \mathrm{H}_{115} \mathrm{O}_{28} \mathrm{NCa} \\
\mathrm{C}_{70} \mathrm{H}_{113} \mathrm{O}_{27} \mathrm{NCa}\end{array}$ & 13 & $\begin{array}{l}-8.38 \\
-3.70 \\
-6.24\end{array}$ & $\mathrm{nd*}$ & & & & & \\
\hline \#17 / A side & $639.3346^{\mathrm{a}}$ & & $2+$ & $\mathrm{C}_{60} \mathrm{H}_{106} \mathrm{O}_{24} \mathrm{~N}_{2} \mathrm{Ca}$ & 9 & -5.40 & $632.3446^{a}$ & & $2+$ & $\mathrm{C}_{60} \mathrm{H}_{108} \mathrm{O}_{23} \mathrm{~N}{ }_{2} \mathrm{Ca}$ & 8 & -6.09 \\
\hline \#17 / B side & $\begin{array}{l}1390.7669^{c} \\
1372.7629^{c}\end{array}$ & $-1 \mathrm{H}_{2} \mathrm{O}$ & $1+$ & $\begin{array}{l}\mathrm{C}_{69} \mathrm{H}_{116} \mathrm{O}_{27} \mathrm{~N} \\
\mathrm{C}_{69} \mathrm{H}_{114} \mathrm{O}_{26} \mathrm{~N}\end{array}$ & 12.5 & $\begin{array}{c}4.72 \\
-0.01\end{array}$ & $1372.7534^{c}$ & $-1 \mathrm{H}_{2} \mathrm{O}$ & $1+$ & $\mathrm{C}_{69} \mathrm{H}_{114} \mathrm{O}_{26} \mathrm{~N}$ & 12.5 & -6.92 \\
\hline \#19 / B side & $804.4338^{b, c}$ & & $1+$ & $\mathrm{C}_{39} \mathrm{H}_{66} \mathrm{O}_{16} \mathrm{~N}$ & & -5.42 & nd* & & & & & \\
\hline \#21 / A side & $\begin{array}{l}1131.5913^{\mathrm{a}} \\
1113.6230^{\mathrm{b}}\end{array}$ & $\begin{array}{l}-1 \mathrm{H}_{2} \mathrm{O} \\
-3 \mathrm{H}_{2} \mathrm{O}\end{array}$ & $2+$ & $\begin{array}{l}\mathrm{C}_{107} \mathrm{H}_{190} \mathrm{O}_{45} \mathrm{~N}_{2} \mathrm{Ca} \\
\mathrm{C}_{107} \mathrm{H}_{186} \mathrm{O}_{43} \mathrm{~N}_{2} \mathrm{Ca}\end{array}$ & & $\begin{array}{c}-19.46 \\
18.17\end{array}$ & $\begin{array}{l}\text { nd* } \\
\text { nd* }\end{array}$ & & & & & \\
\hline \#21 / B side & $406.2235^{a, c}$ & & $1+$ & $\mathrm{C}_{22} \mathrm{H}_{32} \mathrm{O}_{6} \mathrm{~N}$ & 7.5 & 1.33 & $406.2254^{b}$ & & $1+$ & $\mathrm{C}_{22} \mathrm{H}_{32} \mathrm{O}_{6} \mathrm{~N}$ & 7.5 & 6.01 \\
\hline
\end{tabular}

- Elemental formulae of the mono-isotopic ion peaks of the isotopic pattern $(\mathrm{m} / \mathrm{z})$ are reported in ion charge state $(1+, 2+, 3+)$, relative double bond (RDB) and errors $(\mathrm{ppm}) .{ }^{*} \mathrm{nd}=$ not detected; ${ }^{\mathrm{a}}$ : ions in the HR CID MS ${ }^{2}$ spectra of the $[\mathrm{M}+\mathrm{H}+\mathrm{Ca}]^{3+}$ ion of ovatoxin-a $\left(\mathrm{m} / z\right.$ 896.1549) and ovatoxin-h $\left(\mathrm{m} / \mathrm{z}\right.$ 891.4935); ${ }^{\mathrm{b}}:$ ions in the $800 \mathrm{HR}$ CID MS ${ }^{2}$ spectra of the $\left[\mathrm{M}+2 \mathrm{H}-\mathrm{H}_{2} \mathrm{O}\right]^{2+}$ ion of ovatoxin-a $\left(\mathrm{m} / z\right.$ 1315.7479) and ovatoxin-h $(\mathrm{m} / z \mathrm{z} 1308.7580){ }^{\mathrm{c}}{ }^{2}$ ions in the $\mathrm{HR}_{\mathrm{CID} \mathrm{MS}}{ }^{2}$ spectra of the $[\mathrm{M}+2 \mathrm{H}]^{2+}$ ion 801 of ovatoxin-a $(\mathrm{m} / \mathrm{z}, 1324.7543)$ and ovatoxin-h $(\mathrm{m} / \mathrm{z}$ 1317.7627) 
Table 5 Assignment of the internal fragments observed in HR CID MS ${ }^{2}$ spectra of OVTX-a and OVTX-h assigned to corresponding

\begin{tabular}{|c|c|c|c|c|c|c|c|c|c|c|c|c|}
\hline \multirow[b]{2}{*}{ Cleavage [40] } & \multicolumn{6}{|c|}{ OVTX-a } & \multicolumn{6}{|c|}{ OVTX-h } \\
\hline & $\mathrm{m} / \mathrm{z}$ & $\begin{array}{l}\text { Water } \\
\text { loss }\end{array}$ & $\begin{array}{c}\text { lon } \\
\text { charge }\end{array}$ & Formula & $\mathrm{RDB}^{*}$ & $\Delta \mathrm{ppm} \bullet$ & $\mathrm{m} / \mathrm{z}$ & $\begin{array}{l}\text { Water } \\
\text { loss }\end{array}$ & $\begin{array}{c}\text { lon } \\
\text { charge }\end{array}$ & Formula & $\mathrm{RDB}^{*}$ & $\Delta \mathrm{ppm} \bullet$ \\
\hline$\# 1+\# 4$ & $\begin{array}{c}234.1107^{a, b} \\
216.1011^{a, b, c}\end{array}$ & $-1 \mathrm{H}_{2} \mathrm{O}$ & $1+$ & $\begin{array}{l}\mathrm{C}_{13} \mathrm{H}_{16} \mathrm{O}_{3} \mathrm{~N} \\
\mathrm{C}_{13} \mathrm{H}_{14} \mathrm{O}_{2} \mathrm{~N}\end{array}$ & 6.5 & $\begin{array}{l}-9.91 \\
-6.25\end{array}$ & $\begin{array}{l}234.1131^{a, b} \\
216.1016^{a, c}\end{array}$ & $-1 \mathrm{H}_{2} \mathrm{O}$ & $1+$ & $\begin{array}{l}\mathrm{C}_{13} \mathrm{H}_{16} \mathrm{O}_{3} \mathrm{~N} \\
\mathrm{C}_{13} \mathrm{H}_{14} \mathrm{O}_{2} \mathrm{~N}\end{array}$ & 6.5 & $\begin{array}{c}0.34 \\
-3.93\end{array}$ \\
\hline$\# 4+\# 12$ & $364.2005^{\mathrm{a}}$ & & $2+$ & $\mathrm{C}_{36} \mathrm{H}_{64} \mathrm{O}_{12} \mathrm{Ca}$ & 5 & 1.65 & 364.2063 & & $2+$ & $\mathrm{C}_{36} \mathrm{H}_{64} \mathrm{O}_{12} \mathrm{Ca}$ & 5 & 14.0 \\
\hline$\# 4+\# 13$ & $394.2128^{a}$ & & $2+$ & $\mathrm{C}_{38} \mathrm{H}_{68} \mathrm{O}_{14} \mathrm{Ca}$ & 5 & 2.66 & nd* & & & & & \\
\hline$\# 4+\# 15$ & $416.2253^{a}$ & & $2+$ & $\mathrm{C}_{40} \mathrm{H}_{72} \mathrm{O}_{15} \mathrm{Ca}$ & 5 & 1.08 & nd* & & & & & \\
\hline$\# 7+\# 12$ & $521.3132^{\mathrm{a}}$ & & $1+$ & $\mathrm{C}_{28} \mathrm{H}_{49} \mathrm{O}_{6} \mathrm{Ca}$ & 4.5 & -4.41 & $521.3124^{\mathrm{a}}$ & & $1+$ & $\mathrm{C}_{28} \mathrm{H}_{49} \mathrm{O}_{6} \mathrm{Ca}$ & 4.5 & -5.95 \\
\hline$\# 9+\# 12$ & $477.2835^{\mathrm{a}}$ & & $1+$ & $\mathrm{C}_{26} \mathrm{H}_{45} \mathrm{O}_{5} \mathrm{Ca}$ & 4.5 & -12.15 & $477.2870^{a}$ & & $1+$ & $\mathrm{C}_{26} \mathrm{H}_{45} \mathrm{O}_{5} \mathrm{Ca}$ & 4.5 & -4.17 \\
\hline$\# 10+\# 12$ & $447.2779^{a}$ & & $1+$ & $\mathrm{C}_{25} \mathrm{H}_{43} \mathrm{O}_{4} \mathrm{Ca}$ & 4.5 & -1.79 & $447.2775^{a}$ & & $1+$ & $\mathrm{C}_{25} \mathrm{H}_{43} \mathrm{O}_{4} \mathrm{Ca}$ & 4.5 & -4.92 \\
\hline
\end{tabular}

- Elemental formulae of the mono-isotopic ion peaks of the isotopic pattern $(\mathrm{m} / \mathrm{z})$ are reported in ion charge state $(1+, 2+, 3+)$, relative double bond (RDB) and 807 errors $(\mathrm{ppm}){ }^{*} \mathrm{nd}=$ not detected; ${ }^{\mathrm{a}}:$ ions in the HR CID MS${ }^{2}$ spectra of the $[\mathrm{M}+\mathrm{H}+\mathrm{Ca}]^{3+}$ ion of ovatoxin-a $\left(\mathrm{m} / z\right.$ 896.1549) and ovatoxin-h $\left(\mathrm{m} / z\right.$ 891.4935); ${ }^{\mathrm{b}}:$ ions in the $808 \mathrm{HR}_{\mathrm{CID} \mathrm{MS}}{ }^{2}$ spectra of the $\left[\mathrm{M}+2 \mathrm{H}-\mathrm{H}_{2} \mathrm{O}\right]^{2+}$ ion of ovatoxin-a $(\mathrm{m} / \mathrm{z} 1315.7479)$ and ovatoxin-h $(\mathrm{m} / \mathrm{z} 1308.7580){ }^{\mathrm{c}}{ }^{2}$ ions in the $\mathrm{HR}_{\mathrm{CID}} \mathrm{MS}^{2}$ spectra of the $[\mathrm{M}+2 \mathrm{H}]^{2+}$ ion 809 of ovatoxin-a $(\mathrm{m} / \mathrm{z}, 1324.7543)$ and ovatoxin-h $(\mathrm{m} / \mathrm{z}$ 1317.7627)

810 
814 Table 6

815 . Resolution between OVTXs peaks obtained on eight columns.

\begin{tabular}{|c|c|c|c|c|c|c|c|c|}
\hline Compounds & $\begin{array}{c}\text { Gemini } \\
\mathrm{C}_{18}\end{array}$ & $\begin{array}{l}\text { Kinetex } \\
\mathrm{C}_{18}-2.6\end{array}$ & $\begin{array}{c}\text { Kinetex } \\
\mathrm{C}_{18-5}\end{array}$ & $\begin{array}{c}\text { Uptisphere } \\
\mathrm{C}_{18} \text {-TF } \\
\end{array}$ & $\begin{array}{c}\text { Polar } \\
\text { Advantage II }\end{array}$ & $\begin{array}{l}\text { Synergi } \\
\text { Fusion }\end{array}$ & $\begin{array}{l}\text { Polaris } \\
\text { amide }\end{array}$ & PFP \\
\hline OVTX-c & & & & & & & & \\
\hline & 2.28 & 2.35 & 3.28 & 2.04 & 0.98 & 2.10 & 2.53 & 3.51 \\
\hline OVTX-d & \multirow{3}{*}{$2.36\left(^{*}\right)$} & \multirow{2}{*}{0.57} & \multirow{2}{*}{1.32} & \multirow{2}{*}{$>1.5$} & \multirow{3}{*}{$1.65\left(^{*}\right)$} & \multirow{3}{*}{$2.08\left(^{*}\right)$} & \multirow{3}{*}{$1.88\left(^{*}\right)$} & 05 \\
\hline \multirow[t]{2}{*}{ OVTX-e } & & & & & & & & \\
\hline & & 0.71 & 1.89 & $<0.5$ & & & & 0.80 \\
\hline OVTX-b & 2.09 & 1.70 & 2.52 & 1.71 & 1.46 & 2.19 & 2.10 & $2.77\left({ }^{* *}\right)$ \\
\hline OVTX-a & & \multirow{3}{*}{$1.72\left({ }^{\star \star \star}\right)$} & \multirow{3}{*}{$2.55\left(^{* \star \star}\right)$} & \multirow{2}{*}{$<0.5$} & & \multirow{3}{*}{$<0.5\left(^{\star \star \star}\right)$} & \multirow{3}{*}{$2.11\left(^{* * *}\right)$} & \multirow{3}{*}{$4.33\left(^{* * \star}\right)$} \\
\hline OVTX-a' & & & & & & & & \\
\hline OVTX & & & & $>1.5$ & & & & \\
\hline
\end{tabular}

$816 \quad(*)$ no separation for OVTX-d and -e; $(* *)$ shouldered peak $(* * *)$ poor separation 817 between OVTX-a and -a'.

818 


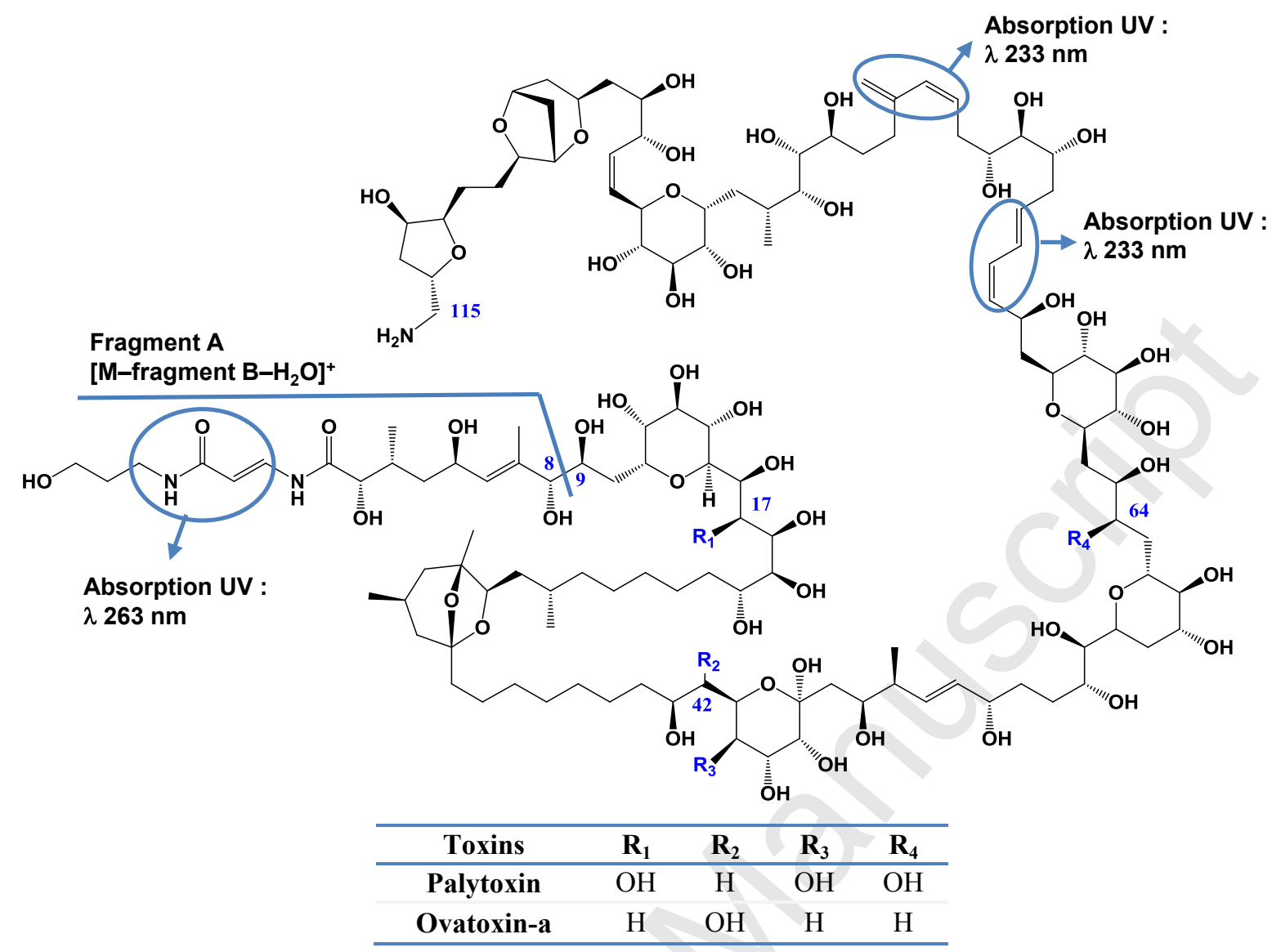



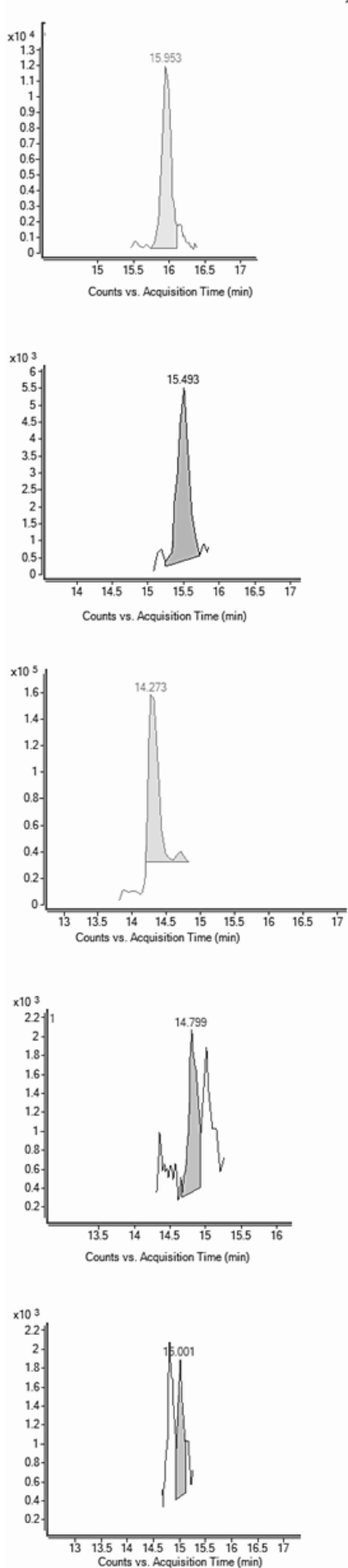

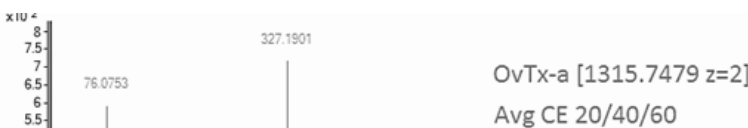

Avg CE 20/40/60

1319.7372

1372.7524

OvTx-b [1337.7574 z=2]

Avg CE 20/40/60
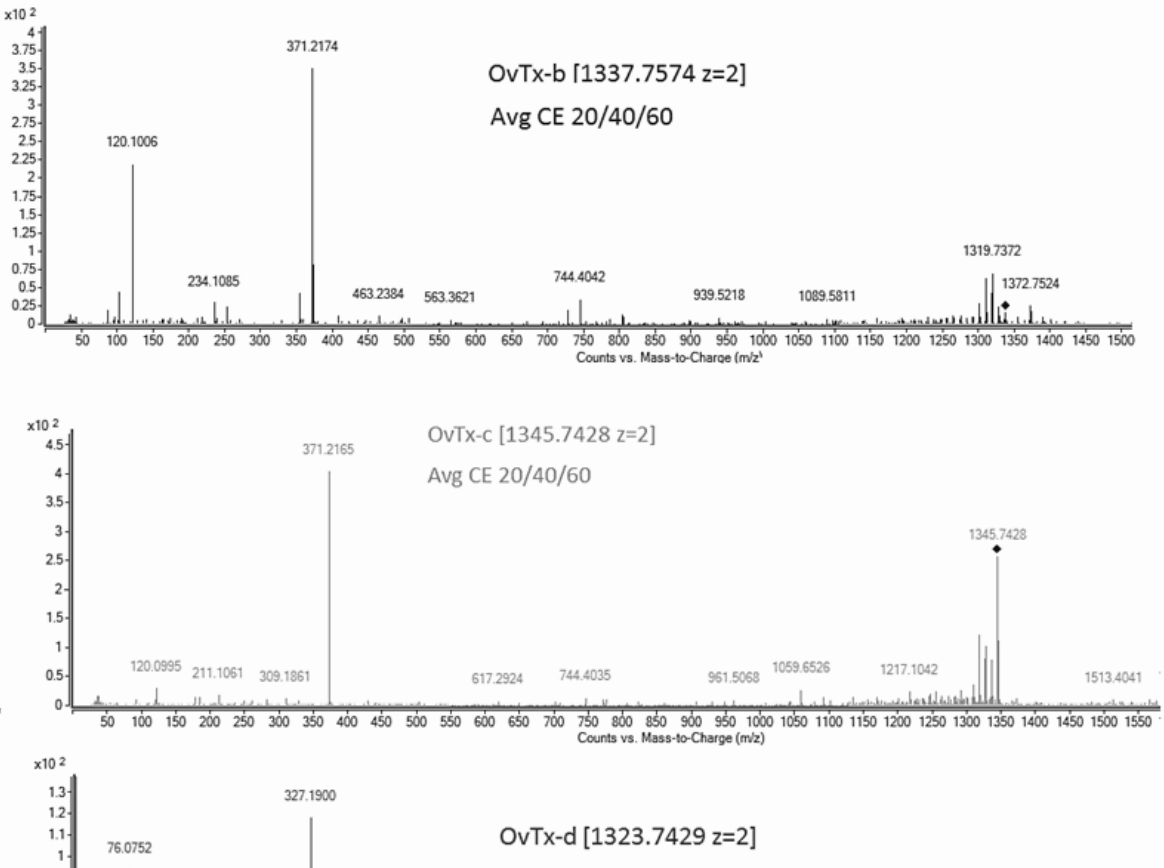

Avg CE 20/40/60

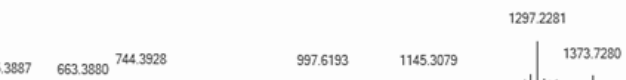

\begin{tabular}{ll|l}
\hline & 1145.3079 & 137.728
\end{tabular}
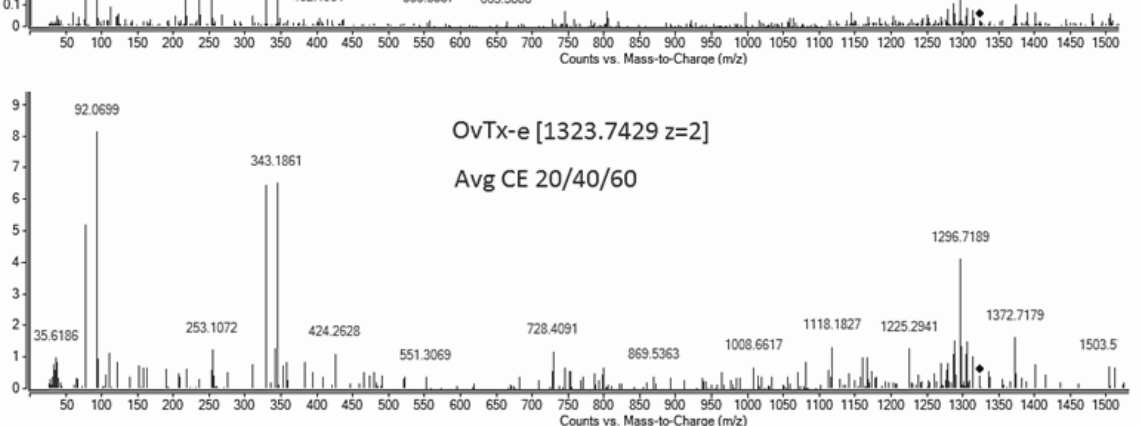


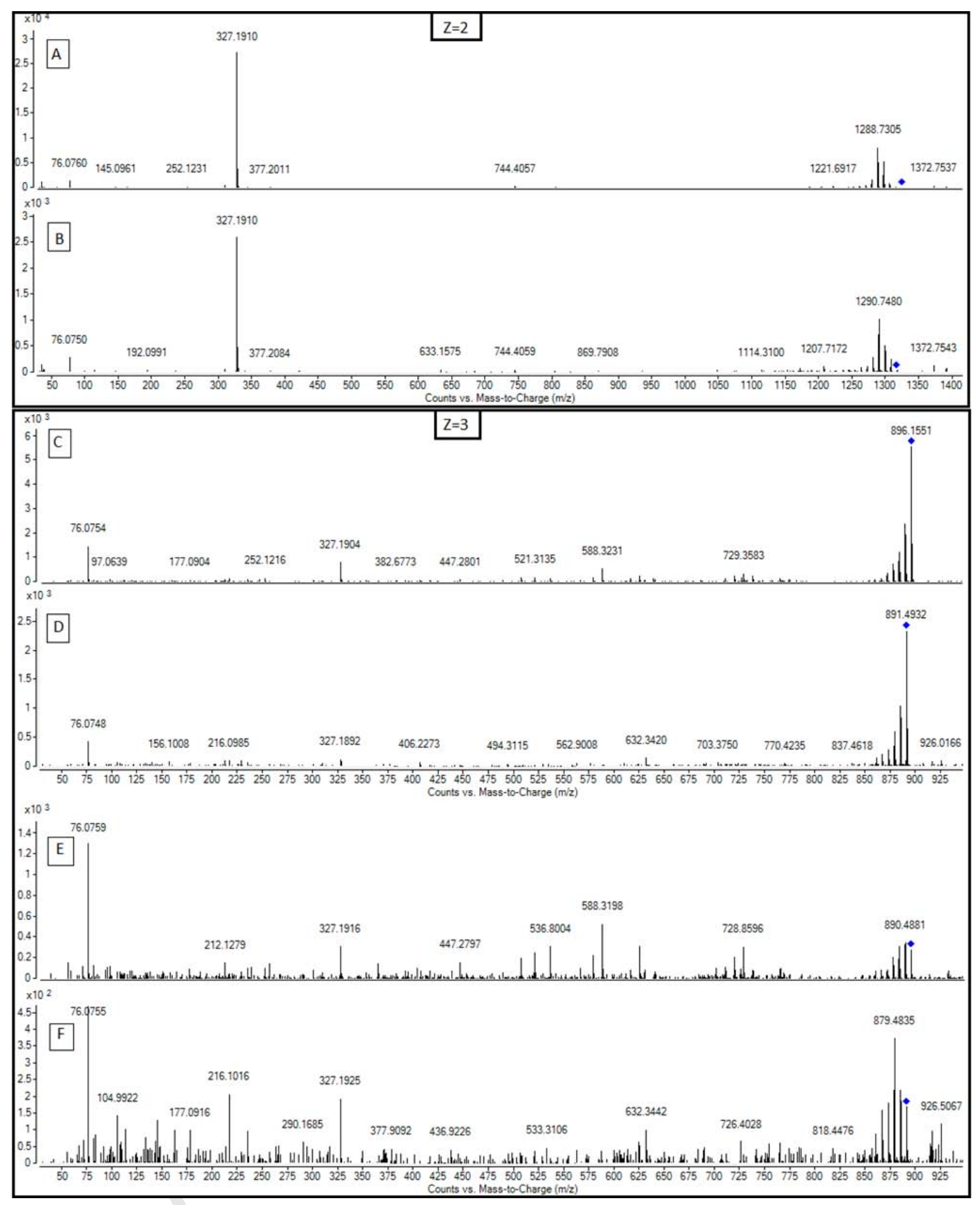




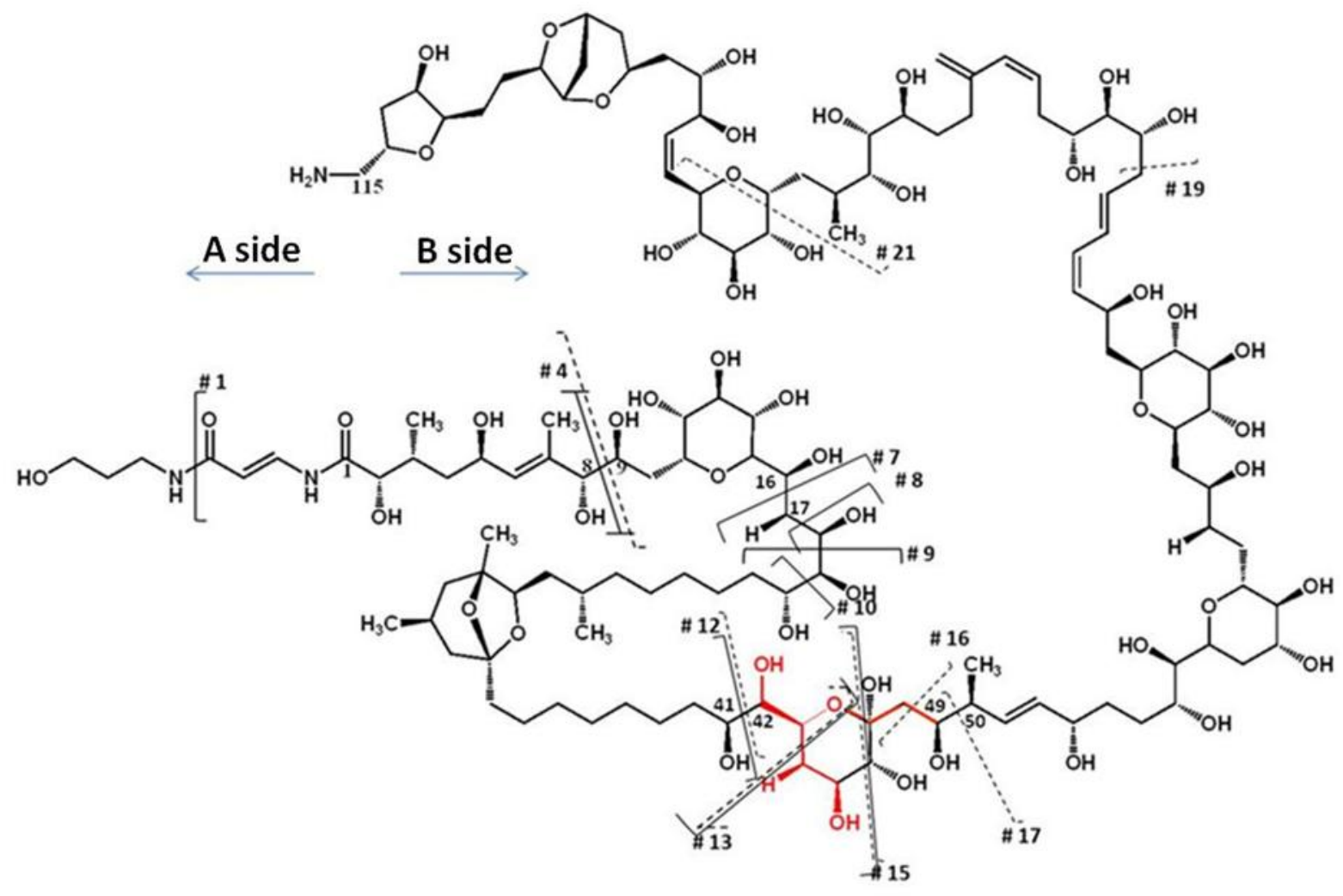




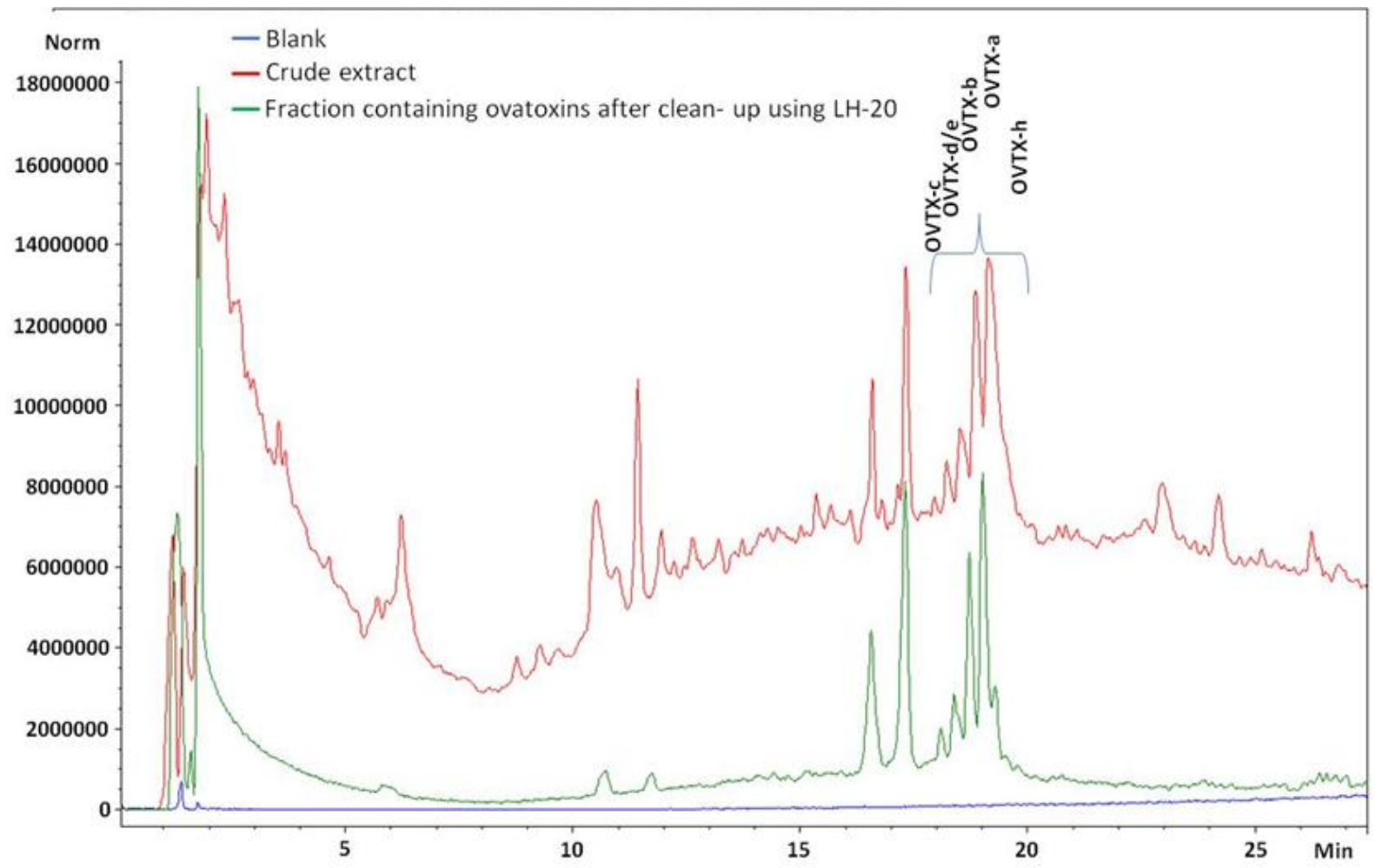


Acclaim Polar Advantage II

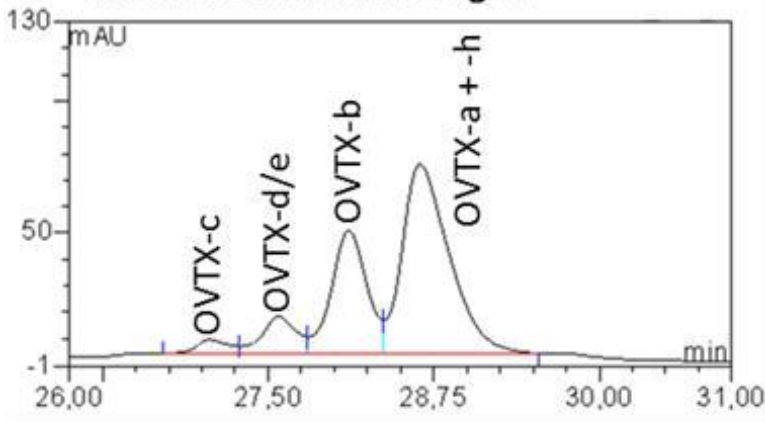

Gemini C18
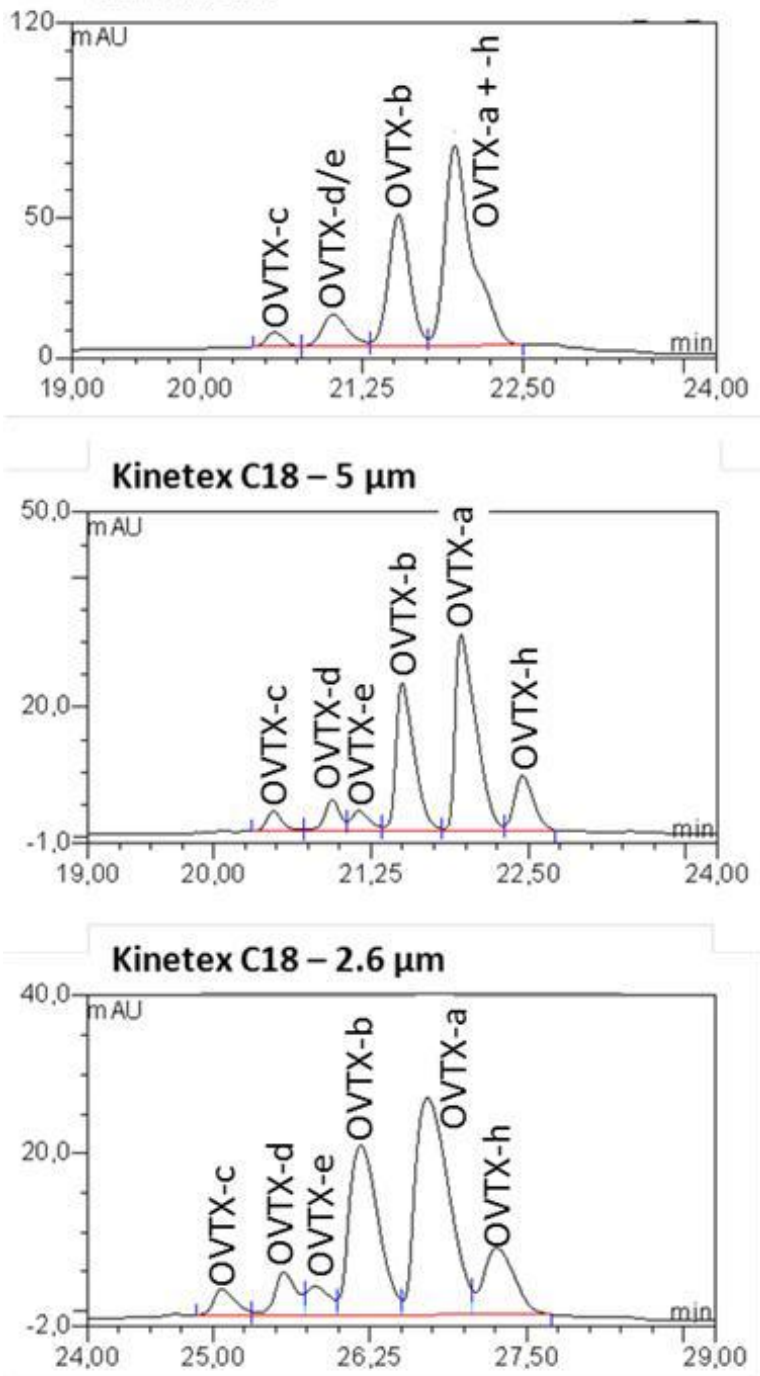

Polaris Amide C18

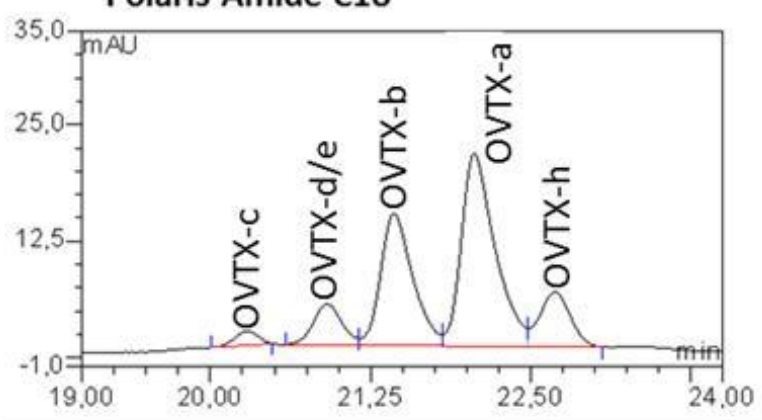

Synergi Fusion RP
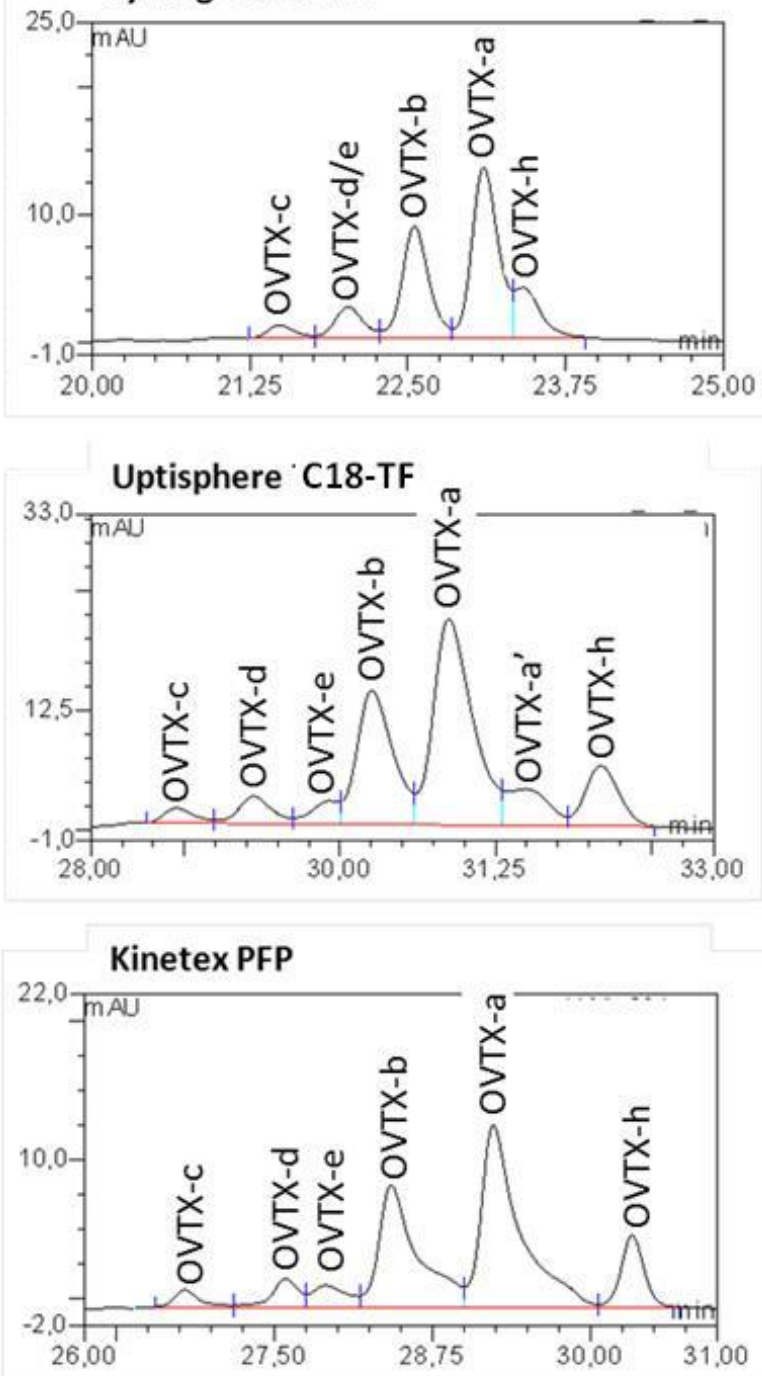

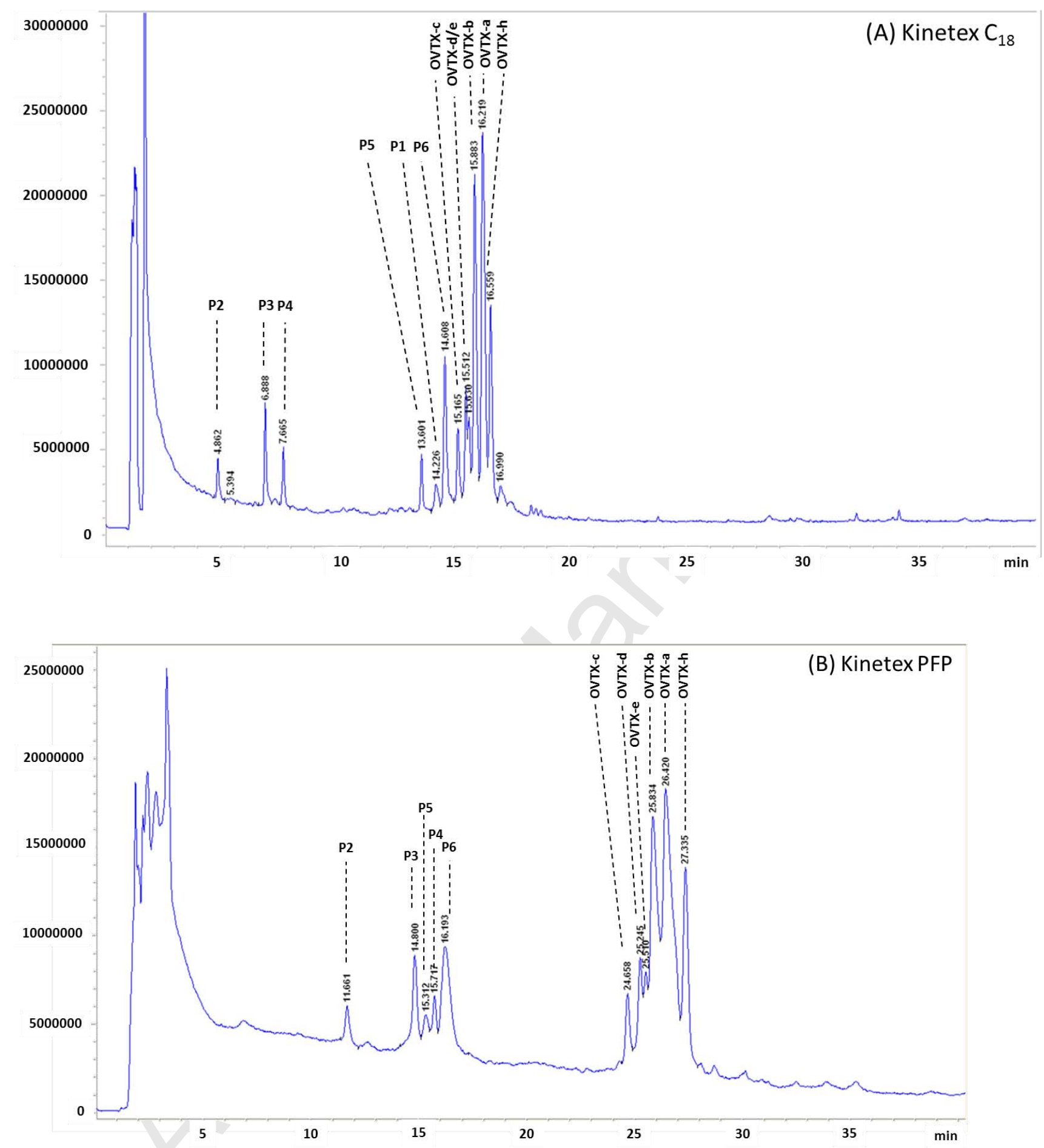


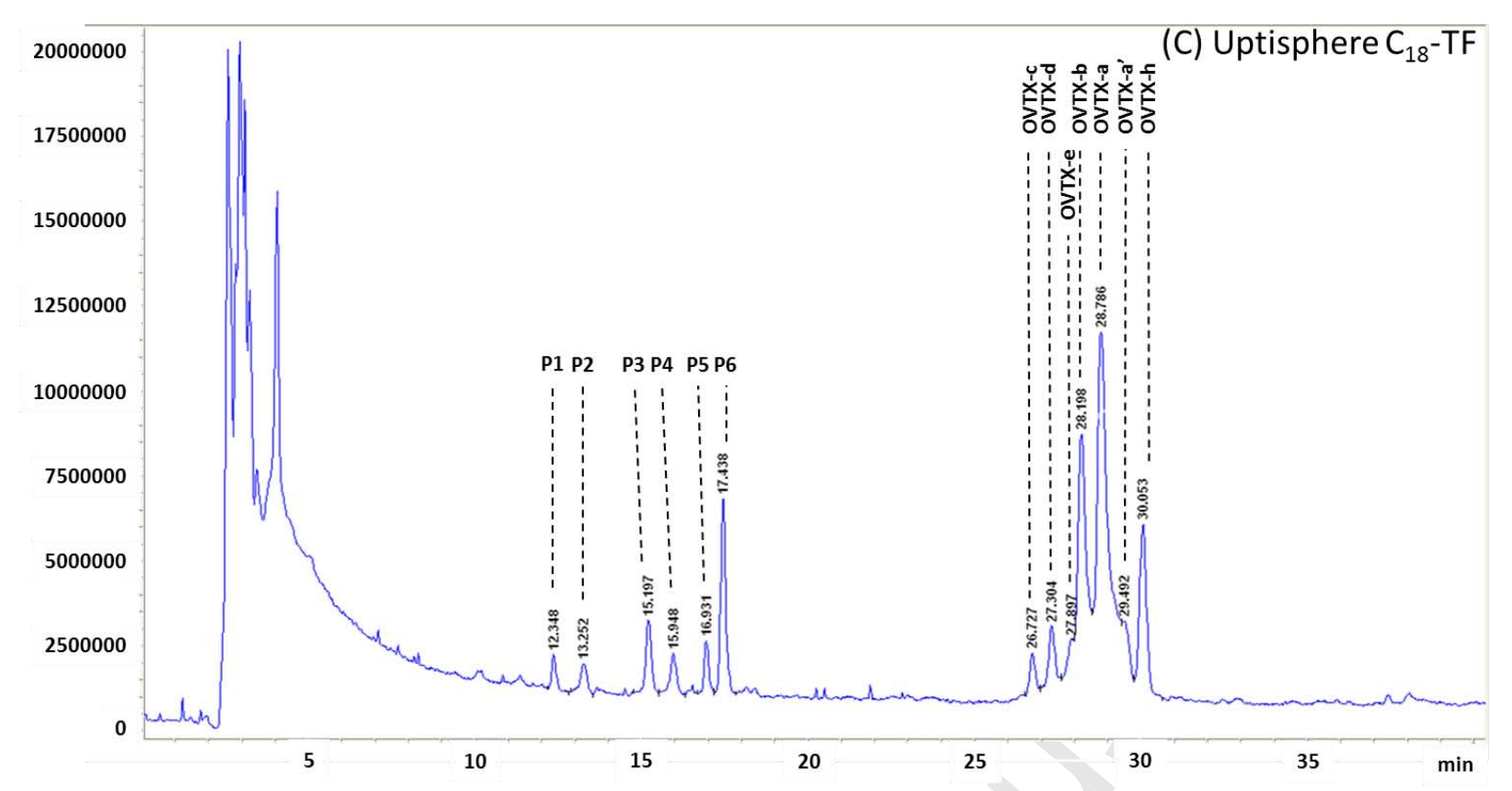


Characterization of ovatoxin-h, a new ovatoxin analogue, and evaluation of chromatographic columns for ovatoxin analysis and purification.

\section{Supplementary data}

${ }^{a}$ Charline Brissard, ${ }^{a}$ Fabienne Hervé, ${ }^{a}$ Manoella Sibat, ${ }^{a}$ Véronique Séchet, ${ }^{a}$ Philipp Hess, ${ }^{\mathrm{a}}$ Zouher Amzil, ${ }^{\mathrm{b}}$ Christine Herrenknecht

a Ifremer, Phycotoxins Laboratory, rue de l'Ile d'Yeu, BP 21105, F-44311 Nantes, France;

b LUNAM, University of Nantes, MMS EA2160, Pharmacy Faculty, 9 rue Bias, F44035 Nantes, France.

* Corresponding author at: LUNAM, University of Nantes, MMS EA2160, Pharmacy Faculty, 9 rue Bias, F-44035 Nantes, France. Tel: +33253484312. E-mail address: Christine.Herrenknecht@,univ-nantes.fr 
Table S1. Characteristics of columns tested for the separation of ovatoxins: dimensions, pore diameter $(\AA)$, particle size $(\mu \mathrm{m})$, specific surface area $\left(\mathrm{m}^{2} / \mathrm{g}\right)$, manufacturer, bonding type and bibliographic reference or $(*)$ information from the manufacturer.

\begin{tabular}{|c|c|c|c|c|c|c|c|c|c|}
\hline $\begin{array}{l}\text { Stationary } \\
\text { phase and } \\
\text { manufacturer }\end{array}$ & $\begin{array}{l}\text { Column } \\
\text { dimension } \\
(\mathbf{m m} \times \mathbf{m m})\end{array}$ & $\begin{array}{l}\text { Particle } \\
\text { size } \\
(\mu \mathrm{m})\end{array}$ & $\begin{array}{l}\text { Pore } \\
\text { size } \\
(\AA)\end{array}$ & $\begin{array}{l}\text { Void } \\
\text { volume } \\
(\mathrm{mL})\end{array}$ & $\begin{array}{c}\text { Specific } \\
\text { surface area } \\
\left(\mathrm{m}^{2} / \mathrm{g}\right)\end{array}$ & $\begin{array}{l}\text { Carbon } \\
\text { content } \%\end{array}$ & Bonding type & $\begin{array}{l}\text { End- } \\
\text { capped }\end{array}$ & Ref \\
\hline \multicolumn{10}{|c|}{ Reversed Phase columns } \\
\hline $\begin{array}{l}\text { Gemini }\left(\mathbf{C}_{18}\right) \\
\text { Phenomenex }\end{array}$ & $150 \times 2$ & 3 & 110 & 0.380 & 390 & 14 & $\begin{array}{c}\mathbf{C}_{18} \text {, fully Porous } \\
\text { organo-silica }\end{array}$ & Yes & [37] \\
\hline $\begin{array}{l}\text { Kinetex }\left(\mathbf{C}_{18}\right) \\
\text { Phenomenex }\end{array}$ & $150 \times 2.1$ & 2.6 & 100 & 0.301 & 200 & 12 & $\begin{array}{c}\mathbf{C}_{18}, \text { with Core-shell } \\
\text { Silica }\end{array}$ & Yes & * \\
\hline $\begin{array}{l}\text { Kinetex }\left(\mathbf{C}_{18}\right) \\
\text { Phenomenex }\end{array}$ & $150 \times 4.6$ & 5 & 100 & 1.392 & 200 & 12 & $\begin{array}{c}\mathbf{C}_{18}, \text { with Core-shell } \\
\text { Silica }\end{array}$ & Yes & * \\
\hline $\begin{array}{c}\text { Uptisphere } \\
\mathbf{C}_{\mathbf{1 8}}-\mathbf{T F} \\
\text { Interchim }\end{array}$ & $150 \times 2.1$ & 5 & 300 & 0.369 & 310 & 14 & $\mathrm{C}_{18}$ polyfunctional & Yes & [37] \\
\hline \multicolumn{10}{|c|}{ Mixed Mode columns } \\
\hline $\begin{array}{c}\text { Acclaim } \\
\text { Polar } \\
\text { Advantage II } \\
\text { Dionex }\end{array}$ & $100 \times 2.1$ & 2.2 & 120 & 0.180 & 300 & 17 & $\begin{array}{l}\text { Amide-embedded } \\
\text { with monomeric } \\
\text { behaviour }\end{array}$ & Yes & [37] \\
\hline $\begin{array}{c}\text { Synergi } \\
\text { fusion RP } \\
\text { Phenomenex }\end{array}$ & $150 \times 4.6$ & 4 & 80 & 1.720 & 475 & 12 & $\begin{array}{l}\text { Mixed classical } \\
\text { and polar } \\
\text { embedded } C_{18} \text {, } \\
\text { fully Porous Silica }\end{array}$ & Yes & $\underset{*}{[37]}$ \\
\hline $\begin{array}{c}\text { Polaris } \mathbf{C}_{18} \\
\text { amide Varian }\end{array}$ & $150 \times 4.6$ & 5 & 200 & 1.877 & 180 & 14.7 & $\begin{array}{l}\text { Amide-embedded } \\
\text { with polymeric } \\
\text { behaviour }\end{array}$ & Yes & $\underset{*}{[37]}$, \\
\hline \multicolumn{10}{|c|}{ Other grafting columns } \\
\hline $\begin{array}{l}\text { Kinetex PFP } \\
\text { Phenomenex }\end{array}$ & $150 \times 2.1$ & 2.6 & 100 & 0.308 & 200 & 9 & $\begin{array}{l}\text { Pentafluorophenyl } \\
\text { core-shell silica }\end{array}$ & Yes & * \\
\hline
\end{tabular}

Table S2. Flow rate and initial isocratic elution time for each column.

\begin{tabular}{|c|c|c|c|c|c|c|c|c|}
\hline Column & $\begin{array}{c}\text { Gemini } \\
C_{18}\end{array}$ & $\begin{array}{c}\text { Kinetex } \\
\mathrm{C}_{18-2.6 \mu \mathrm{m}}\end{array}$ & $\begin{array}{l}\text { Kinetex } \\
\mathrm{C}_{18-5 \mu \mathrm{m}}\end{array}$ & $\begin{array}{c}\text { Uptisphere } \\
\mathrm{C}_{18}-\mathrm{TF}\end{array}$ & $\begin{array}{c}\text { Polar } \\
\text { Advantage II }\end{array}$ & $\begin{array}{l}\text { Synergi } \\
\text { Fusion }\end{array}$ & $\begin{array}{l}\text { Polaris } \\
\text { Amide }\end{array}$ & PFP \\
\hline $\begin{array}{l}\text { Flow rate } \\
\text { (mL/min) }\end{array}$ & 0.252 & 0.200 & 0.924 & 0.245 & 0.120 & 1.142 & 1.246 & 0.205 \\
\hline $\begin{array}{c}\text { Isocratic } \\
\text { time x } \\
\text { (min) }\end{array}$ & 3.0 & 2.3 & 5.0 & 2.9 & 0.0 & 5.2 & 5.2 & 5.4 \\
\hline
\end{tabular}




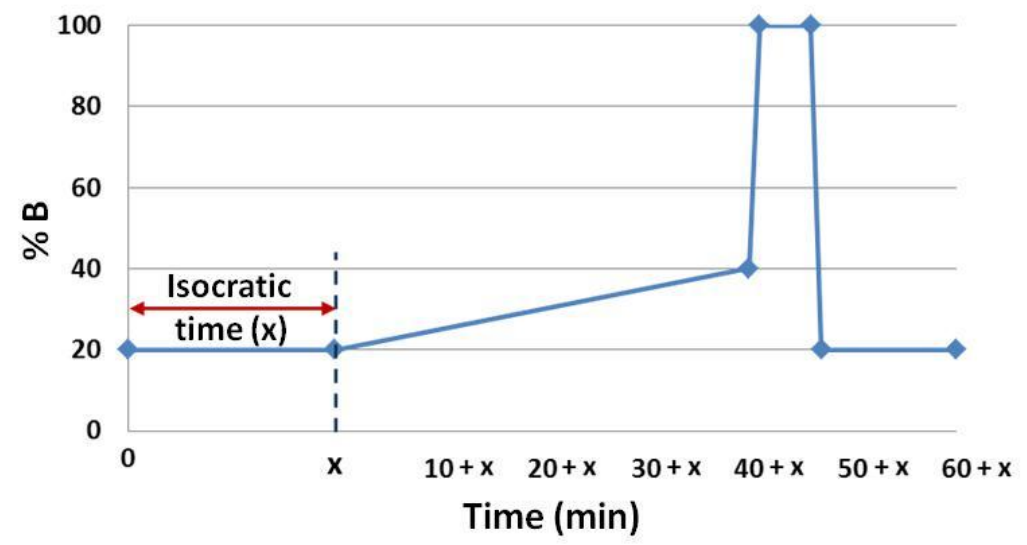

Figure S1. Linear gradient elution used to select columns able to separate OVTXs. The duration of isocratic elution time at the beginning of gradient was represented by " $x$ ". 
Table S3. Fragment attribution obtained from CID spectra of tricharged ions of OVTX-a, -b, -c, -d and -e. Elemental formulae of mono-isotopic ions $(\mathrm{m} / \mathrm{z})$ are reported in charge state $(1+, 2+, 3+)$, and errors in ppm.

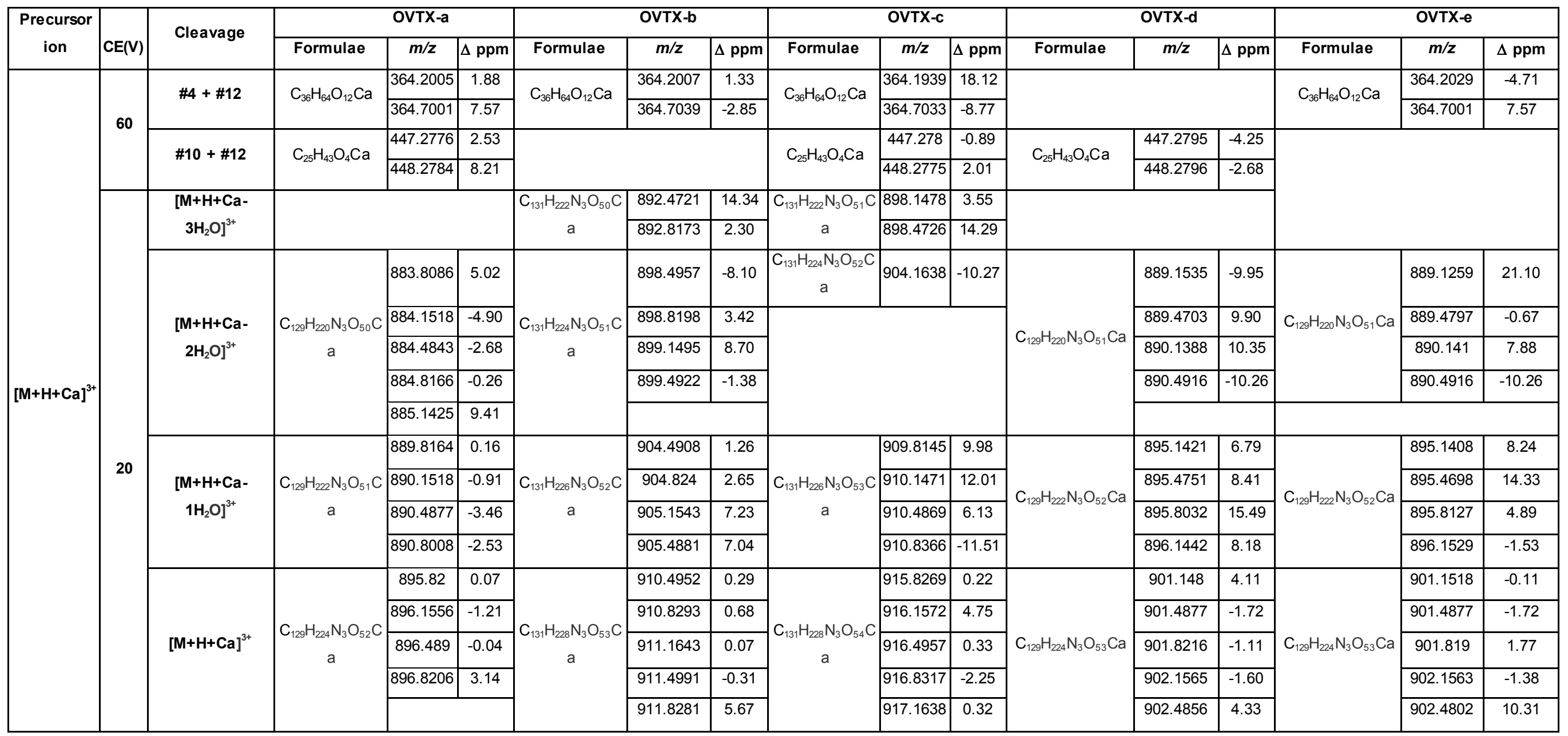


Table S4. Fragment attribution obtained from CID spectra of dicharged ions of OVTX-a, -b, -c, -d and -e. Elemental formulae of mono-isotopic ions $(\mathrm{m} / \mathrm{z})$ are reported in charge state $(1+, 2+, 3+)$, and errors in ppm.

\begin{tabular}{|c|c|c|c|c|c|c|c|c|c|c|c|c|c|c|c|c|c|}
\hline \multirow{2}{*}{ Precursor ion } & \multirow{2}{*}{ CE (V) } & \multirow{2}{*}{ Cleavage } & \multicolumn{3}{|c|}{ OVTX-a } & \multicolumn{3}{|c|}{ OVTX-b } & \multicolumn{3}{|c|}{ OVTX-c } & \multicolumn{3}{|c|}{ OVTX-d } & \multicolumn{3}{|c|}{ OVTX-e } \\
\hline & & & Formulae & $m / z$ & $\Delta \mathrm{ppm}$ & Formulae & $m / z$ & $\Delta \mathrm{ppm}$ & Formulae & $m / z$ & $\Delta \mathrm{ppm}$ & Formulae & $m / z$ & $\Delta \mathrm{ppm}$ & Formulae & $m / z$ & $\Delta \mathrm{ppm}$ \\
\hline \multirow{19}{*}[\mathrm{M}+2\mathrm{H}-\mathrm{H}_{2}\mathrm{O}]{$^{2+}$} & \multirow{9}{*}{30} & $\# 1$-A side & $\mathrm{C}_{3} \mathrm{H}_{10} \mathrm{O}_{1} \mathrm{~N}_{1}$ & 76.0757 & 7.10 & $\mathrm{C}_{5} \mathrm{H}_{14} \mathrm{O}_{2} \mathrm{~N}_{1}$ & 120.1016 & 7.08 & $\mathrm{C}_{5} \mathrm{H}_{14} \mathrm{O}_{2} \mathrm{~N}_{1}$ & 120.1012 & 10.4078 & $\mathrm{C}_{3} \mathrm{H}_{10} \mathrm{O}_{1} \mathrm{~N}_{1}$ & 76.0755 & 9.73 & & & \\
\hline & & \multirow{4}{*}{$\# 4$} & \multirow{2}{*}{$\mathrm{C}_{16} \mathrm{H}_{27} \mathrm{O}_{5} \mathrm{~N}_{2}$} & 327.1907 & 3.97 & \multirow{2}{*}{$\mathrm{C}_{18} \mathrm{H}_{31} \mathrm{~N}_{2} \mathrm{O}_{6}$} & 371.217 & 3.26 & \multirow{2}{*}{$\mathrm{C}_{18} \mathrm{H}_{31} \mathrm{~N}_{2} \mathrm{O}_{6}$} & 371.2166 & 4.34 & \multirow{2}{*}{$\mathrm{C}_{16} \mathrm{H}_{27} \mathrm{O}_{5} \mathrm{~N}_{2}$} & 327.1894 & 7.95 & \multirow{2}{*}{$\mathrm{C}_{16} \mathrm{H}_{27} \mathrm{~N}_{2} \mathrm{O}_{6}$} & 343.1857 & 3.53 \\
\hline & & & & 328.1925 & 8.68 & & 372.2194 & 5.83 & & 372.2193 & 6.10 & & 328.1928 & 7.77 & & 344.1855 & 13.86 \\
\hline & & & & & & & & & & & & & 343.1857 & 3.53 & & & \\
\hline & & & & & & & & & & & & ${ }_{16} \Pi_{27} \mathrm{l}_{2} \cup_{6}$ & 344.1855 & 13.86 & & & \\
\hline & & \multirow{2}{*}{$\begin{array}{c}\# 17-\mathrm{B} \text { side - } \\
\mathrm{H}_{2} \mathrm{O}\end{array}$} & \multirow{2}{*}{$\mathrm{C}_{69} \mathrm{H}_{114} \mathrm{O}_{26} \mathrm{~N}$} & 1372.7495 & 9.77 & \multirow{2}{*}{$\mathrm{C}_{69} \mathrm{H}_{114} \mathrm{O}_{26} \mathrm{~N}$} & 1372.7526 & 7.51 & \multirow{2}{*}{$\mathrm{C}_{69} \mathrm{H}_{114} \mathrm{O}_{26} \mathrm{~N}$} & 1372.7608 & 1.54 & \multirow{2}{*}{$\mathrm{C}_{69} \mathrm{H}_{114} \mathrm{O}_{26} \mathrm{~N}$} & 1372.7576 & 3.87 & \multirow{2}{*}{$\mathrm{C}_{69} \mathrm{H}_{114} \mathrm{O}_{26} \mathrm{~N}$} & 1372.7482 & 10.72 \\
\hline & & & & 1373.7633 & 2.15 & & 1373.7538 & 9.07 & & 1373.7791 & -9.35 & & & & & & \\
\hline & & \multirow{2}{*}{ \#17 - side B } & \multirow{2}{*}{$\mathrm{C}_{69} \mathrm{H}_{116} \mathrm{O}_{27} \mathrm{~N}$} & 1390.7669 & 4.72 & \multirow{2}{*}{$\mathrm{C}_{69} \mathrm{H}_{116} \mathrm{O}_{27} \mathrm{~N}$} & 1390.7677 & 4.15 & \multirow{2}{*}{$\mathrm{C}_{69} \mathrm{H}_{116} \mathrm{O}_{27} \mathrm{~N}$} & 1390.7596 & 9.97 & \multirow{2}{*}{$\mathrm{C}_{69} \mathrm{H}_{116} \mathrm{O}_{27} \mathrm{~N}$} & & & & & \\
\hline & & & & 1391.7729 & 2.82 & & 1391.7543 & 16.19 & & 1391.7574 & 13.96 & & & & & & \\
\hline & \multirow{10}{*}{10} & \multirow{3}{*}[\mathrm{M}+2\mathrm{H}-6\mathrm{H}_{2}\mathrm{O}]{$^{2+}$} & \multirow{3}{*}{$\mathrm{C}_{129} \mathrm{H}_{213} \mathrm{~N}_{3} \mathrm{O}_{46}$} & 1270.2202 & 0.64 & & & & & & & & 1278.7166 & 2.78 & & & \\
\hline & & & & 1270.7066 & 12.66 & & & & & & & $\mathrm{C}_{129} \mathrm{H}_{213} \mathrm{~N}_{3} \mathrm{O}_{47}$ & 1279.22 & 1.43 & & & \\
\hline & & & & 1271.2211 & 2.57 & & & & & & & & & & & & \\
\hline & & & & 1279.2244 & 1.48 & & & & & 1309.2365 & 0.27 & & 1287.1936 & 23.43 & & 1287.715 & 8.18 \\
\hline & & {$\left[\mathrm{M}+2 \mathrm{H}-5 \mathrm{H}_{2} \mathrm{O}\right]^{2+}$} & $\mathrm{C}_{129} \mathrm{H}_{215} \mathrm{~N}_{3} \mathrm{O}_{47}$ & 1279.7205 & 5.84 & & & & $\mathrm{C}_{131} \mathrm{H}_{219} \mathrm{~N}_{3} \mathrm{O}_{49}$ & 1309.7268 & 8.96 & $\mathrm{C}_{129} \mathrm{H}_{215} \mathrm{~N}_{3} \mathrm{O}_{48}$ & 1287.6862 & 30.47 & $\mathrm{C}_{129} \mathrm{H}_{215} \mathrm{~N}_{3} \mathrm{O}_{48}$ & 1288.218 & 7.30 \\
\hline & & & & 1280.2182 & 8.94 & & & & & 1310.2401 & 0.09 & & 1288.228 & -0.69 & & & \\
\hline & & & & 1288.2297 & 1.46 & & 1310.2368 & 6.02 & & 1318.2392 & 2.23 & & 1296.2282 & 0.64 & & 1296.222 & 5.35 \\
\hline & & $\mathrm{CM}+2 \mathrm{H}_{4} \mathrm{AH} \mathrm{OI}^{2+}$ & $\mathrm{CO}_{\mathrm{H}}$ & 1288.729 & 3.30 & $\mathrm{C}$ & 1310.7392 & 5.47 & $\mathrm{C}_{131} \mathrm{H}_{221} \mathrm{~N}_{3} \mathrm{O} 5$ & 1318.7407 & 2.37 & $C$ & 1296.7288 & 1.48 & $c$ & 1296.723 & 5.87 \\
\hline & & 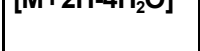 & 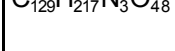 & 1289.2269 & 6.23 & $\mathrm{C}_{131} \mathrm{C}_{221} \mathrm{I}_{3} \mathrm{U}_{4} \mathrm{~S}$ & 1311.2426 & 4.15 & & 1319.2437 & 1.36 & $\mathrm{C}_{129} \cap_{217} \mathrm{I}_{3} \mathrm{U}_{49}$ & 1297.2164 & 12.33 & ] $\cup_{129} \Pi_{217} \mathfrak{N}_{3} \cup_{49}$ & 1297.226 & 5.08 \\
\hline & & & & 1289.7331 & 2.72 & & & & & 1319.7422 & 3.77 & & & & & & \\
\hline
\end{tabular}




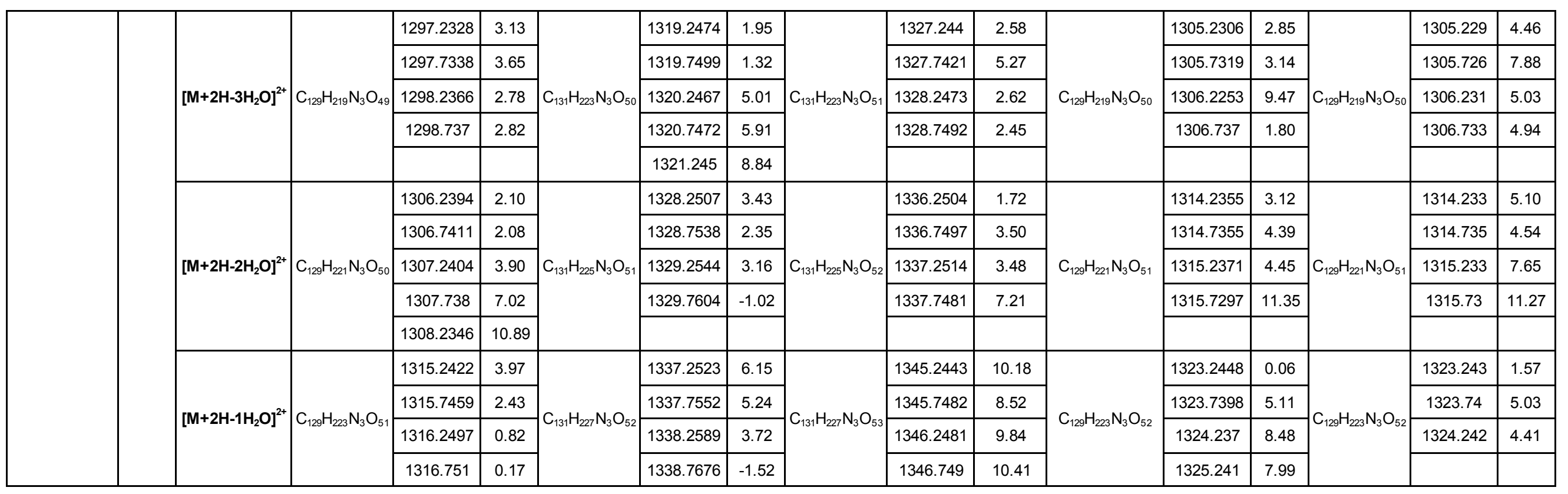


Table S5. Fragment attribution obtained from CID spectra of tricharged ions of OVTX-a and OVTX-h. The isotopic profile for all the molecular tricharged ions (with adducts and water losses) are reported with the errors (ppm) calculated by comparing with the two different hypothesis for OVTX-h.

\begin{tabular}{|c|c|c|c|c|c|c|}
\hline \multirow[b]{2}{*}{ Isotopic profile } & \multicolumn{2}{|c|}{$\begin{array}{c}\text { OVTX-a : } \mathrm{C}_{129} \mathrm{H}_{223} \mathrm{~N}_{3} \mathrm{O}_{52} \\
\text { Precursor : }[\mathrm{M}+\mathrm{H}+\mathrm{Ca}]^{3+} \text { at } \mathrm{m} / \mathrm{z} 896.1555\end{array}$} & \multicolumn{2}{|c|}{$\begin{array}{c}\text { OVTX-h : } \mathrm{C}_{129} \mathrm{H}_{225} \mathrm{~N}_{3} \mathrm{O}_{51} \\
\text { Precursor : }[\mathrm{M}+\mathrm{H}+\mathrm{Ca}]^{3+} \text { at } \mathrm{m} / \mathrm{z} 891.4935\end{array}$} & \multicolumn{2}{|c|}{$\begin{array}{c}\text { OVTX-h : } \mathrm{C}_{128} \mathrm{H}_{221} \mathrm{~N}_{3} \mathrm{O}_{52} \\
\text { Precursor : }[\mathrm{M}+\mathrm{H}+\mathrm{Ca}]^{3+} \text { at } \mathrm{m} / \mathrm{z} 891.4935\end{array}$} \\
\hline & $m / z$ & $\Delta \mathrm{ppm}$ & $m / z$ & $\Delta \mathrm{ppm}$ & $m / z$ & $\Delta \mathrm{ppm}$ \\
\hline \multirow{5}{*}[\mathrm{M}+\mathrm{H}+\mathrm{Ca}]{$^{3+}$} & 895.8196 & -0.52 & 891.1586 & -1.92 & 891.1586 & 11.52 \\
\hline & 896.1543 & -0.24 & 891.4937 & -1.19 & 891.4937 & 12.38 \\
\hline & 896.4883 & -0.74 & 891.8285 & -0.80 & 891.8285 & 12.90 \\
\hline & 896.8234 & -0.02 & 892.1631 & -0.63 & 892.1631 & 12.82 \\
\hline & 897.1552 & -2.98 & 892.4962 & -2.15 & 892.4962 & 11.43 \\
\hline \multirow{4}{*}[\mathrm{M}+\mathrm{H}+\mathrm{Ca}-\mathrm{H}_{2}\mathrm{O}]{$^{3+}$} & 890.1502 & -0.89 & 885.4921 & 0.97 & 885.4921 & 14.79 \\
\hline & 890.4831 & -2.64 & 885.8250 & -0.78 & 885.8250 & 12.79 \\
\hline & 890.8179 & -2.24 & 886.1583 & -2.08 & 886.1583 & 11.62 \\
\hline & 891.1506 & -4.21 & 886.4870 & -8.57 & 886.4870 & 5.26 \\
\hline \multirow{4}{*}[\mathrm{M}+\mathrm{H}+\mathrm{Ca}-2\mathrm{H}_{2}\mathrm{O}]{$^{3+}$} & 883.8103 & -3.08 & 879.1517 & -1.78 & 879.1517 & 12.02 \\
\hline & 884.1463 & -1.33 & 879.4890 & 1.46 & 879.4890 & 15.25 \\
\hline & 884.4816 & -0.37 & 879.8246 & 2.76 & 879.8246 & 16.55 \\
\hline & 884.8144 & -2.23 & 880.1529 & -4.23 & 880.1529 & 9.55 \\
\hline \multirow{4}{*}[\mathrm{M}+\mathrm{H}+\mathrm{Ca}-3\mathrm{H}_{2}\mathrm{O}]{$^{3+}$} & 877.8092 & -0.34 & 873.1446 & -5.89 & 873.1446 & 8.00 \\
\hline & 878.1406 & -3.81 & 873.4846 & 0.46 & 873.4846 & 14.35 \\
\hline & 878.4767 & -1.94 & 873.8150 & -4.17 & 873.8150 & 9.70 \\
\hline & 878.8094 & -3.93 & 874.1508 & -2.63 & 874.1508 & 11.25 \\
\hline \multirow{4}{*}[\mathrm{M}+\mathrm{H}+\mathrm{Ca}-4\mathrm{H}_{2}\mathrm{O}]{$^{3+}$} & 871.8011 & -5.59 & & & & \\
\hline & 872.1384 & -2.33 & & & & \\
\hline & 872.4706 & -4.91 & & & & \\
\hline & 872.8076 & -1.99 & & & & \\
\hline
\end{tabular}


Table S6. Fragment attribution obtained from CID spectra of dicharged ions of OVTX-a and OVTX-h. The isotopic profile for all the molecular dicharged ions (with adducts and water losses) are reported with the errors (ppm) calculated by comparing with the two differ ent hypothesis for OVTX-h.

\begin{tabular}{|c|c|c|c|c|c|c|}
\hline \multirow[b]{2}{*}{ Isotopic profile } & \multicolumn{2}{|c|}{$\begin{array}{c}\text { OVTX-a : } \mathrm{C}_{129} \mathrm{H}_{223} \mathrm{~N}_{3} \mathrm{O}_{52} \\
\text { Precursor : }[M+2 \mathrm{H}]^{2+} \text { at } \mathrm{m} / \mathrm{z} 1324.7543\end{array}$} & \multicolumn{2}{|c|}{$\begin{array}{c}\text { OVTX-h : } \mathrm{C}_{129} \mathrm{H}_{225} \mathrm{~N}_{3} \mathrm{O}_{51} \\
\text { Precursor : }[\mathrm{M}+2 \mathrm{H}]^{2+} \text { at } \mathrm{m} / \mathrm{z} 1317.7627\end{array}$} & \multicolumn{2}{|c|}{$\begin{array}{c}\text { OVTX-h : } \mathrm{C}_{128} \mathrm{H}_{221} \mathrm{~N}_{3} \mathrm{O}_{52} \\
\text { Precursor : }[\mathrm{M}+2 \mathrm{H}]^{2+} \text { at } \mathrm{m} / \mathrm{z} 1317.7627\end{array}$} \\
\hline & $m / z$ & $\Delta \mathrm{ppm}$ & $m / z$ & $\Delta \mathrm{ppm}$ & $m / z$ & $\Delta \mathrm{ppm}$ \\
\hline \multirow{3}{*}[\mathrm{M}+2\mathrm{H}]{$^{2+}$} & $1324.2299^{a}$ & -17.22 & 1317.2569 & -4.71 & 1317.2569 & 9.11 \\
\hline & $1324.7267^{\mathrm{a}}$ & -20.91 & 1317.7602 & -3.45 & 1317.7602 & 10.36 \\
\hline & $1325.2394^{\mathrm{a}}$ & -12.56 & 1318.2599 & -4.97 & 1318.2599 & 8.84 \\
\hline \multirow{3}{*}[\mathrm{M}+2\mathrm{H}-\mathrm{H}_{2}\mathrm{O}]{$^{2+}$} & 1315.2406 & -5.21 & 1308.2519 & -4.51 & 1308.2519 & 9.40 \\
\hline & 1315.7391 & -7.60 & 1308.758 & -1.15 & 1308.758 & 12.76 \\
\hline & 1316.2432 & -5.77 & 1309.2508 & -7.91 & 1309.2508 & 6.00 \\
\hline \multirow{4}{*}[\mathrm{M}+2\mathrm{H}-2\mathrm{H}_{2}\mathrm{O}]{${ }^{2+}$} & 1306.2312 & -8.38 & 1299.2474 & -3.93 & 1299.2474 & 10.08 \\
\hline & 1306.7402 & -2.79 & 1299.7493 & -3.77 & 1299.7493 & 10.23 \\
\hline & 1307.2467 & 0.92 & 1300.2508 & -3.88 & 1300.2508 & 10.08 \\
\hline & 1307.7467 & -0.38 & 1300.7457 & -9.11 & & \\
\hline \multirow{4}{*}[\mathrm{M}+2\mathrm{H}-3\mathrm{H}_{2}\mathrm{O}]{$^{2+}$} & 1297.2351 & -1.35 & 1290.2434 & -2.98 & 1290.2434 & 11.12 \\
\hline & 1297.7313 & -5.59 & 1290.7453 & -2.79 & 1290.7453 & 11.31 \\
\hline & 1298.2364 & -2.93 & 1291.2484 & -1.70 & 1291.2484 & 12.39 \\
\hline & 1298.717 & -19.17 & 1291.7461 & -4.76 & 1291.7461 & 9.33 \\
\hline \multirow{4}{*}[\mathrm{M}+2\mathrm{H}-4\mathrm{H}_{2}\mathrm{O}]{$^{2+}$} & 1288.2223 & -7.22 & 1281.2314 & -8.23 & 1281.2314 & 5.96 \\
\hline & 1288.7251 & -6.32 & 1281.7373 & -4.95 & 1281.7373 & 9.26 \\
\hline & 1289.2297 & -4.07 & 1282.24 & -4.13 & 1282.24 & 10.05 \\
\hline & $1289.7094^{a}$ & -21.09 & & & & \\
\hline
\end{tabular}


Figure S2. Chromatogram of a fraction containing ovatoxins after a clean-up of Ostreopsis cf. ovata extract using Sephadex LH-20 and mass spectra "full scan" of compound of interest obtained using Agilent 1160 LC-MS

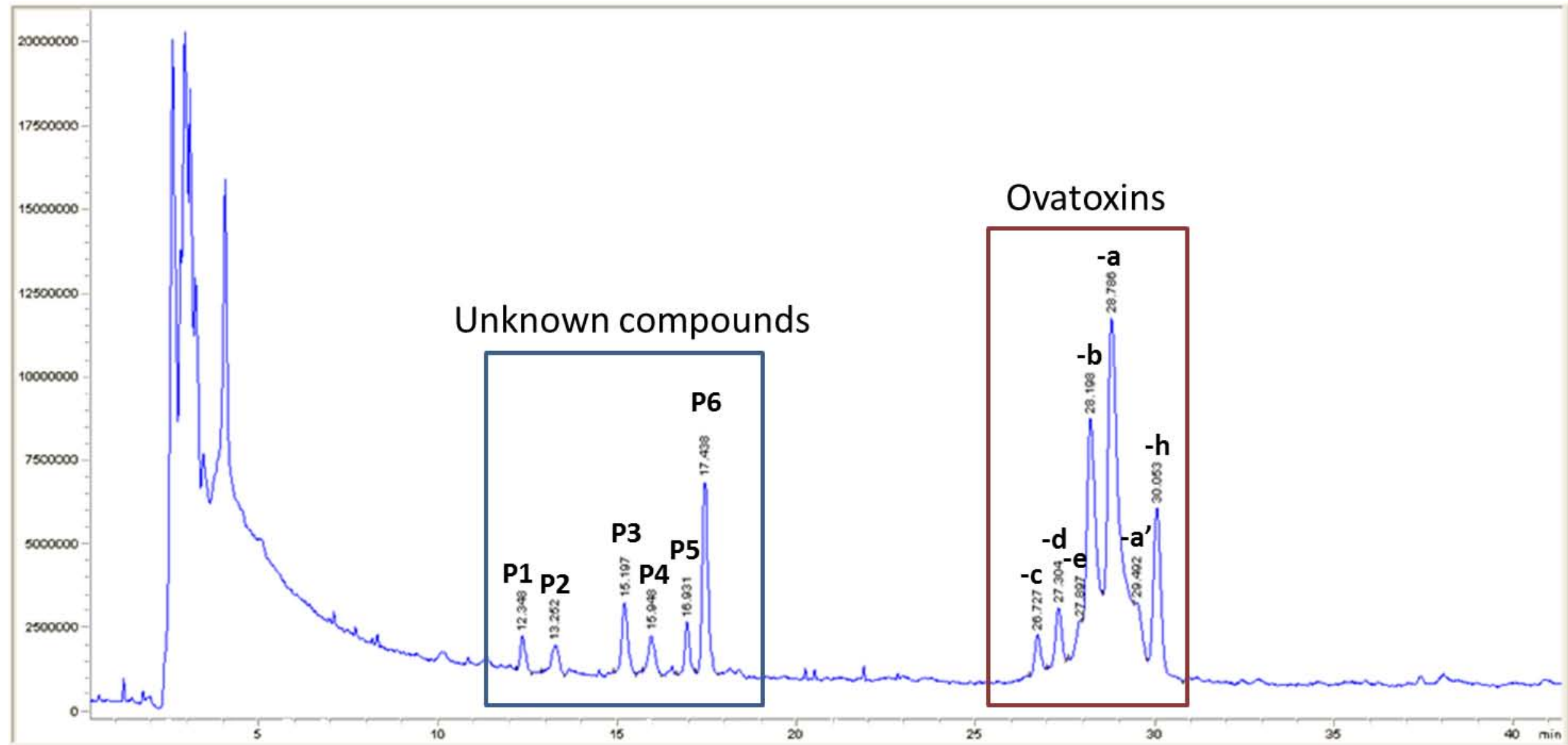

Column Uptisphere $\mathrm{C}_{18} \mathrm{TF}(250 \times 4.6 \mathrm{~mm}, 5 \mu \mathrm{m})$. Separation was carried out with linear gradient elution with water (eluent $\left.\mathrm{A}\right)$ and $95 \%$ acetonitrile/water (eluent B), both containing $0.2 \%$ of acetic acid, and changing percentage of B from $20 \%$ to $50 \%$ over 40 min. Flow rate: $1 \mathrm{~mL} / \mathrm{min}$. Injected volumes $20 \mu \mathrm{L}$. Detection used Full Scan MS $(\mathrm{m} / z$ [300-1450]). 
Figure S2.a: Full scan MS spectrum of unknown compound P1 (at $12.3 \mathrm{~min}$ ), acquired on Agilent single quadrupole 1160

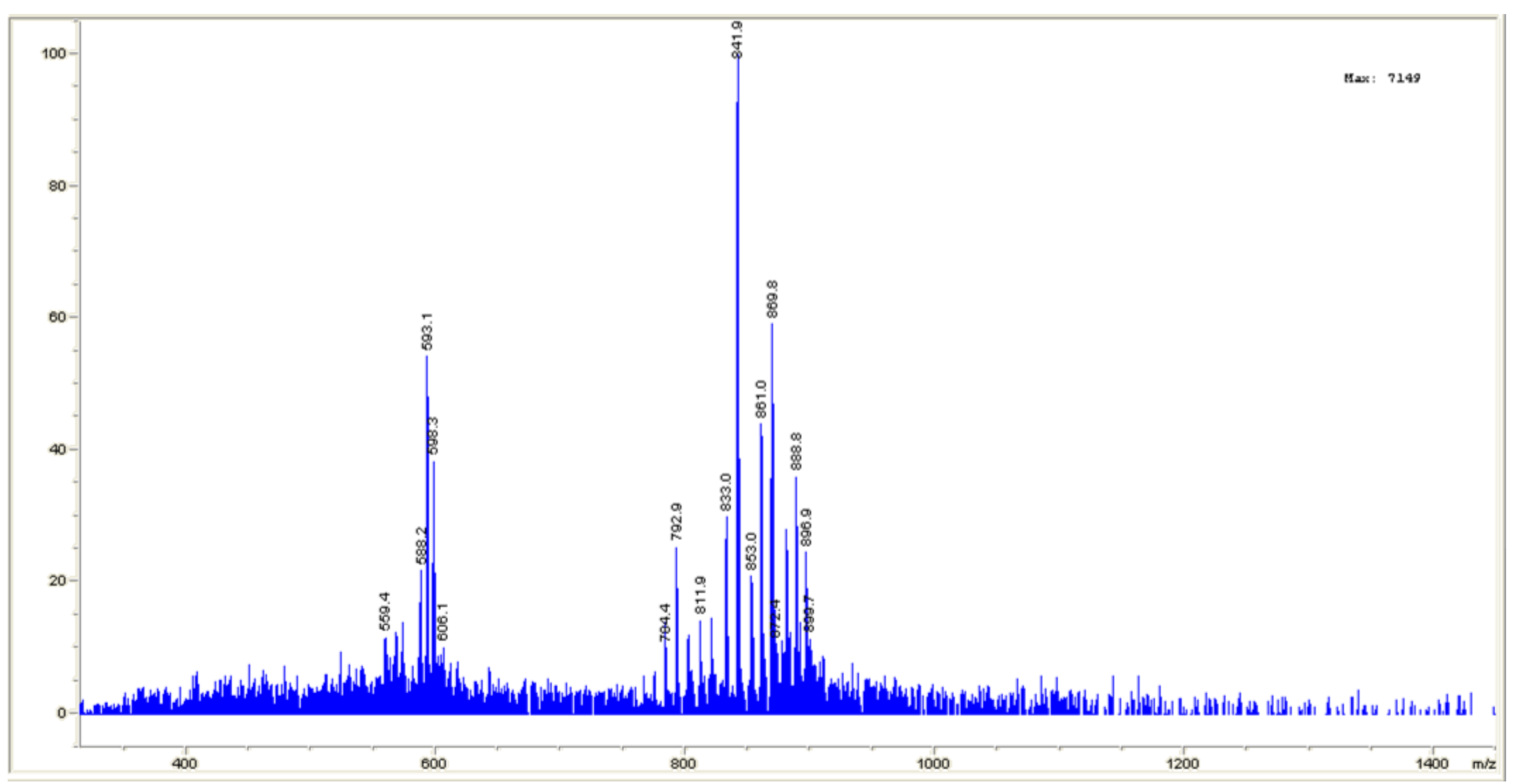


Figure S2.b: Full scan MS spectrum of unknown compound P2 (at $13.3 \mathrm{~min}$ ), acquired on Agilent single quadrupole 1160

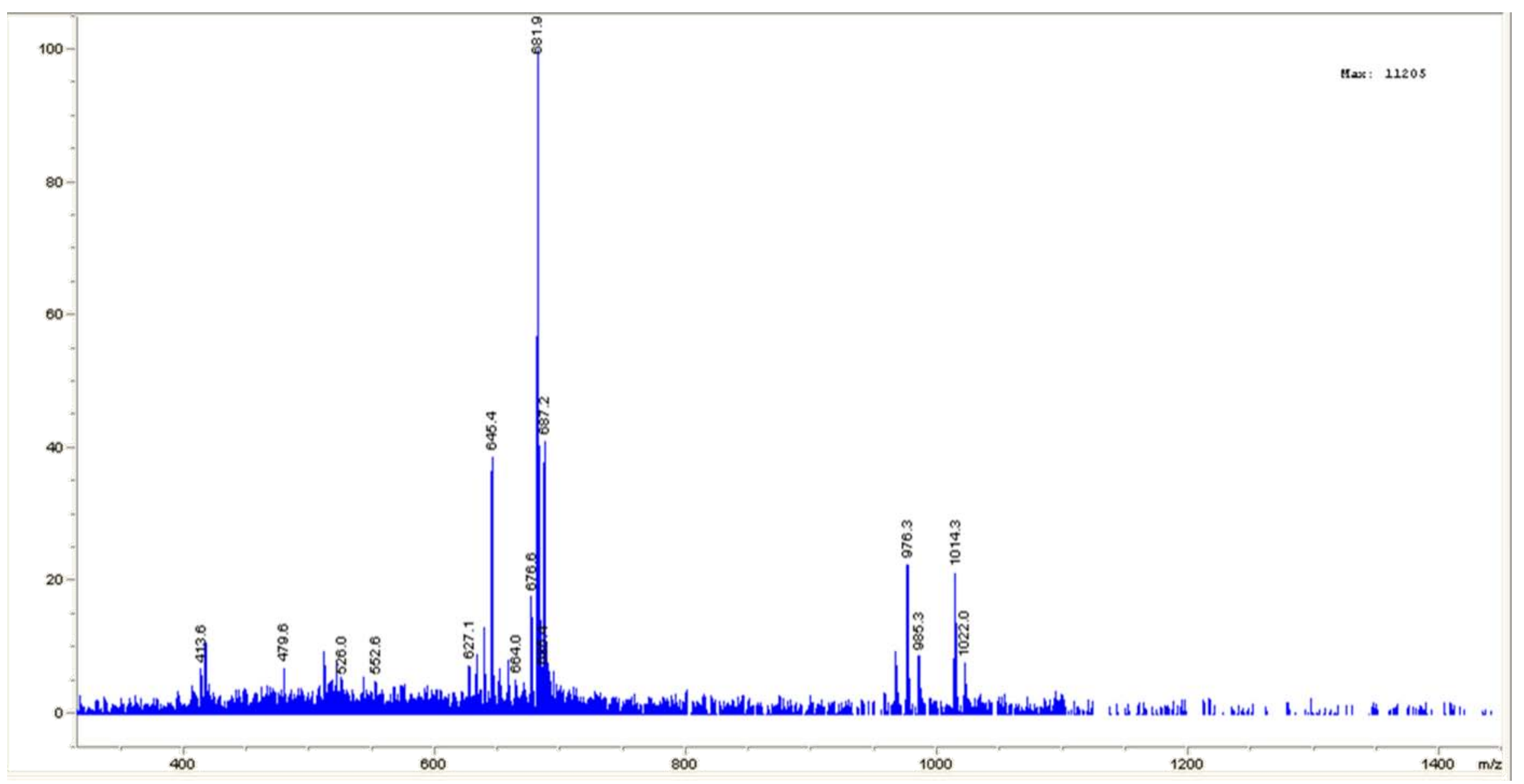


Figure S2.c: Full scan MS spectrum of unknown compound P3 (at 15.2 min), acquired on Agilent single quadrupole 1160

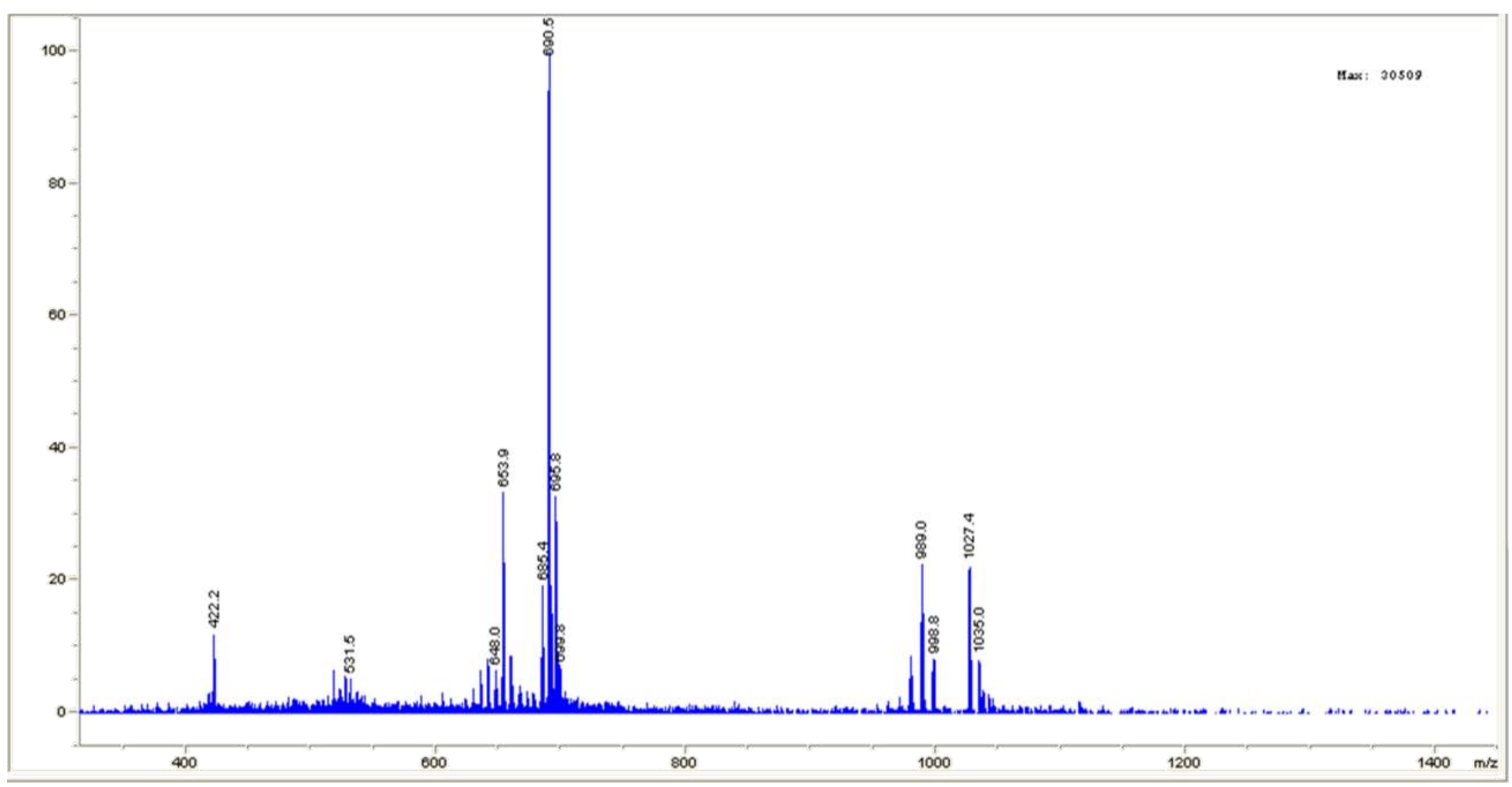


Figure S2.d: Full scan MS spectrum of unknown compound P4 (at 15.9 min), acquired on Agilent single quadrupole 1160

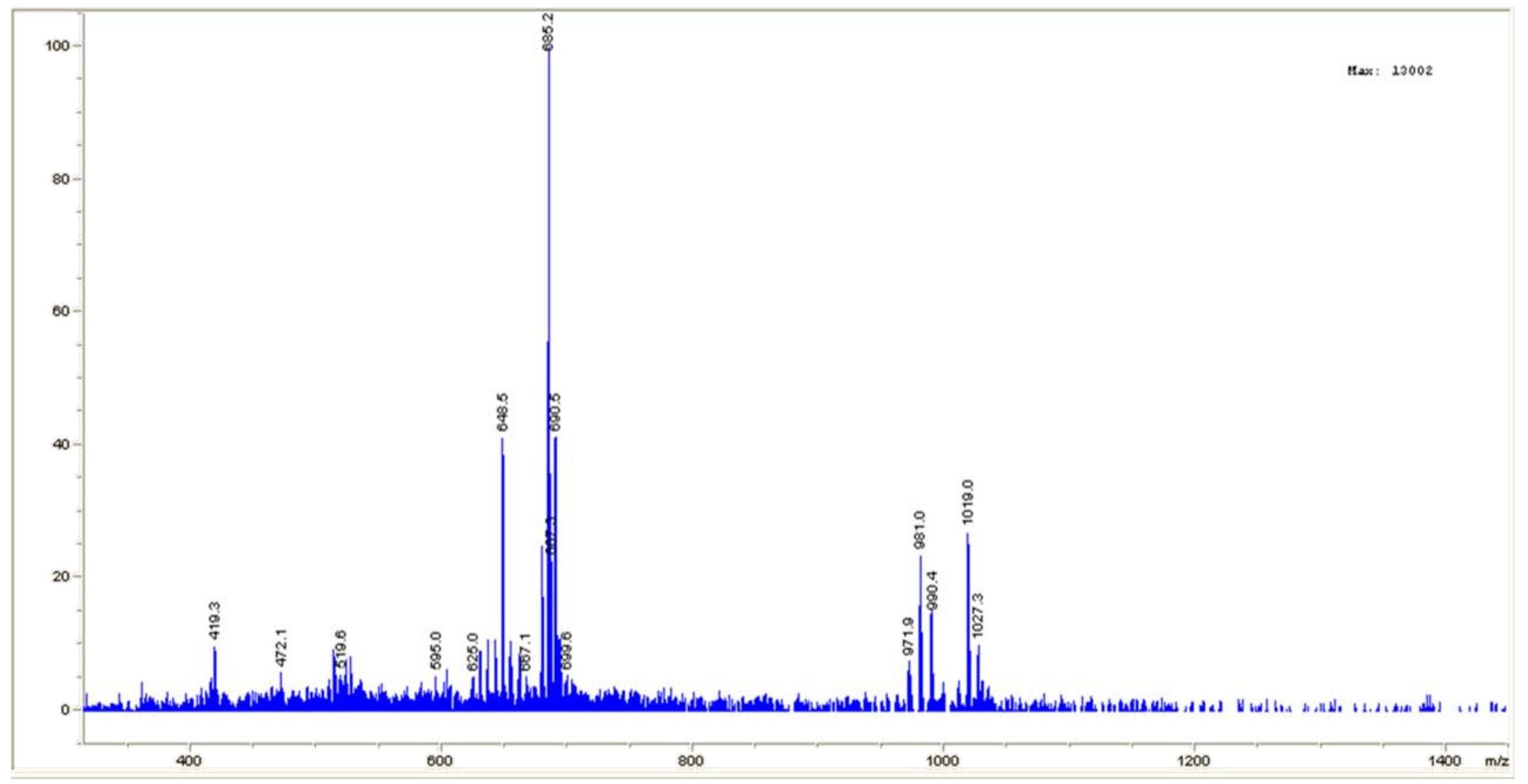


Figure S2.e: Full scan MS spectrum of unknown compound P5 (at 16.9 min), acquired on Agilent single quadrupole 1160

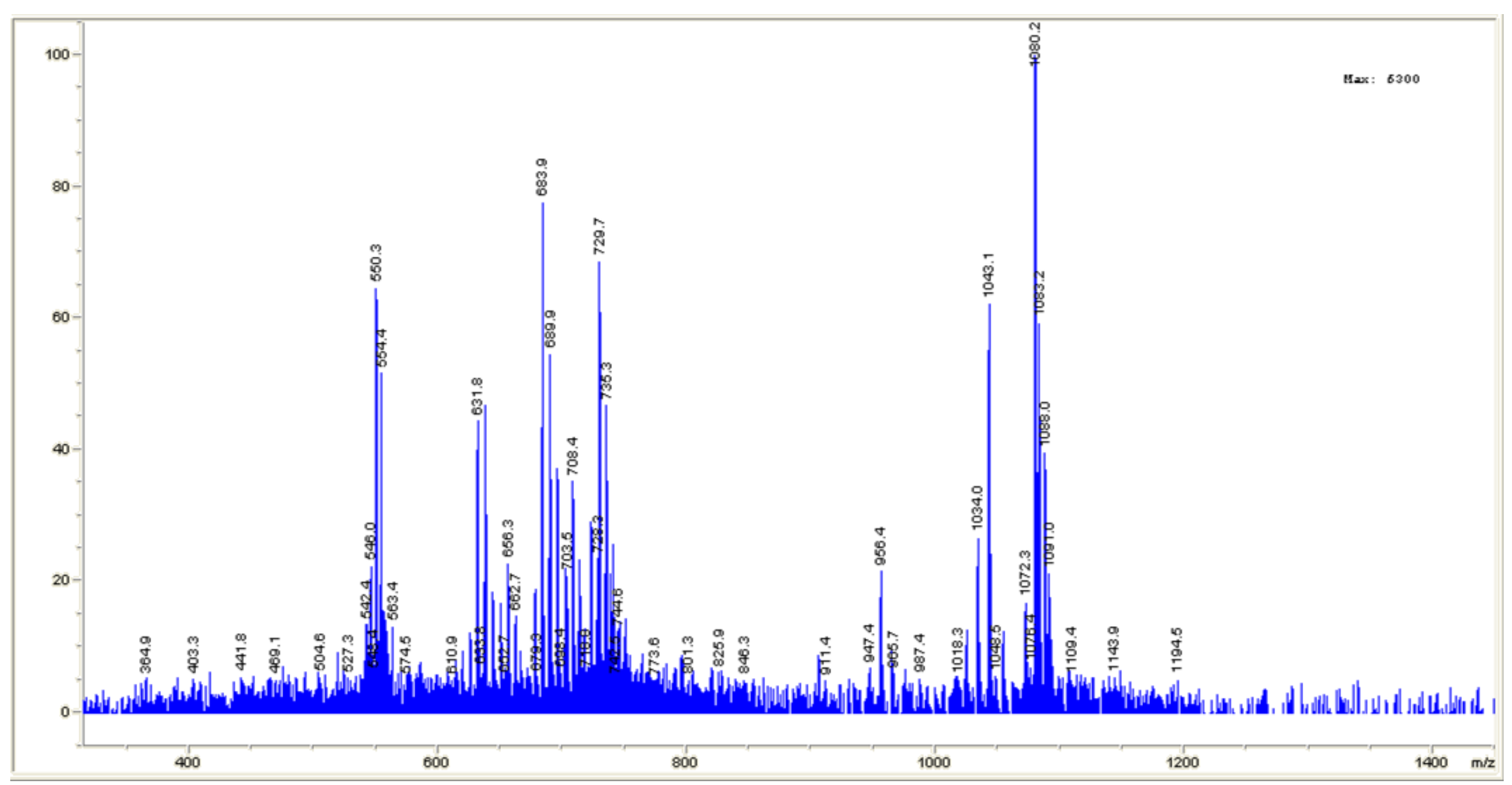


Figure S2.f: Full scan MS spectrum of unknown compound P6 (at $17.4 \mathrm{~min}$ ), acquired on Agilent single quadrupole 1160

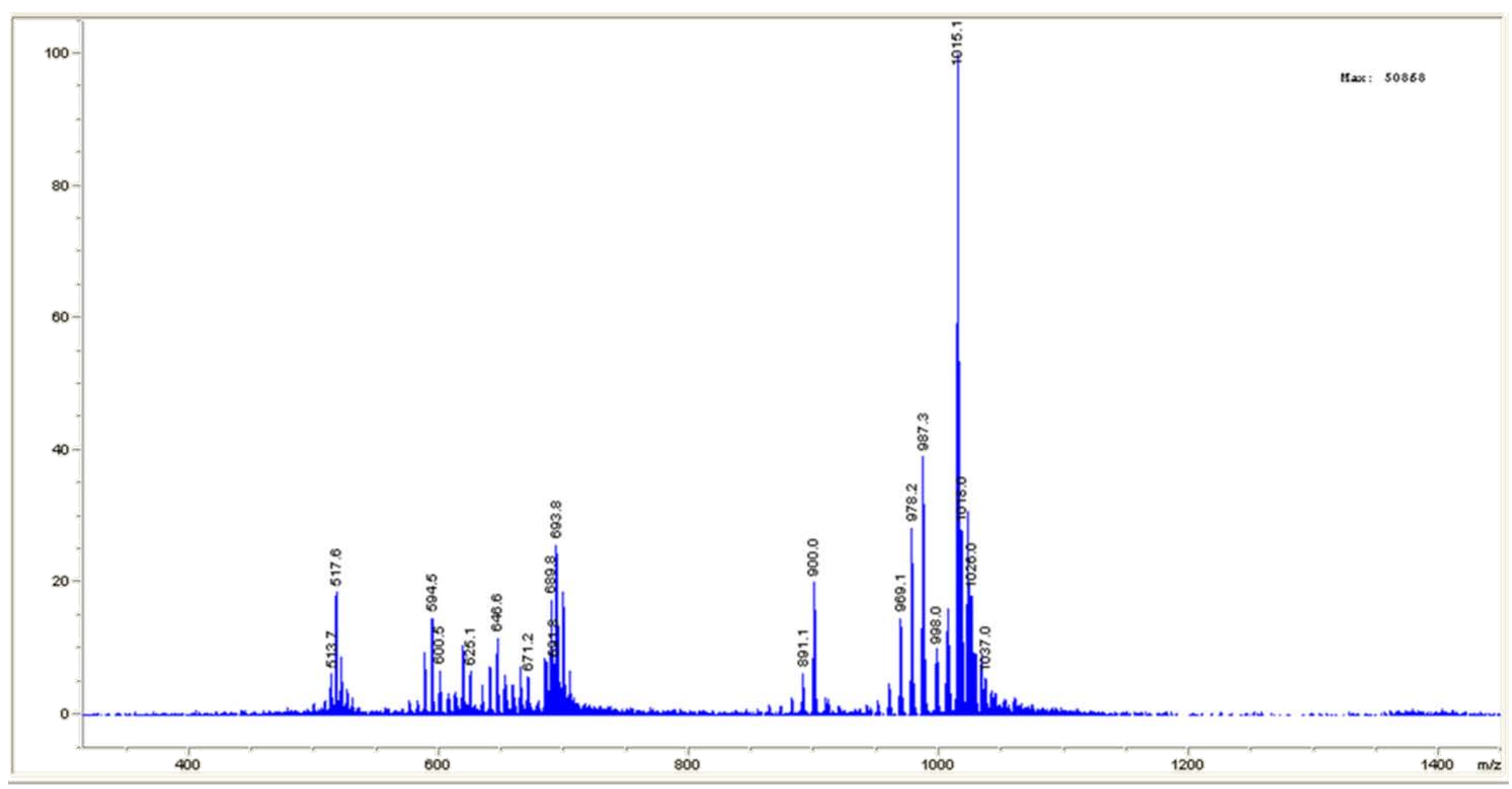


Figure S2.g: Full scan MS spectrum of OVTX-c (at $26.7 \mathrm{~min}$ ), acquired on Agilent single quadrupole 1160

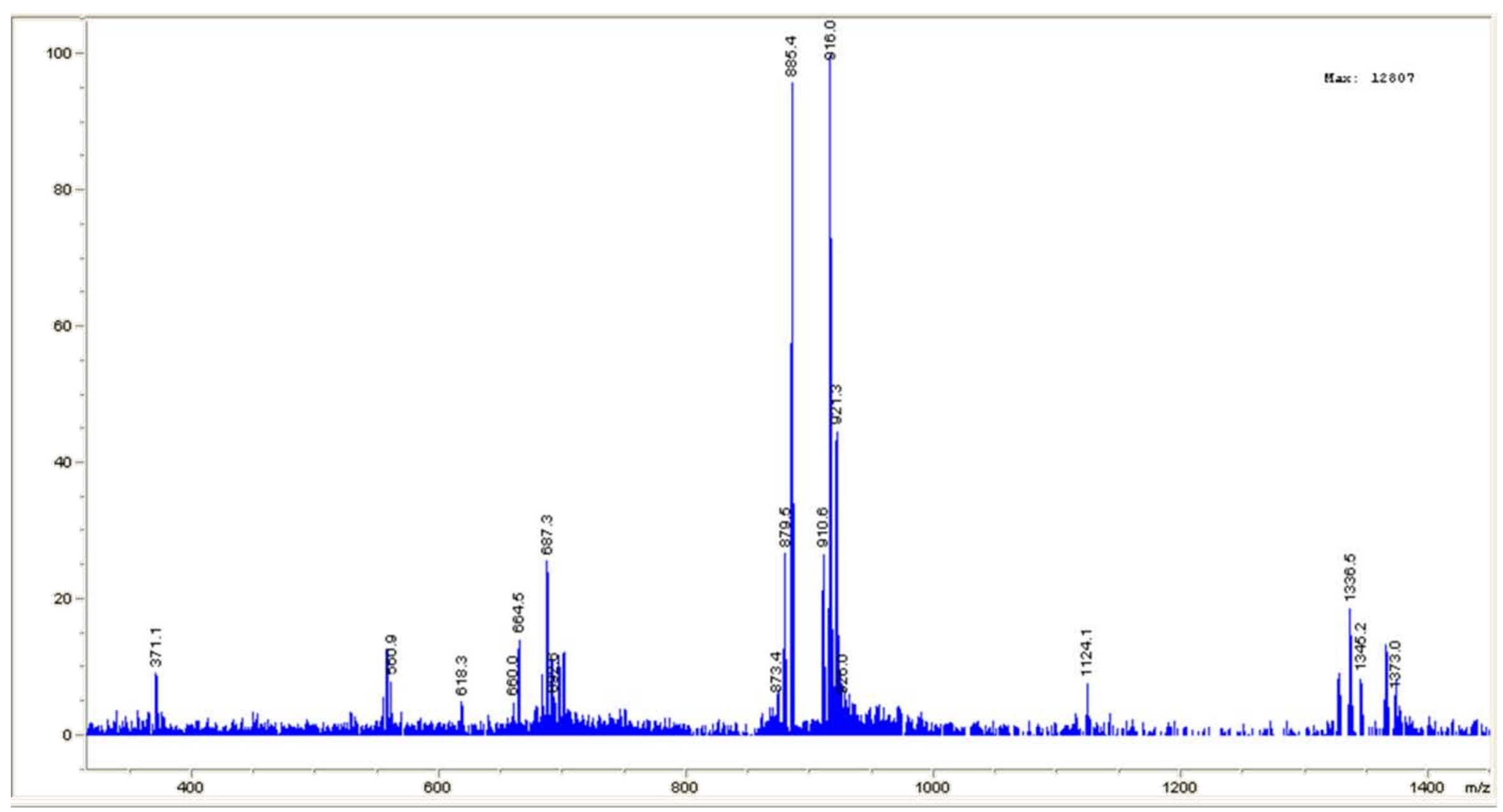


Figure S2.h: Full scan MS spectrum of OVTX-d (at $27.3 \mathrm{~min}$ ), acquired on Agilent single quadrupole 1160

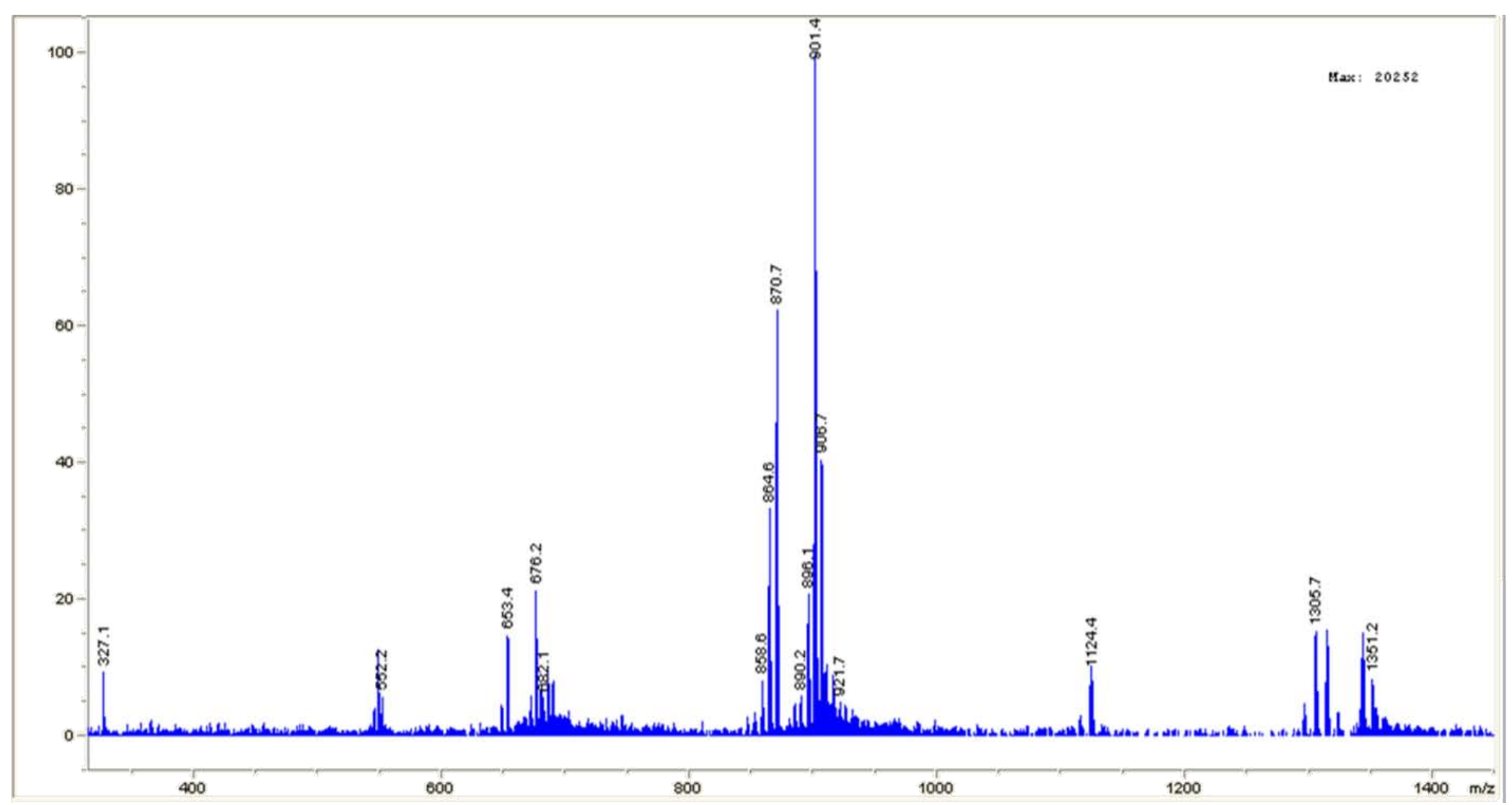


Figure S2.i: Full scan MS spectrum of OVTX-e (at 27.9 min), acquired on Agilent single quadrupole 1160

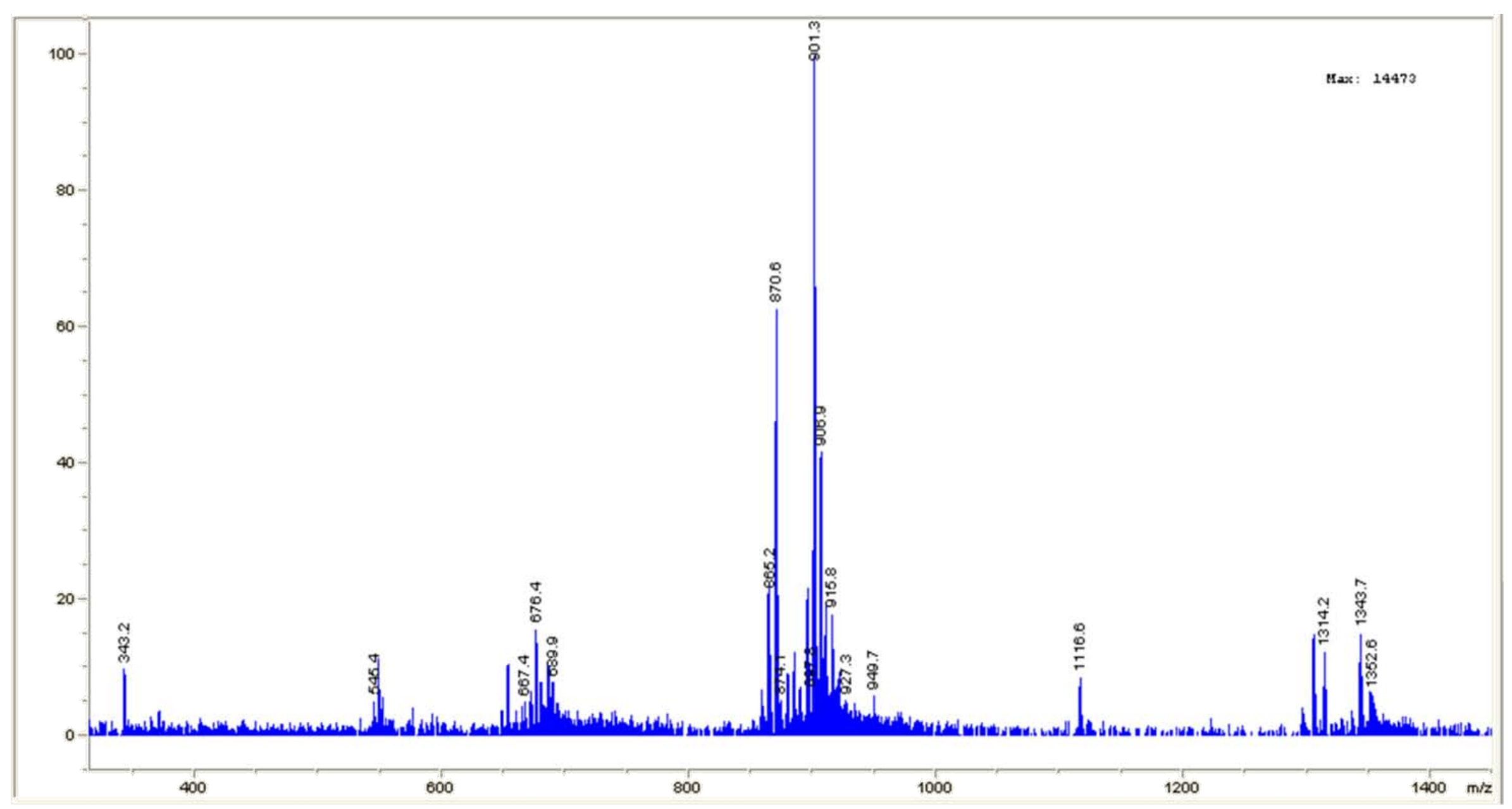


Figure S2.j: Full scan MS spectrum of OVTX-b (at $28.2 \mathrm{~min}$ ), acquired on Agilent single quadrupole 1160

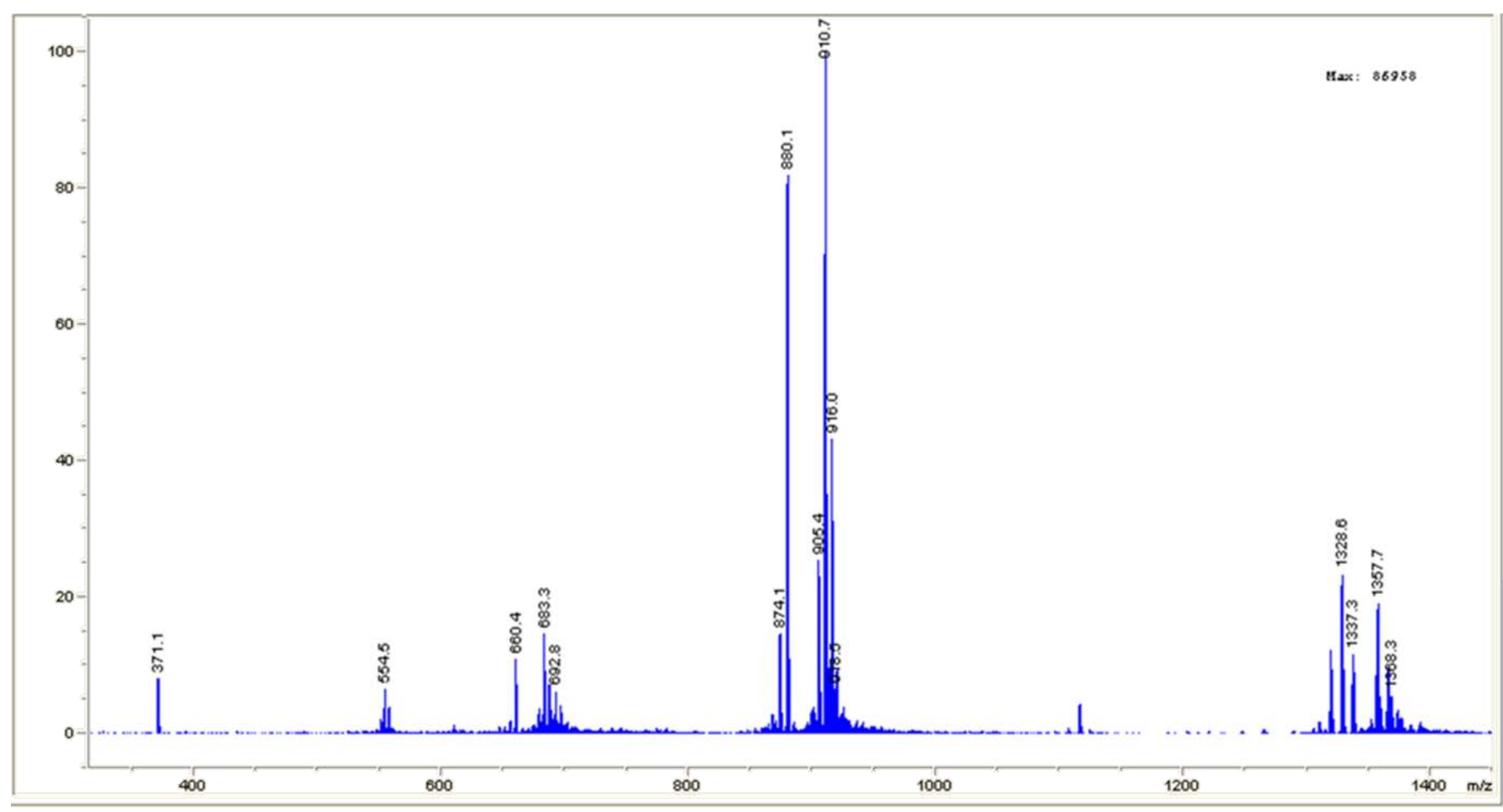


Figure S2.k: Full scan MS spectrum of OVTX-a (at $28.8 \mathrm{~min}$ ), acquired on Agilent single quadrupole 1160

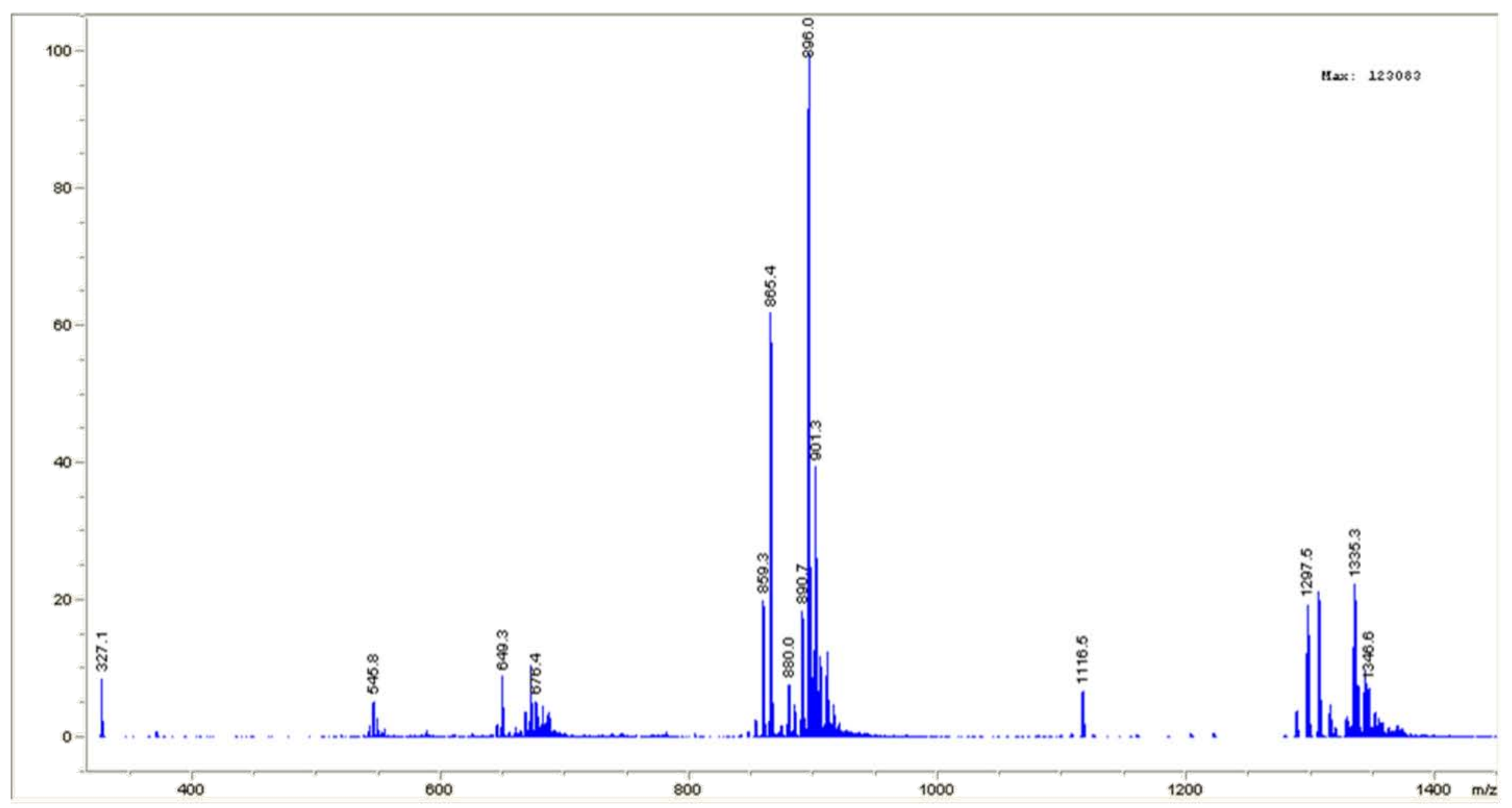


Figure S2.I: Full scan MS spectrum of OVTX-a' (at $29.5 \mathrm{~min}$ ), acquired on Agilent single quadrupole 1160

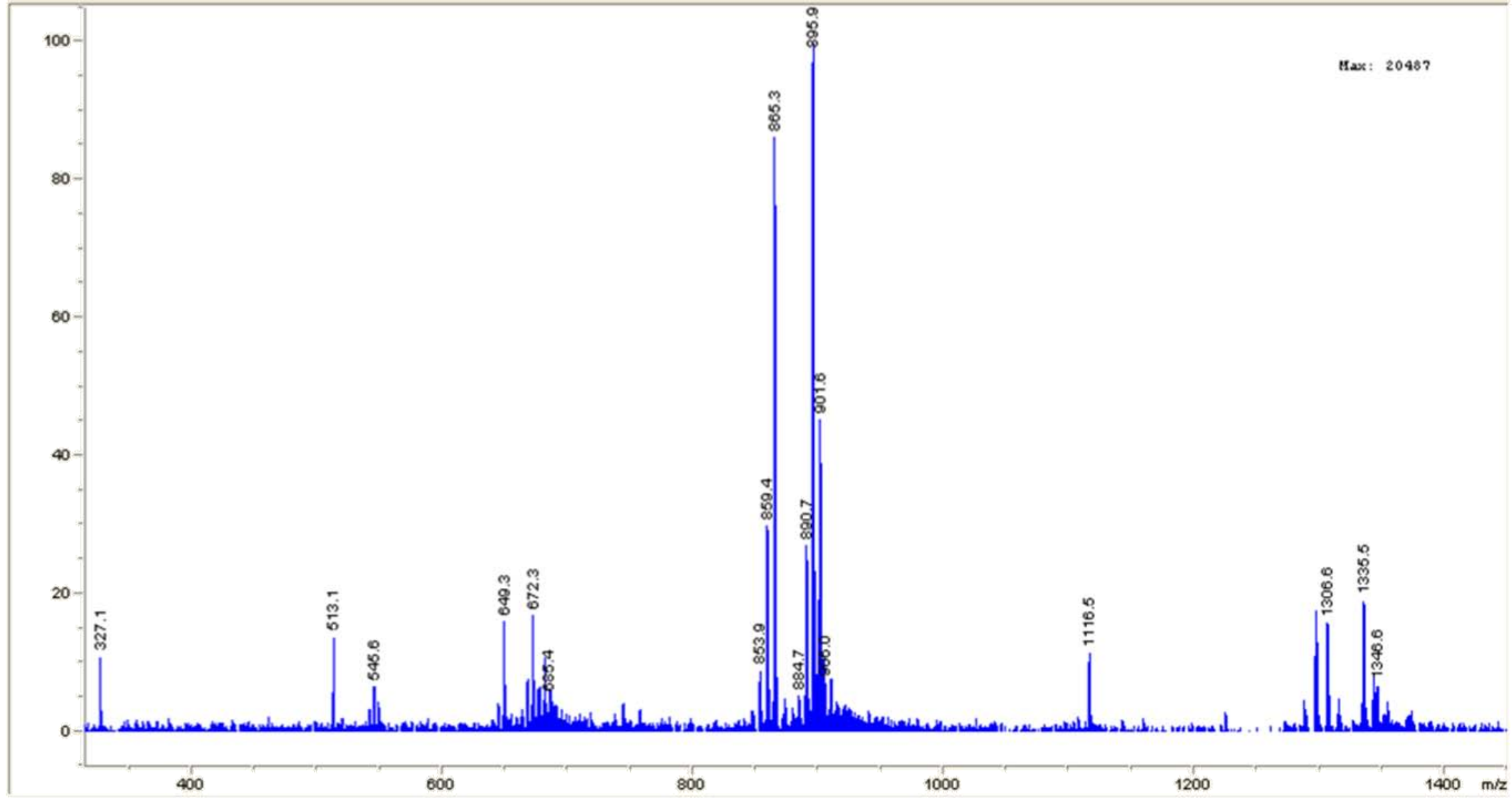


Figure S2.m: Full scan MS spectrum of OVTX-h (at $30.1 \mathrm{~min}$ ), acquired on Agilent single quadrupole 1160

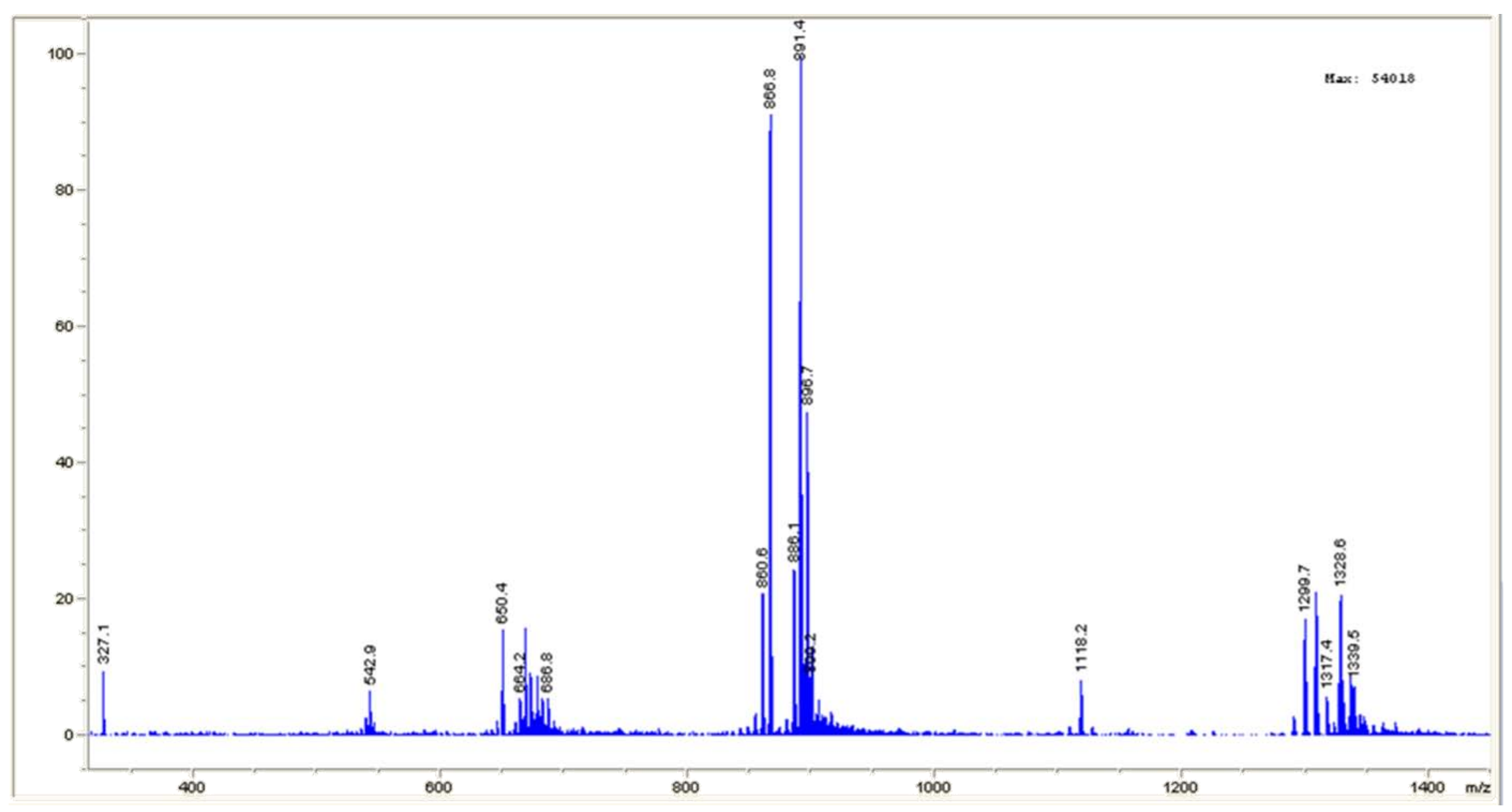


Table S7. Characterization of the different columns tested by the simplified Engelhardt test. Retention factors $(\mathrm{k})$, selectivity $(\alpha)$ and tailing factors (=asymmetry ratios) are given.

\begin{tabular}{|c|c|c|c|c|c|c|c|c|c|}
\hline $\begin{array}{c}\text { Stationary } \\
\text { phase and } \\
\text { manufacturer }\end{array}$ & $\begin{array}{c}\text { Column } \\
\text { dimension } \\
(\mathrm{mm} \times \mathrm{mm})\end{array}$ & $\begin{array}{l}\text { Particle } \\
\text { size }(\mu \mathrm{m})\end{array}$ & $\begin{array}{l}\text { Pore } \\
\text { size } \\
(A)\end{array}$ & $A s_{D M A} / A s_{E}$ & $\mathbf{k}_{\mathbf{T}}$ & $\mathbf{k}_{\mathrm{E}}$ & $\mathbf{k}_{\mathrm{DMA}}$ & $\alpha_{E T}$ & $\alpha_{\text {DMAT }}$ \\
\hline \multicolumn{10}{|c|}{ Reversed Phase columns } \\
\hline $\begin{array}{l}\text { Gemini }\left(\mathbf{C}_{18}\right) \\
\text { Phenomenex }\end{array}$ & $150 \times 2$ & 3 & 110 & 0.97 & 4.54 & 7.82 & 3.13 & 1.72 & 0.69 \\
\hline $\begin{array}{c}\text { Kinetex }\left(\mathbf{C}_{18}\right) \\
\text { Phenomenex }\end{array}$ & $150 \times 2.1$ & 2.6 & 100 & 1.18 & 3.93 & 6.95 & 2.73 & 1.77 & 0.70 \\
\hline $\begin{array}{l}\text { Kinetex }\left(\mathbf{C}_{18}\right) \\
\text { Phenomenex }\end{array}$ & $150 \times 4.6$ & 5 & 100 & 1.08 & 3.73 & 6.53 & 2.62 & 1.75 & 0.70 \\
\hline $\begin{array}{c}\text { Uptisphere } \\
\mathbf{C}_{18-T F} \\
\text { Interchim }\end{array}$ & $150 \times 2.1$ & 5 & 300 & 1.50 & 2.04 & 3.42 & 2.12 & 1.67 & 1.04 \\
\hline \multicolumn{10}{|c|}{ Mixed Mode columns } \\
\hline $\begin{array}{c}\text { Acclaim } \\
\text { Polar } \\
\text { Advantage II } \\
\text { Dionex }\end{array}$ & $100 \times 2.1$ & 2.2 & 120 & 1.04 & 3.74 & 6.11 & 2.88 & 1.64 & 0.77 \\
\hline $\begin{array}{c}\text { Synergi } \\
\text { fusion RP } \\
\text { Phenomenex }\end{array}$ & $150 \times 4.6$ & 4 & 80 & 1.08 & 4.25 & 7.33 & 3.20 & 1.72 & 0.75 \\
\hline $\begin{array}{l}\text { Polaris } \mathbf{C}_{18} \\
\text { Amide Varian }\end{array}$ & $150 \times 4.6$ & 5 & 200 & 1.06 & 1.32 & 2.00 & 1.15 & 1.52 & 0.88 \\
\hline \multicolumn{10}{|c|}{ Other grafting columns } \\
\hline $\begin{array}{l}\text { Kinetex PFP } \\
\text { Phenomenex }\end{array}$ & $150 \times 2.1$ & 2.6 & 100 & 2.19 & 2.36 & 3.52 & 9.84 & 1.49 & 4.18 \\
\hline
\end{tabular}

